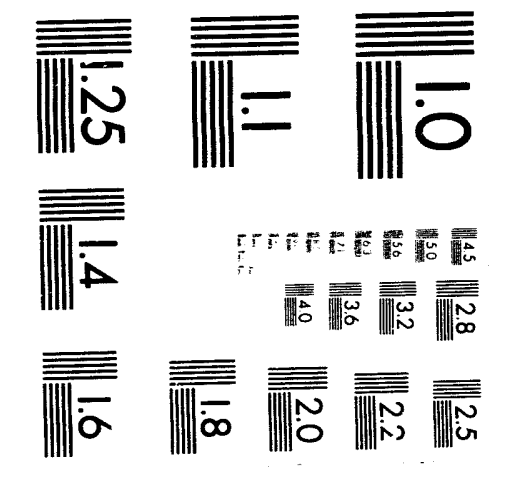



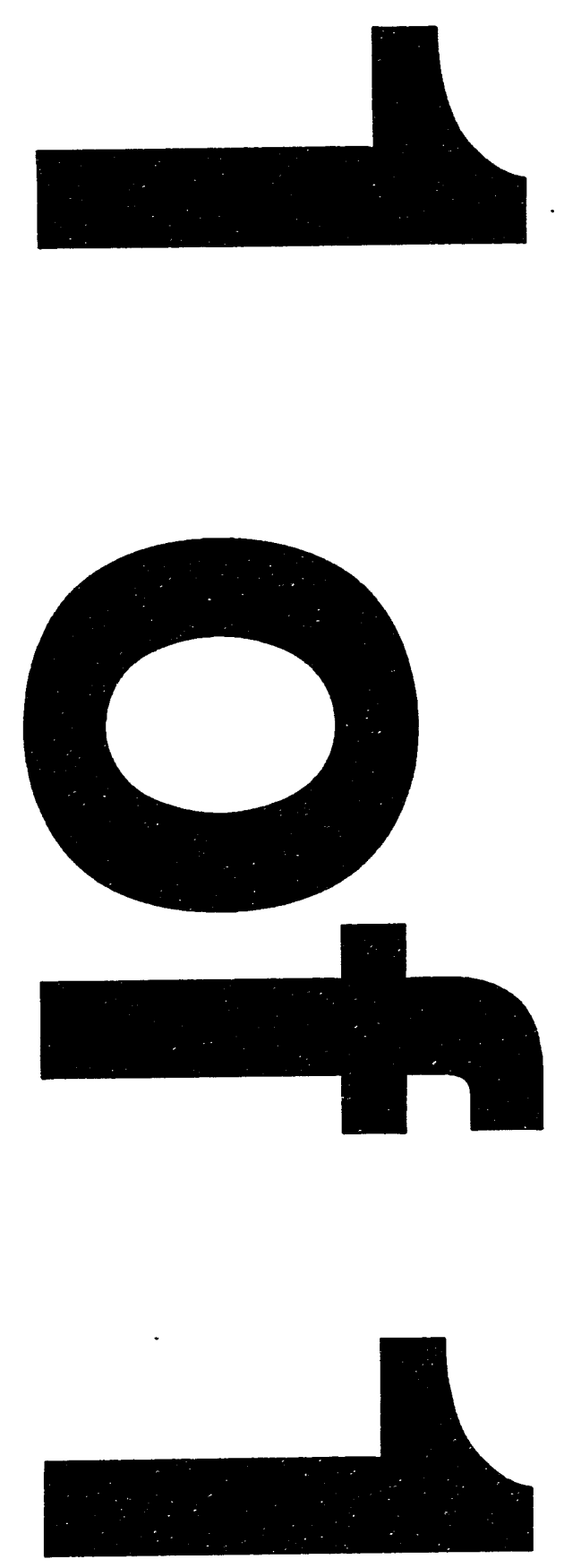


\section{Potential Impacts of Title I Nonattainment on the Electric Power Industry: A Chicago Case Study (Phase 2)}

by M.E. Fernau, W.J. Makofske, and D.W. South

Policy and Economic Analysis Group, Decision and Information Sciences Division,

Argonne National Laboratory, 9700 South Cass Avenue, Argonne, Illinois 60439

June 1993

Work sponsored by United States Department of Energy,

Office of the Assistant Secretary for Policy, Planning and Program Evaluation,

Office of Environmental Analysis 


\section{CONTENTS}

ACKNOWLEDGMENTS $\ldots \ldots \ldots \ldots \ldots \ldots \ldots \ldots \ldots \ldots \ldots$ vii

NOTATION $\ldots \ldots \ldots \ldots \ldots \ldots \ldots \ldots \ldots \ldots \ldots \ldots \ldots \ldots \ldots \ldots \ldots \ldots \ldots \ldots \ldots$

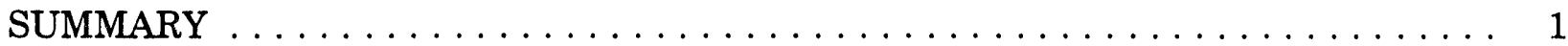

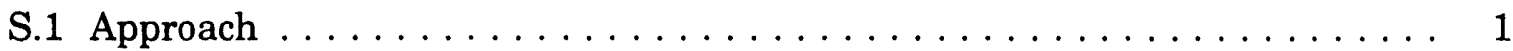

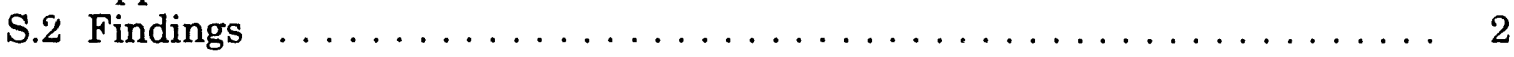

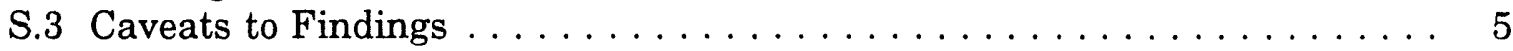

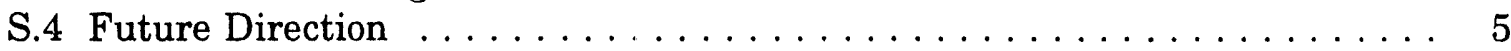

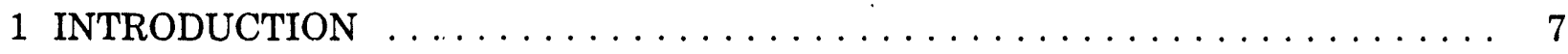

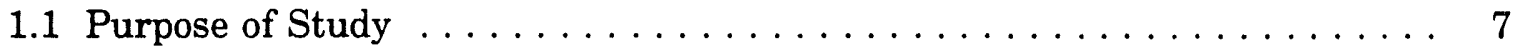

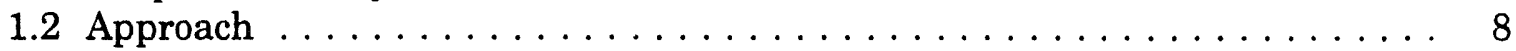

2 IMPROVEMENT OF THE 1988 BASE CASE $\ldots \ldots \ldots \ldots \ldots \ldots \ldots$

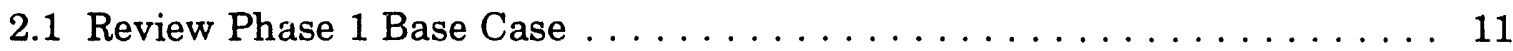

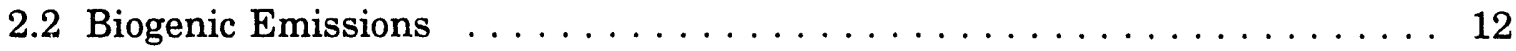

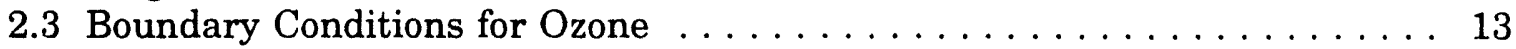

2.4 Initial and Boundary Conditions for $\mathrm{NO}_{\mathrm{x}} \ldots \ldots \ldots \ldots \ldots \ldots \ldots$

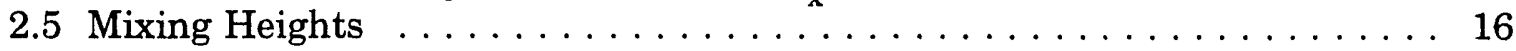

2.6 New Combined Base Case $\ldots \ldots \ldots \ldots \ldots \ldots \ldots \ldots \ldots \ldots \ldots \ldots$

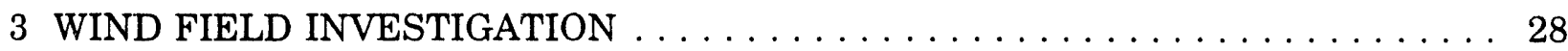

3.1 Sensitivity to Number of Stations in Weighted Average $\ldots \ldots \ldots \ldots 28$

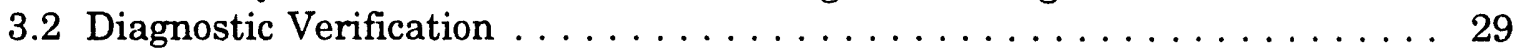

4 GROSS SENSITIVITY TESTS AGAINST THE 1988 BASE CASE $\ldots \ldots \ldots \ldots .32$

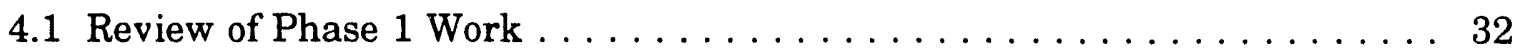

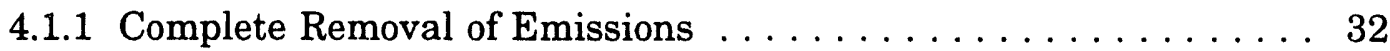

4.1 .2 Removal of Utility Emissions $\ldots \ldots \ldots \ldots \ldots \ldots \ldots \ldots \ldots, 32$

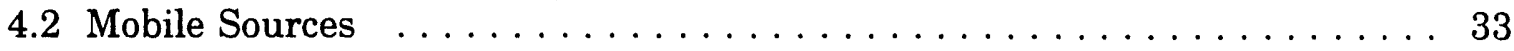

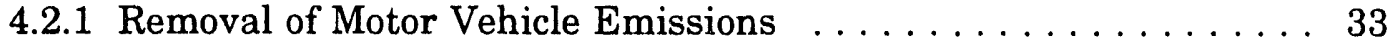

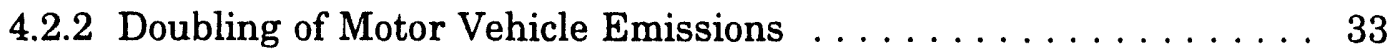

4.2.3 Doubled Motor Vehicle Scenario with New Base Case . . . . . . . . 35

4.3 Industrial Sources: Removal of Industrial Emissions . . . . . . . . . . . 36

52010 FUTURE EMISSIONS CASES $\ldots \ldots \ldots \ldots \ldots \ldots \ldots \ldots \ldots \ldots \ldots \ldots$

5.1 Review of Phase 1 Work . . . . . . . . . . . . . . . . . . 42

5.1 .1 Base Case 1996 New Nuclear . . . . . . . . . . . . . . . . 42

5.1 .2 Base Case 2000 New Nuclear . . . . . . . . . . . . . . 42

5.1 .3 High Fossil Fuel Use $\ldots \ldots \ldots \ldots \ldots \ldots \ldots \ldots \ldots \ldots . \ldots 2$ 


\section{CONTENTS (Cont.)}

5.1.4 High Fossil Fuel Use with High $\mathrm{NO}_{\mathrm{x}}$ Control . . . . . . . . . . . 42

5.1 .5 Removal of Utility Emissions ... . . . . . . . . . . . 43

5.2 Sensitivity of Previous Results to New Base Case . . . . . . . . . . . . 43

5.2 .1 Base Case 2000 New Nuclear . . . . . . . . . . . . . . . . 43

5.2 .2 High Fossil Use with High $\mathrm{NO}_{\mathrm{x}}$ Control . . . . . . . . . . . . 44

5.2 .3 No Utility Emissions . . . . . . . . . . . . . . . . . . 45

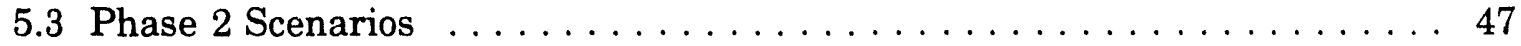

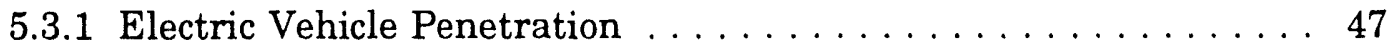

5.3.2 Improved Industrial Growth and Controls . . . . . . . . . . . . 47

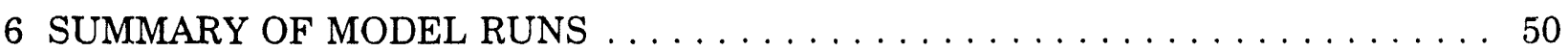

6.1 Comparison of Input Parameter Sensitivity Runs . . . . . . . . . . . 50

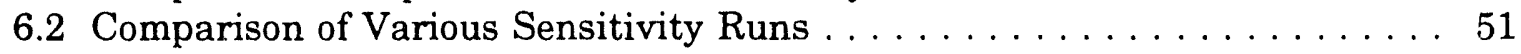

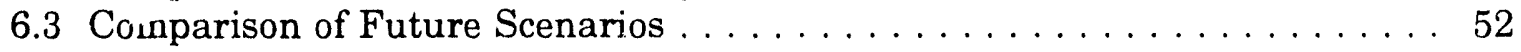

7 MAJOR FINDINGS AND FUTURE DIRECTIONS $\ldots \ldots \ldots \ldots \ldots \ldots \ldots$

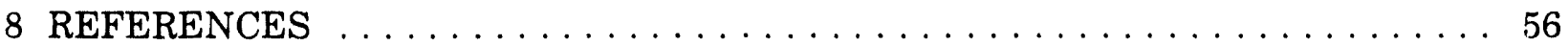

APPENDLX A: Nonemissions Model Input Data Preparation . . . . . . . . . . . . . 59

APPENDIX B: Preparation of Present and Future Emissions Input $\ldots \ldots \ldots 7$

\section{TABLES}

S.1 Summary of Ozone Concentrations and Attainment Status by Case,

Compared with Case B1 . . . . . . . . . . . . . . . . . . 4

S.2 Summary of Ozone Concentrations and Attainment Status by Case,

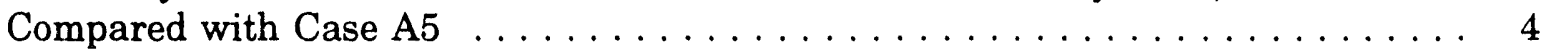

1 Comparison of the Results of Several Statistical Tests for Cases B1 and A1-A5

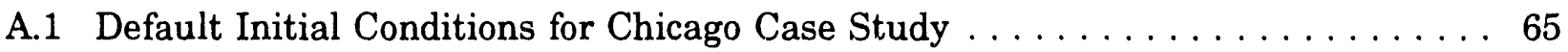

\section{FIGURES}

1 UAM Modeling Grid Showing Locations of Utility Point Sources . . . . . . . . . 9

2 Predicted Maximum Hourly Ozone Concentrations for July 6, 1988:

Phase 1 Base Case 


\section{FIGURES (Cont.)}

3 Predicted Maximum Hourly Ozone Concentrations for 1200 to 2000 LST on July 6, 1988: Biogenic Emissions Sensitivity Case . . . . . . . . . . . 14

4 Ozone Boundary Conditions for Case A2 from 1200 LST on July 5, 1988, to 2000 LST on July $6,1988 \ldots \ldots \ldots \ldots \ldots \ldots \ldots \ldots \ldots \ldots \ldots \ldots$

5 Predicted Maximum Hourly Ozone Concentrations for 1200 to 2000 LST

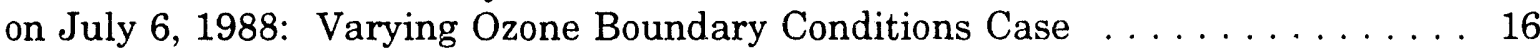

6 Predicted Maximum Hourly Ozone Concentrations for 1200 to 2000 LST on July 6, 1988: Increased $\mathrm{NO}_{\mathrm{x}}$ Initial and Boundary Conditions Case . . . . . 17

7 Predicted Maximum Hourly Ozone Concentrations for 1200 to 2000 LST on July 6, 1988: Mixing Height Sensitivity Case . . . . . . . . . . . . . . . . 19

8 Predicted Maximum Hourly Ozone Concentrations for 1200 to 2000 LST

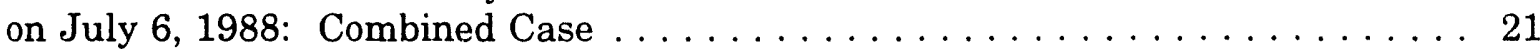

$9 \quad$ Percentile Plot of Cases B1 and A5 vs. Observations $\ldots \ldots \ldots \ldots \ldots \ldots \ldots 22$

10 Time Series Plot of Hourly Ozone Concentrations for July 6, 1988, at Evanston, Illinois: Case B1, Case A5, and Observations . . . . . . . . . . 24

11 Time Series Plot of Hourly Ozone Concentrations for July 6, 1988, at Pleasant Prairie, Wisconsin: Case B1, Case A5, and Observations . . . . . . 25

12 Time Series Plot of Hourly Ozone Concentrations for July f 1988 , at North Ashland and Edgewater Chicago Site: Case B1, vase A5,

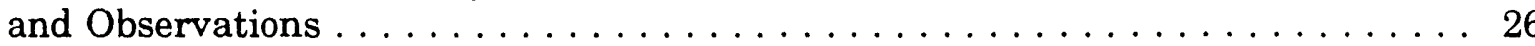

13 Time Series Plot of Hourly Ozone Concentrations for July 6, 1988, at Peoria, Illinois: Case B1, Case A5, and Observations . . . . . . . . . 27

14 Wind Vector Grid Plot for 0900 LST on July 6, 1988, for the Lowest Vertical Layer, Using 1-Station Averaging . . . . . . . . . . . 29

15 Wind Vector Grid Plot for 0900 LST on July 6, 1988, for the Lowest Vertical Layer, Using 5-Station Averaging . . . . . . . . . . . 30

16 Wind Vector Grid Plot for 1600 LST on July 6, 1988, for the Lowest Vertical Layer $\ldots \ldots \ldots \ldots \ldots \ldots \ldots \ldots \ldots$

17 Predicted Maximum Hourly Ozone Concentrations for 1200 to 2000 LST on July 6, 1988: No Motor Vehicle Emissions Sensitivity Case . . . . . . . . . 34

18 Predicted Maximum Hourly Ozone Concentrations for 1200 to 2000 LST on July 6, 1988: Doubled Motor Vehicle Emissions 


\section{FIGURES (Cont.)}

19 Predicted Maximum Hourly Ozone Concentrations for 1200 to 2000 LST on July 6, 1988: Doubled Motor Vehicle Emissions Combined with Case A5 . . . 37

20 Hourly Ozone Concentrations for Edgewater and North Ashland Site, Chicago, on July 6, 1988: Cases B1, A5, and A6 and Observations . . . . . 38

21 Hourly Ozone Concentrations for Evanston Site, Chicago, on July 6, 1988:

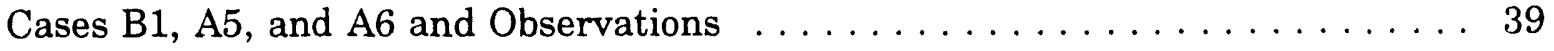

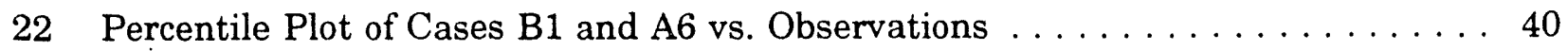

23 Predicted Maximum Hourly Ozone Concentrations for 1200 to 2000 LST

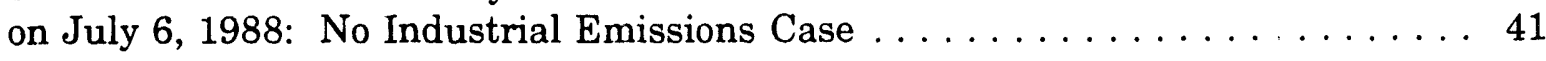

24 Predicted Maximum Hourly Ozone Concentrations for 1200 to 2000 LST on July 6, 1988: N2 with New Base Case A5 . . . . . . . . . . . . . 44

25 Predicted Maximum Hourly Ozone Concentrations for 1200 to 2000 LST

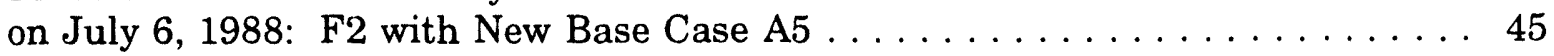

26 Predicted Maximum Hourly Ozone Concentrations for 1200 to 2000 LST

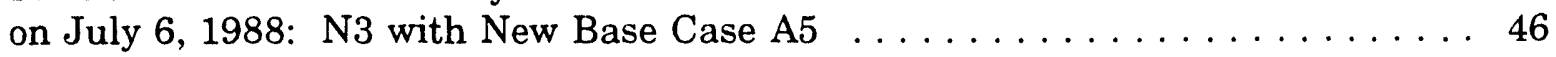

27 Predicted Maximum Hourly Ozone Concentrations for 1200 to 2000 LST

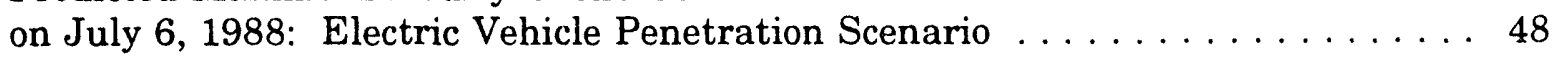

28 Predicted Maximum Hourly Ozone Concentrations for 1200 to 2000 LST on July 6, 1988: Improved Industrial Control Scenario 


\section{ACKNOWLEDGMENTS}

The authors thank Eric Maloney, Argonne National Laboratory (ANL), for performing computer modeling and analyzing model results during Phase 2 of the study. Karen Guziel and Guy Pandola (ANL) provided data and interpretation for the electricity load demand aspects of the electric vehicle study. Christopher Saricks of Argonne's Center for Transportation Research provided the guidelines for development of the electricity penetration scenario. Lisa Holic and Deborah Stegmeyer provided secretarial assistance for the project and report. The many people who contributed to Phase 1 are listed in Fernau et al. 1992.

U.S. Department of Energy project officer Jean Vernet of the Office of Environmental Analysis (OEA) provided guidance and advice during Phase 2 of this report. Richard Ball of OEA provided technical input as well. The authors especially thank William Breed of OEA for his careful reading and thoughtful comments during both phases of this project. Useful comments also were received from Akhtar Awan of the Office of Electricity and Generating Fuels Policy and Douglas Carter of the Office of Planning and Environment. 


\section{NOTATION}

The following is a list of the acronyms, initialisms, and abbreviations (including units of measure) used in this document.

\section{ACRONYMS, INITLALISMS, AND ABBBREVIATIONS}

\begin{tabular}{|c|c|}
\hline $\begin{array}{l}\text { AIRS } \\
\text { ANL } \\
\text { ARGUS }\end{array}$ & $\begin{array}{l}\text { Aerometric Information Retrieval System } \\
\text { Argonne National Laboratory } \\
\text { Argonne Utility Simulation }\end{array}$ \\
\hline $\begin{array}{l}\text { CAAA } \\
\text { CO } \\
\text { Com Ed } \\
\text { CTR }\end{array}$ & $\begin{array}{l}\text { Clean Air Act Amendments of } 1990 \\
\text { carbon monoxide } \\
\text { Commonwealth Edison } \\
\text { Center for Transportation Research (at Argonne) }\end{array}$ \\
\hline DWM & Diagnostic Wind Model \\
\hline EPA & U.S. Environmental Protection Agency \\
\hline FY & fiscal year \\
\hline GEAP & Gross Error of All Pairs \\
\hline LST & Local Standard Time \\
\hline MSCET & Month and State Current Emissions Trends \\
\hline $\begin{array}{l}\text { NAAQS } \\
\text { NAPAP } \\
\text { NBASP } \\
\text { NBT } \\
\text { NCAR } \\
\text { NCDC } \\
\text { NES } \\
\text { NESEAM } \\
\text { NO } \\
\text { NSC }\end{array}$ & $\begin{array}{l}\text { National Ambient Air Quality Standards } \\
\text { National Acid Precipitation Assessment Program } \\
\text { Normalized Bias of All Station Peaks } \\
\text { Normalized Bias Test } \\
\text { National Center for Atmospheric Research } \\
\text { National Climatic Data Center } \\
\text { National Energy Strategy } \\
\text { NES Environmental Analysis Model } \\
\text { nitrogen oxides } \\
\text { NAPAP source category }\end{array}$ \\
\hline $\mathrm{O}_{3}$ & ozone \\
\hline $\begin{array}{l}\mathrm{SIC} \\
\mathrm{SO}_{2}\end{array}$ & $\begin{array}{l}\text { standard industrial classification } \\
\text { sulfur dioxide }\end{array}$ \\
\hline $\begin{array}{l}\text { THC } \\
\text { TSP }\end{array}$ & $\begin{array}{l}\text { total hydrocarbons } \\
\text { total suspended particulate }\end{array}$ \\
\hline
\end{tabular}




$\begin{array}{ll}\text { UAM } & \text { Urban Airshed Model } \\ \text { UHPA } & \text { Unpaired Highest Prediction Accuracy } \\ \text { VT } & \begin{array}{l}\text { vehicle-miles traveled } \\ \text { vOC }\end{array} \\ \text { volatile organic compound }\end{array}$

UNITS OF MEASURE

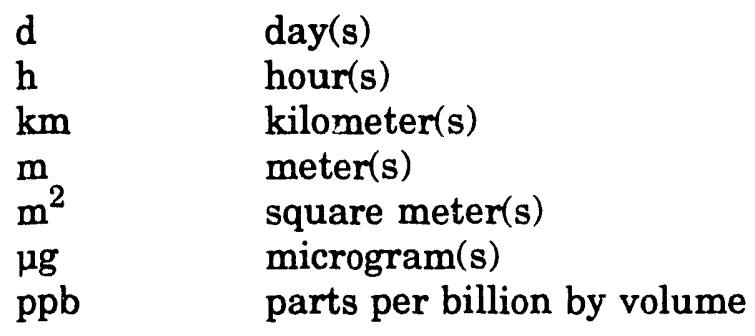

$i x$ 


\title{
POTENTIAL IMPACTS OF TITLE I NONATTAINMENT \\ ON THE ELECTRIC POWER INDUSTRY: \\ A CHICAGO CASE STUDY (Phase 2)
}

by

\author{
M.E. Fernau, W.J. Makofske, and D.W. South
}

\section{SUMMARY}

This study uses version IV of the Urban Airshed Model (UAM-IV) to examine the potential impacts of Title I (nonattainment) and Title IV (acid rain) of the Clean Air Act Amendments of 1990 (CAAA) on the utility industry. The UAM is run for a grid that covers the Commonwealth Edison Power Pool and encompasses the greater Chicago area and surrounding rural areas. Meteorological conditions are selected from an ozone $\left(\mathrm{O}_{3}\right)$ episode on July 5 and 6, 1988.

\section{S.1 APPROACH}

The UAM is a computer model recommended by the U.S. Environmental Protection Agency (EPA) for use in nonattainment compliance planning; the model uses the laws of physics and chemistry to simulate the production, transport, and destruction of ground-level ozone over urban areas. The two-day episode is modeled to test the performance of UAM (Case B1) and simulate the effects of different utility emissions control strategies to determine the potential role of electric utilities in urban ozone attainment.

The Argonne Utility Simulation (ARGUS) model and other Argonne National Laboratory (ANL) sectoral models are used to model the effects of the CAAA and the National Energy Strategy (NES) on utility and other emissions sources in 2010; ANL selected the year 2010 because Chicago must be in attainment of the ozone ambient air quality standard by 2007. These models project an emissions database representative of the area for 2010 from the historical emissions database. The 2010 database incorporates features of Title II (alternative fuels) and Title IV of the CAAA and reflects other actions that are part of the NES.

Phase 1 of the study examined two UAM sensitivity studies with the 1988 emissions database - one in which all emissions were turned off (Case B3) and one in which only utility emissions were turned off (Case B2). Using the 2010 database gave an additional five cases for examination with UAM. In the future base case (N1), utilities were permitted to construct new nuclear capacity beginning in 1996. In the sensitivity case (N2), new nuclear capacity was deferred until 2000. In the third case (F1), the construction of any new nuclear capacity was precluded, which emphasized fossil fuels to satisfy future load requirements. In the fourth case (F2), case $\mathrm{F} 1$ was expanded, by requiring 95\% nitrogen oxides $\left(\mathrm{NO}_{\mathrm{x}}\right)$ controls on all fossil-fuel-fired power plants. All four cases contained $\mathrm{NO}_{\mathrm{x}}$ controls that 
reflected the Title IV requirements and proposed EPA NO $\mathrm{x}_{\mathrm{x}}$ rules. The final case removed all utility emissions from the 2010 emissions database (N3).

Phase 2 makes an effort to reduce some of the uncertainty present in the base case (B1). A corrected volatile organic compound (VOC) emissions factor for corn is applied to the old base case (A1). This application is used in subsequent base-case sensitivity cases. Ozone boundary conditions are varied with time (Case A2) to reduce their influence and lower nighttime predictions. $\mathrm{NO}_{\mathrm{x}}$ initial and boundary conditions are increased in another test (Case A3). The time-varying ozone boundary values are combined with a different mixing height calculation scheme (Case A4). Finally, cases A1 through A4 are combined to make a new base case (Case A5), which is used in Phase 2.

Phase 2 also examines the sensitivity of ozone to gross changes in sectors other than the utility sector. Cases are conducted in which (1) motor vehicle emissions (MV1) and industrial emissions (I1) are removed completely and (2) motor vehicle emissions are doubled (MV2). In another test (Case A6), Case MV2 is combined with Case A5 to produce good results compared with observations.

Several Phase 1 cases are conducted with the new base-case conditions. Cases N2A and F2A rerun the nuclear $2000(\mathrm{~N} 2)$ and 95\% $\mathrm{NO}_{\mathrm{x}}$ control (F2) cases, respectively. Case N3 is also rerun (N3A), but it has not been analyzed completely. Finally, two new cases are conducted: an electric vehicle penetration case (MV3) and a more realistic industrial control case (I2). Findings from all these UAM simulations are reported in Section S.2.

\section{S.2 FINDINGS}

Phase 1 of this study found that, for the episode modeled, compliance with Title IV regulations for utility $\mathrm{NO}_{\mathrm{x}}$ emissions did not significantly affect air quality in Chicago. Complete removal of utility emissions did not lead to attainment (i.e., improving air quality by $20-25 \%$ of the improvement that is predicted from removal of all emissions), which shows that nonutility sources contribute substantially to the ozone problem in the region. A major finding of Phase 1 was that the region appears to be $\mathrm{NO}_{\mathrm{x}}$-limited, except for a very limited area in the vicinity of large power plants. Thus, reductions in $\mathrm{NO}_{\mathbf{x}}$ emissions should not lead to deterioration in air quality over most of the area.

In Phase 2 of the study it was determined that (1) $\mathrm{NO}_{\mathrm{x}}$ controls on utility power plants can help improve air quality within the Chicago area but will not unilaterally bring the region into attainment and (2) uniform $\mathrm{NO}_{\mathrm{x}}$ controls on fossil-fired power plants will not necessarily be beneficial to ozone conditions in the region, because of $\mathrm{NO}_{\mathrm{x}}$-limiting conditions around power plants. Instead, to be most effective and efficient, $\mathrm{NO}_{\mathrm{x}}$ control levels on utility boilers should be determined as part of a more comprehensive ozone strategy, which takes into account both mobile and industrial sources, together with the geographic contribution of all these sources to ozone formation. However, when all emission sources were included in the UAM simulations, ozone conditions in the region improved, but they did not improve 
enough to produce a significant difference in air quality. The principal findings of the individual cases examined are summarized below.

The 1988 base-case model simulates the high ozone concentrations of July 6, with relative accuracy, based on EPA standards, but underpredicts the magnitude of the highest concentrations. In addition, ozone concentrations in the early morning hours are systematically overpredicted. Because of this bias, attainment is expressed by comparing simulation percent changes in the maximum ozone, relative to the base case, to the percent change needed to bring the observations to 120 parts per billion by volume (ppb). This process is also used in reporting Phase 2 results. Tables S.1 and S. 2 summarize the following findings by case:

- The four order-of-magnitude error in the VOC emissions factor for corn present in the old EPA biogenic emissions model does not affect this ozone episode and thus does not weaken the findings of Phase 1 (Case A1).

- Initial and boundary condition specifications of atmospheric pollutant concentrations are improved on the basis of observations. Alternative mixing height calculations enhance nighttime mixing. These changes significantly improve the base case, making it more credible as a starting point for cases. However, prediction of the highest $10 \%$ of observations deteriorates slightly, making it necessary to continue use of relative rather than absolute changes to examine nonattainment issues (cases A2 through A5).

- Doubling motor vehicle emissions (Case MV2) gives a better fit to observations, especially when combined with the other changes in the base case (Case A6). Although the arbitrary nature of the emissions change precludes its use in the new base case, it does support the widespread evidence that motor vehicle emissions inventories are underestimated substantially in ozone nonattainment areas.

- The mobile source sector (Case MV1) contributes more to high ozone concentrations than do the utility (Case B2) or industrial (Case I1) sectors, based on selective removal of emissions. The utility and industrial sectors appear to contribute equally to ozone concentrations. Attainment cannot be achieved by eliminating any one sector's emissions.

- An industrial control strategy (Case I2) that is more realistic than that used in Case N2 lowers ozone relative to the Phase 1 future base case (Case N2A) but still is not as effective as $95 \%$ control on utility sources (Case F2A). None of the emission reduction strategies examined contributed significantly to achieving attainment, except for complete removal of emissions. 
TABLE S.1 Summary of Ozone Concentrations and Attainment Status by Case, Compared with Case B1

\begin{tabular}{lrrrrrrrr}
\hline \multicolumn{1}{c}{$\begin{array}{c}\text { Ozone Concentration/ } \\
\text { Attainment Status }\end{array}$} & B1 & B2 & B3 & N1 & N2 & F1 & F2 & N3 \\
\hline $\begin{array}{l}\text { Predicted maximum }\left(\mathrm{O}_{3}\right) \\
\begin{array}{l}\text { Number of sites in nonattainment } \\
\text { (31 possible) }\end{array}\end{array}$ & 159 & 145 & 88 & 157 & 157 & 162 & 142 & 140 \\
Number of grid cells $>120$ ppb $^{\text {b }}$ & 254 & 159 & 2 & 13 & 13 & 12 & 13 & 12 \\
\hline
\end{tabular}

a On a percentage basis (based on percent change, not absolute concentration).

b On an absolute basis (model output concentration $>120 \mathrm{ppb}$ ).

TABLE S.2 Summary of Ozone Concentrations and Attainment Status by Case, Compared with Case A5

\begin{tabular}{|c|c|c|c|c|c|}
\hline $\begin{array}{l}\text { Ozone Concentration } \\
\text { Attainment Status }\end{array}$ & A5 & N2A & F2A & MV3 & $\mathrm{I} 2$ \\
\hline Predicted maximum $\left(\mathrm{O}_{3}\right)$ & 158 & 153 & 140 & 150 & 147 \\
\hline $\begin{array}{l}\text { Number }\left(f \text { sites in nonattainment }{ }^{a}\right. \\
\text { ( } 31 \text { possible) }\end{array}$ & 14 & 13 & 13 & 12 & 12 \\
\hline Number of grid cells $>120 \mathrm{ppb}^{b}$ & 119 & 101 & 64 & 86 & 77 \\
\hline
\end{tabular}

- Electric vehicles effectively reduce downtown ozone relative to the amount of emissions reductions gained from them, but the absolute amount of penetration projected in 2010 is not large enough to make a significant difference in air quality (Case MV3).

- Although some areas of uncertainty remain in the treatment of initial and boundary conditions and the projection of emissions to 2010, the results from Phase 1 are not contradicted by additional work and remain valid. Some evidence exists that the specification of the base case can affect the extent to which $\mathrm{NO}_{\mathrm{x}}$ controls are effective, but this fact needs to be investigated further. 
In summary, these findings suggest that utilities play a role in producing high ozone concentrations in the Chicago region for the modeled episode. $\mathrm{NO}_{\mathrm{x}}$ controls on utility power plants will help to alleviate the problem but will not solve the problem. Mobile sources play the biggest role in ozone pollution. Utilities and industry contribute about equally to the problem. Electric vehicles effectively reduce downtown ozone but will not be implemented in sufficient numbers by 2010 to play an effective role. Given these findings and the large emissions reductions that will be necessary to achieve attainment in the Chicago area, even if utility $\mathrm{NO}_{\mathrm{x}}$ emissions reductions beyond Title IV are required, additional controls from other sectors will be necessary to reach attainment. The Lake Michigan Ozone Control Program, soon to be implemented by regional authorities, will provide additional evidence to confirm or weaken this finding.

\section{S.3 CAVEATS TO FINDINGS}

While Phase 2 answered some of the questions that remained after Phase 1, other scientific and modeling issues could not be resolved. For example, given the complex nature of photochemical modeling, uncertainties still remain because (1) generic uncertainty is associated with this type of work (e.g., it is difficult to fully characterize anthropogenic and natural emissions; knowledge of ozone chemistry is incomplete; and it is difficult to depict the exact wind field) and (2) the influence of the initial conditions on the simulations has not been fully resolved. In addition, the emissions projections contain uncertainties because it is difficult to anticipate all possible structural changes in the use of energy that could occur in the next 20 years.

Lastly, although the state of the science lags behind the needs of the policy makers, and the current generation of models may be inadequate for firm regulatory decisions, states will be using UAM to determine control strategies. Given the uncertainties associated with photochemical modeling even when a high-quality data set is used for model inputs and testing, the models should be regarded as tools that can guide decision making but that cannot provide precise answers.

\section{S.4 FUTURE DIRECTION}

Phase 2 resulted in a number of uncertainties that still need to be investigated. A number of these areas of concern are described here, and possible directions for reducing the remaining uncertainties are given.

Argonne did not specifically examine the effects of initial conditions on the model results. The base case could possibly be improved by beginning the model run earlier, for example, at 0000 Local Standard Time on July 5. Starting the model run earlier might prevent the very high initial conditions from significantly influencing overnight ozone values. This change would be relatively easy to implement. 
Changing the boundary conditions for ozone to time-varying values improves overall model performance, but it causes the secondary ozone maximum modeled on the south shore of Lake Michigan to dissipate. Because this feature is present in the observations, it may be tied to transport into the eastern boundary of the grid. Additional boundary condition tests (e.g., a separate value for the eastern boundary or higher daytime values) could be investigated to see if the feature can be resolved.

Switching to the improved base case appears to make the model more sensitive to ozone scavenging by $\mathrm{NO}_{\mathrm{x}}$ downwind of large $\mathrm{NO}_{\mathrm{x}}$ sources. The effect is still localized, but the spatial extent spread by several tens of kilometers and the magnitude of air quality deterioration increase. Additional cases or sensitivity studies could be conducted to investigate this fact further to identify the exact conditions causing the phenomenon.

The VOC projections used in Phase 2 can be refined by using new VOC modeling. New VOC modeling uses the latest interpretations of the impacts of the CAAA on VOC emissions and incorporates market-based incentives such as trading schemes, the form of which are better known than when previous NES and National Acid Precipitation Assessment Program work was done.

The Lake Michigan Ozone Study, a $\$ 13$ million project to develop new models and databases to help the states to achieve attainment, is nearing completion. The data are being readied for public access and could be used to model additional time periods with better data or at least to improve boundary conditions and other inputs.

Argonne has gained much experience with UAM in the last year and has improved the base case to the point where cost-effectiveness issues of various control strategies could be examined. Individual UAM runs can now be developed, modeled, and analyzed in less than a week, once the case is defined. 


\section{INTRODUCTION}

\subsection{PURPOSE OF STUDY}

Titles I and IV of the Clean Air Act Amendments of 1990 (CAAAs; Public Law 101-549) require reductions in emissions of sulfur dioxide $\left(\mathrm{SO}_{2}\right)$, nitrogen oxides $\left(\mathrm{NO}_{\mathrm{x}}\right)$, and volatile organic compounds (VOCs) to reduce the number of pollutants in the atmosphere and to limit subsequent damaging effects. Title IV aims at reducing acidic deposition and requires utilities to reduce $\mathrm{SO}_{2}$ and $\mathrm{NO}_{\mathrm{x}}$ emissions to specified levels. Consequently, many utilities will need to install technologies to control $\mathrm{SO}_{2}$ and $\mathrm{NO}_{\mathrm{x}}$. Title I aims at bringing regions into compliance with the National Ambient Air Quality Standards (NAAQS) for the criteria pollutants, including ozone $\left(\mathrm{O}_{3}\right)$. The NAAQS for ozone is 120 parts per billion by volume (ppb) hourly average concentration, not to be exceeded four times in three years.

Ozone is a secondary pollutant formed in the atmosphere when $\mathrm{NO}_{\mathrm{x}}$ and VOCs react together in the presence of sunlight. Utilities are a significant source of $\mathrm{NO}_{\mathrm{x}}$ and an insignificant source of VOCs. The ratio of VOCs to $\mathrm{NO}_{\mathrm{x}}$ in the atmosphere determines whether $\mathrm{NO}_{\mathrm{x}}$ reductions are harmful to air quality; because of the complex chemistry involved, ratios below about 8:1 may cause increased ozone formation when $\mathrm{NO}_{\mathrm{x}}$ is reduced. In the past, ozone control strategy has focused on reducing VOC emissions because it was thought that reducing $\mathrm{NO}_{\mathrm{x}}$ could increase ozone concentrations. However, this approach has not worked, perhaps because natural and manmade VOC emissions and transport of ozone from other regions have been underestimated (National Research Council 1991). According the U.S. Environmental Protection Agency (EPA [1991a]), computer modeling has shown that for many highly polluted areas, massive $\mathrm{NO}_{\mathrm{x}}$ reductions may be necessary in addition to or in place of VOC controls. Utilities are a potential source of these $\mathrm{NO}_{\mathrm{x}}$ reductions.

Title I of the CAAAs ranks regions by the degree to which they exceed the ozone NAAQS and requires varying levels of $\mathrm{NO}_{x}$ and VOC emissions control depending on that ranking. $\mathrm{NO}_{\mathrm{x}}$ controls are required unless studies show that their imposition would be harmful to ozone attainment prospects. The question for utilities is the degree to which Title I will require them to reduce their $\mathrm{NO}_{\mathrm{x}}$ emissions beyond efforts they must undertake to satisfy Title IV. ${ }^{1}$ The answer provided by regulatory agencies will depend on the results of computer modeling of photochemical air pollution transport and transformation (EPA 1991b). The answer clearly has economic, technological, and fuel choice implications for utilities and is thus of great interest to them. The EPA has set Title I NO $\mathrm{N}_{\mathrm{x}}$ requirements at the same level as those required under Title $I V$ but has given the states room for stricter regulations. Several northeastern states already have proposed stricter standards.

1 The issue for utilities is both the level of $\mathrm{NO}_{\mathrm{x}}$ reduction required and the timing of the reduction because they will affect (1) the technology selected for control and (2) the ability to select a single technology to comply with both Title IV and Title I requirements at the same time so as to optimize the control strategy and its cost-effectiveness. 
This report extends and expands an earlier report that describes the fiscal year (FY) 1992 work (Phase 1) and results (Fernau et al. 1992). The current report summarizes the previous work and findings and describes in detail FY 1993 accomplishments (Phase 2) and findings. More detailed descriptions of Phase 1 efforts are given in Fernau et al. (1992; $1993 \mathrm{a} ; 1993 \mathrm{~b})$. The major purpose of the Phase 2 work is to address the areas of uncertainty in the Phase 1 modeling that prevented firm conclusions from being drawn and to expand upon the scenarios investigated in that study. Specifically, this report focuses on (1) improving characterization of the effects of uncertainty in various areas of the modeling procedure and improving model performance, and (2) examining several additional sensitivity scenarios involving different emission sectors. The conclusions and policy implications of the previous study are reexamined in light of these new studies.

Argonne National Laboratory's (ANL's) overall study addresses the policy question of how the CAAA and, specifically, Title I will affect electric utility compliance in the Chicago region. Specifically, ground-level ozone is examined; Chicago is designated severe nonattainment for this pollutant, as defined in the CAAA.

This study and the Phase 1 work examine several different emissions scenarios possible under the provisions of the CAAA. The aim is to determine impacts on air quality in the Chicago area and examine the trade-offs in adopting different strategies for achieving attainment. A number of specific questions are addressed:

- The importance of $\mathrm{NO}_{\mathrm{x}}$ reductions in achieving CAAA goals,

- The degree to which Title IV (acid rain) reductions of $\mathrm{NO}_{\mathrm{x}}$ will be adequate to address nonattainment issues, and

- The effectiveness of targeting transportation and other source categories vs. electric utilities in ozone nonattainment strategies.

This analysis helps to define $\mathrm{NO}_{\mathrm{x}}$ regulatory restrictions that could apply to new and existing power plants and examines the potential impact of these requirements on utility planning decisions regarding fuel and technology choice.

\subsection{APPROACH}

This study uses photochemical modeling to examine the above questions for the metropolitan Chicago area and surrounding regions. The Urban Airshed Model (UAM) is used to examine the relative roles of the electric utility industry and other sectors in contributing to an elevated ozone episode in the Chicago area. The Argonne Utility Simulation Model (ARGUS) is used to model future utility emissions. Both the National Energy Strategy (NES) and CAAA are used as guidelines to project emissions to the year 2010. Meteorology is based on a two-day period (July 5-6, 1988).

The UAM is an Eulerian photochemical grid model that simulates ozone and other pollutant concentrations to a several kilometer grid resolution for urban areas of several 
hundred kilometers on a side, given initial and boundary air quality conditions, meteorological conditions, and an emissions inventory (EPA 1990a). It is run for episodes of several days' duration. The EPA has approved the UAM for use by the states in developing state implementation plans for reducing ozone in nonattainment areas (EPA 1991b). This study uses UAM-IV, which is distributed by EPA. Within UAM, pollutants are emitted, undergo chemical transformations, and are transported within the grid by winds.

Argonne selected Chicago for analysis for several reasons. It is classified as a "severe" ozone nonattainment area, has an interesting mix of source categories, is dominated by one utility system with a mix of nuclear and fossil fuel-fired plants, and may be a viable market both for new nuclear capacity and electric vehicles. Argonne selected the UAM grid because it is large enough to encompass most of the utility plants operated by Commonwealth Edison (Com Ed). It is 50 cells $\times 50$ cells, and each cell has $5 \mathrm{~km}$ on a side. Therefore, grid size is $250 \times 250 \mathrm{~km}$. The grid boundaries and the utility emissions point sources included in it are shown in Figure 1.

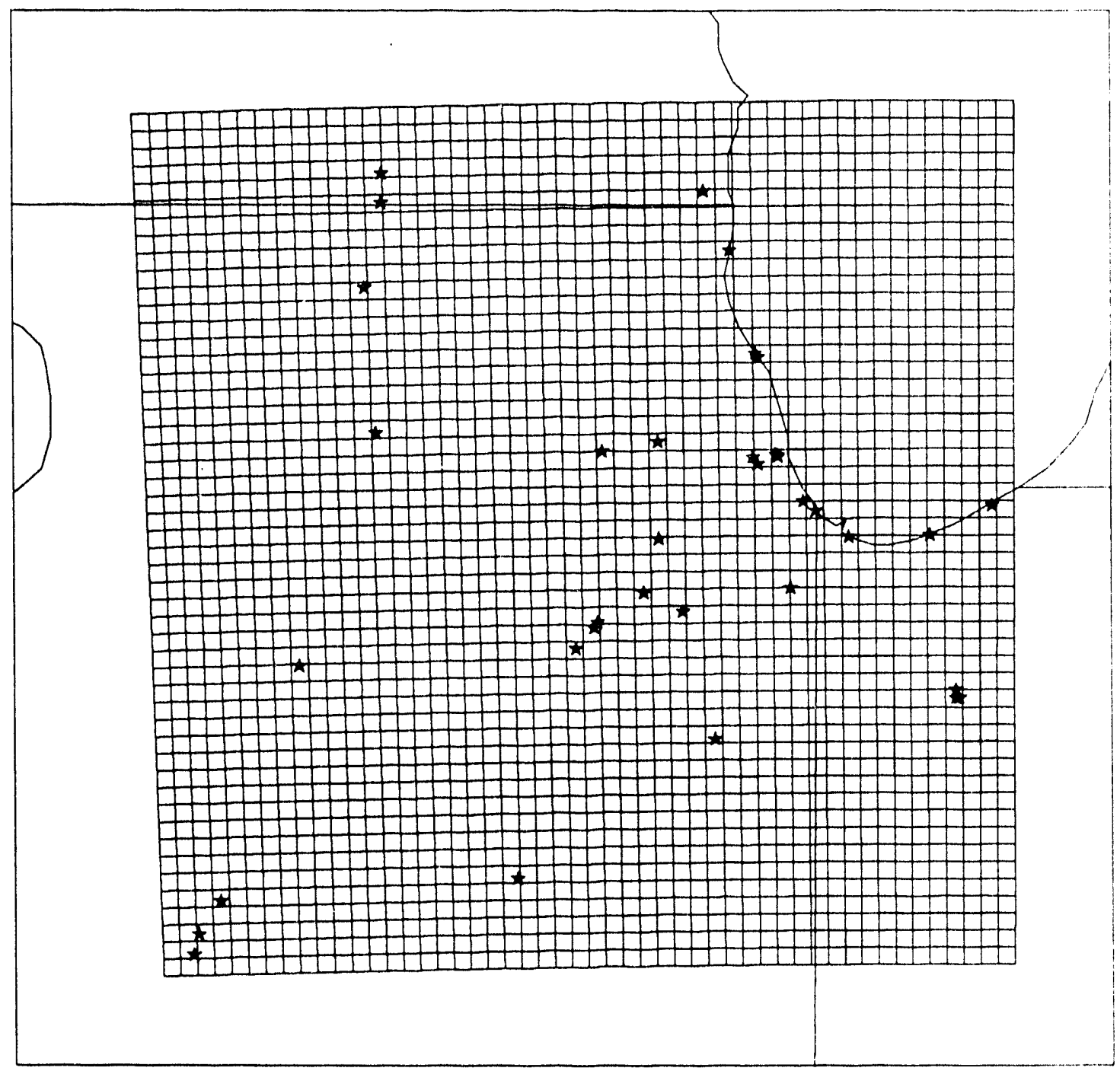

FIGURE 1 UAM Modeling Grid Showing Locations of Utility Point Sources 
The study uses a historical ozone episode to verify the model's performance and project current emissions to a future year. Within this base case, several cases of interest are presented. Argonne selected a two-day period (July 5 and 6,1988 ) that had some of the highest ozone concentrations of the year in the Chicago region. On these days, a slow-moving high-pressure system provided abundant sunlight and stagnant conditions, which allowed pollutants to build up. The UAM was run from 1200 Local Standard Time (LST) on July 5 to 2000 LST on July 6. Day 1 was used to let the model come to equilibrium, and day 2 was used for the analysis.

The UAM is a complicated system of computer models that requires the acquisition and preparation of raw data followed by several dozen different computer preprocessor runs to produce the input for one UAM simulation (EPA 1990a). SUN and IBM RISC workstations execute the codes and simulate with UAM a 32-h episode using about 4-5 hours of computer time on the IBM or about 15-17 hours on the SUN, excluding data preparation and preprocessing.

Phase 1 partially validated the UAM for the July 1988 episode. Scenarios of future utility energy use and associated emissions in 2010 were defined by using ARGUS in the Com Ed service territory. Nonutility emissions were projected through use of other ANL models. These future scenarios were run using UAM and historical episode meteorology to examine the effect of altered emissions profiles in 2010 on ozone concentrations. The scenarios focused mainly on options for the utility industry (Fernau et al. 1992).

Phase 2 examines the sensitivity of ozone concentrations to emissions changes in other sectors. Gross sensitivity tests of large changes in motor vehicle emissions are investigated, and a future scenario that assumes some electric vehicle penetration into the region is run. Argonne also conducted a gross sensitivity test to examine changes in industrial emissions and investigated a more realistic future industrial scenario based on implementation of the CAAA. This study uses a methodology similar to that used in Phase 1; i.e., new emission files are created, UAM is run using historical episode meteorology, and the resulting changes in ozone concentration are compared with a base-case UAM run. The results from the Phase 2 cases are compared with the Phase 1 results. Appendixes A and B describe in detail the mechanics of the UAM modeling performed in this study.

The verification of the 1988 base case in Phase 1 was not as good as desired. Overnight ozone was greatly overpredicted, and maximum ozone values were underpredicted to some extent (Fernau et al. 1992). Phase 2 addresses the potential reasons for these performance problems. This Phase 2 report examines the sensitivity of UAM results to various input parameter changes and to a corrected biogenic emissions factor. This procedure improves understanding of the effects of uncertainty in the modeling process and allows ANL to determine the robustness of results from Phase 1. In addition to the effects of the improved biogenic emissions factor, this report investigates the impact of changes in initial and boundary conditions for ozone and $\mathrm{NO}_{\mathrm{x}}$, and changes in the method of calculating mixing heights over the grid region. The resulting changes in ozone concentrations from these UAM simulations are compared with previous results to determine the sensitivity of UAM to these parameter changes. 


\section{IMPROVEMENT OF THE 1988 BASE CASE}

\subsection{REVIEW PHASE 1 BASE CASE (CASE B1)}

In Phase 1 before examining future scenarios, ANL evaluated the performance of the model for the selected episode, examined the spatial pattern of the simulated ozone maxima, compared the time series of the simulated ozone at individual monitoring sites with observations, and computed various statistics, as described below. This case is designated as Case B1.

The model captured the spatial distribution of maximum ozone concentrations during the day on July 6. It showed an extensive area of 1-h average ozone concentrations above $140 \mathrm{ppb}$ along the western shore of Lake Michigan north of Chicago. The simulated maximum of $159 \mathrm{ppb}$ was only about 10 or $15 \mathrm{~km}$ from the location of the observed maximum of $222 \mathrm{ppb}$, and it catches the secondary area of high ozone along the south shore of the lake in Indiana, as shown in Figure 2. Although the spatial pattern given by the model corroborates well, the absolute value of peak ozone is underpredicted by $28 \%$, and the average monitoring station peak is underestimated by $22 \mathrm{ppb}$ or $19 \%$. The average bias from all hourly prediction-observation pairs for observed values greater than $60 \mathrm{ppb}$ is underpredicted by $2 \mathrm{ppb}$. The model overpredicts lower ozone values, mostly at night.

The problems with overprediction at night and underprediction of maximum ozone probably are due to the particular values of evening mixing height and initial and boundary concentrations assigned in the preprocessors. The effect of altering these values is investigated later in this section. To accommodate for biases in the model, ANL staff took two actions when presenting results. First, they described changes in maximum ozone under different control scenarios generally in terms of percent changes from the base line, rather than as absolute changes and compared them with the percent change needed at each monitoring site to each attainment. This method more accurately assesses the attainment effectiveness of a given strategy than does looking at absolute values.

Secondly, when discussing and plotting peak ozone fields, ANL staff used only maxima occurring from noon onward on July 6. A sensitivity test in which all emissions, both natural and manmade, were removed from the grid (Section 4.1.1) showed that the specified initial and boundary conditions significantly affected modeled ozone concentrations and allowed ozone concentrations to fall only slowly with time. Complete removal of emissions led to attainment, on a percentage basis, at 29 of 31 sites and barely brought the grid maximum value to attainment. Overnight ozone was still very high in this case and only fell tn low values $(60-80 \mathrm{ppb})$ by afternoon on July 6 . This fact accounts for the nighttime overprediction in the model and causes rural areas in the grid that are not significantly influenced by the emissions field to experience peak ozone at night in all other cases. Restriction of the analysis to afternoon removes these rural artifacts without affecting the urban concentrations that actually are influenced by the emissions patterns. 


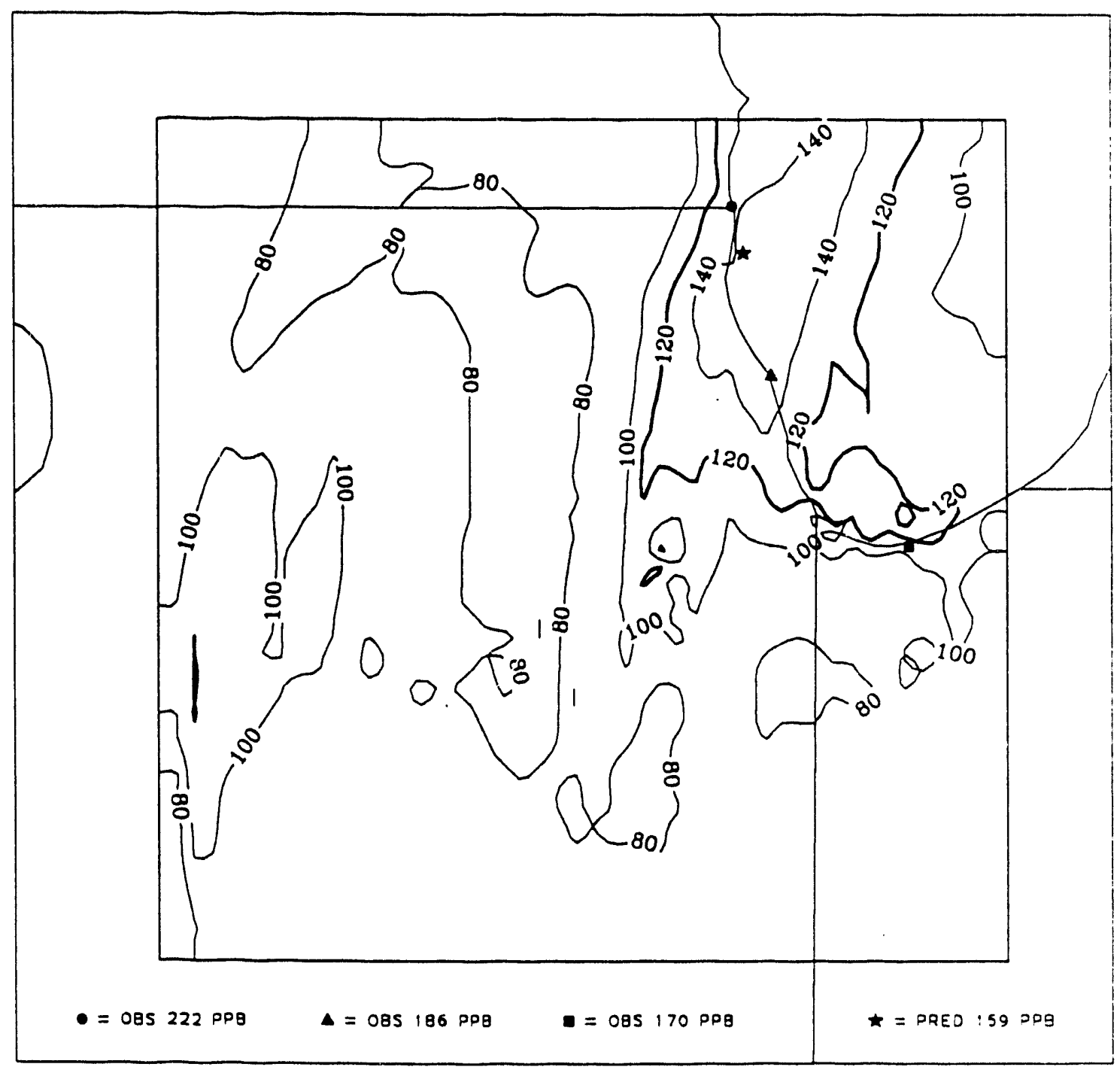

FIGURE 2 Predicted Maximum Hourly Ozone Concentrations for July 6, 1988: Phase 1 Base Case (B1) (maxima are based on the period from 1200 to 2000 Local Standard Time; see text for explanation)

Parameter investigation to improve the 1988 base case is described in the remainder of Section 2. This analysis focuses on an improved biogenic emissions factor, more realistic ozone boundary conditions, increased $\mathrm{NO}_{\mathrm{x}}$ initial and boundary conditions, a new mixing height algorithm, and a combination of parameter changes.

\subsection{BIOGENIC EMISSIONS (CASE A1)}

As noted in Fernau et al. (1992), recent scientific findings indicate that the EPA has overestimated the natural VOC emissions factor from corn by four orders of magnitude in their biogenic emissions model (Sharkey 1992). The incorrect biogenic emissions model used 
a flux of about $3,500 \mu \mathrm{g} / \mathrm{m}^{2} / \mathrm{h}$, while the latest field and laboratory studies yield a flux of about $0.5 \mathrm{\mu g} / \mathrm{m}^{2} / \mathrm{h}$. For this study, correcting the biogenic emissions model with the new factor reduced the biogenic VOC emissions from 2,079 to 232 ton/d.

A UAM simulation, referred to as Case A1, was run with the new biogenic emissions, holding all the other inputs the same as in the $1988 \mathrm{~B} 1$ base-case run. The results were minimally different from the previous base-case run B1. The gridwide predicted maximum was reduced from 159 to $158 \mathrm{ppb}$, and the maximum at most grid cells changed by $1 \%$ or less. Over the city of Chicago, ozone maxima decreased by about $2 \%$; to the west of Chicago in one area, maxima decreased by 2 to $5 \%$. Finally, in two small areas in the west-central part of the grid, ozone maxima decreased by $2 \%$.

Since manmade VOC emissions for the base case were 2,626 ton/d (Fernau et al. 1992), the biogenic emissions reduction represented an overall $39 \%$ decrease in VOCs. As noted in Fernau et al. (1992), the $\mathrm{VOC} / \mathrm{NO}_{\mathrm{x}}$ ratio for this episode over the grid region is relatively high at ground level, well above an 8:1 ratio. The grid region is therefore a $N O_{x}$ limited region, causing the maximum ozone predictions to be very insensitive to rather large changes in VOCs. A contour plot of maximum ozone levels (Figure 3 ) shows that the spatial pattern is almost identical to the base case presented in Figure 2. It appears that the reduction in VOCs from the new corn emissions factor has relatively little impact on the resulting predictions for the current set of modeling parameters and emission inventories. Statistical tests and site-specific changes for this run are compared to the previous base case in Sections 2.6 and 6.1.

\subsection{BOUNDARY CONDITIONS FOR OZONE (CASE A2)}

The no-emissions case described in Section 2.1 showed that the ozone on July 6 was very sensitive to initial and boundary conditions. The ozone initial conditions are set by measurements, but the ozone boundary conditions for the base case arbitrarily were held at $80 \mathrm{ppb}$ throughout the $32-\mathrm{h}$ run. No measurements were made along the border, but it was felt initially that this concentration could represent transport of ozone from areas to the south and west of the grid.

Argonne made an additional test of the sensitivity to boundary conditions by choosing more realistic time-varying boundary conditions for ozone, to see if the nighttime overpredictions could be lowered. The time-varying ozone values chosen were based on measured ozone values at monitoring stations throughout the grid region, particularly those closer to the boundary. As shown in Figure 4, the ozone boundary conditions start on day 1 at $80 \mathrm{ppb}$, drop to $40 \mathrm{ppb}$ at 2000 LST on day 1 , drop to $20 \mathrm{ppb}$ at 0200 on day 2, rise to $40 \mathrm{ppb}$ at 0700 on day 2 , and finally rise to $80 \mathrm{ppb}$ at 0900 on day 2 , remaining constant thereafter. 


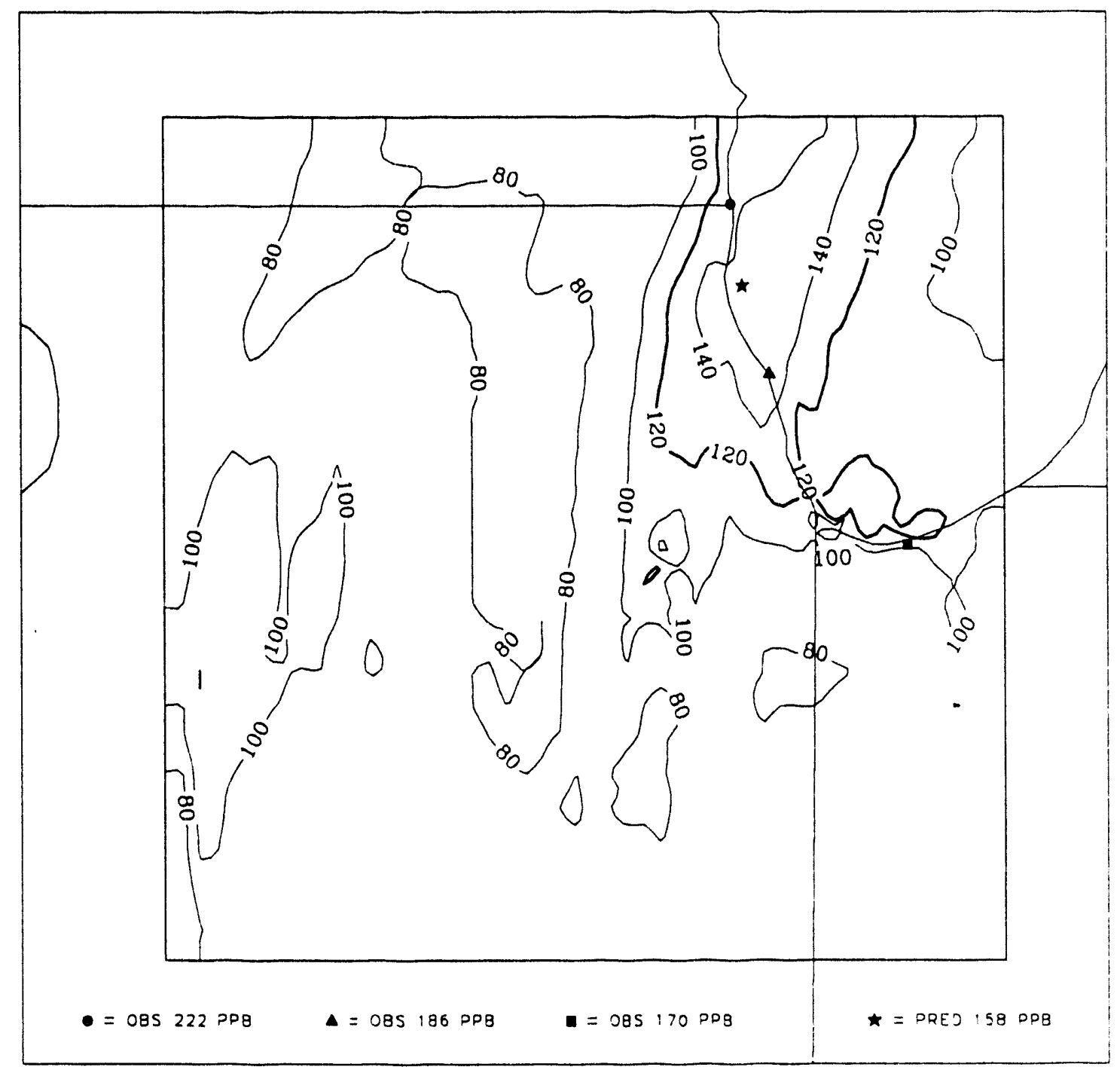

FIGURE 3 Predicted Maximum Hourly Ozone Concentrations for 1200 to 2000 LST on July 6, 1988: Biogenic Emissions Sensitivity Case (A1) (maxima are based on the period from 1200 to 2000 LST)

Argonne staff compared the resulting UAM run from this change, designated Case A2 and including the new biogenic emission factor, with the original base case B1. (Note: Cases B1 and A1 are almost identical.) The maximum ozone prediction was reduced from 159 to 147, although the maximum location was minimally changed. Figure 5 shows a contour plot of the maximum hourly ozone concentrations (1200-2000 LST) for July 6, 1988 (day 2). Maximum ozone predictions at measured sites, generally occurring in midafternoon on day 2, dropped by $10 \mathrm{ppb}$ at most sites to as much as $30 \mathrm{ppb}$ at a few sites. Predicted minimums, generally occurring in the early morning hours on day 2 , also drop significantly, in many cases by $10 \mathrm{ppb}$ to as much as $30 \mathrm{ppb}$. Generally, sites that are close to the boundary feel the impacts of changes in the ozone boundary conditions more quickly than interior sites. 


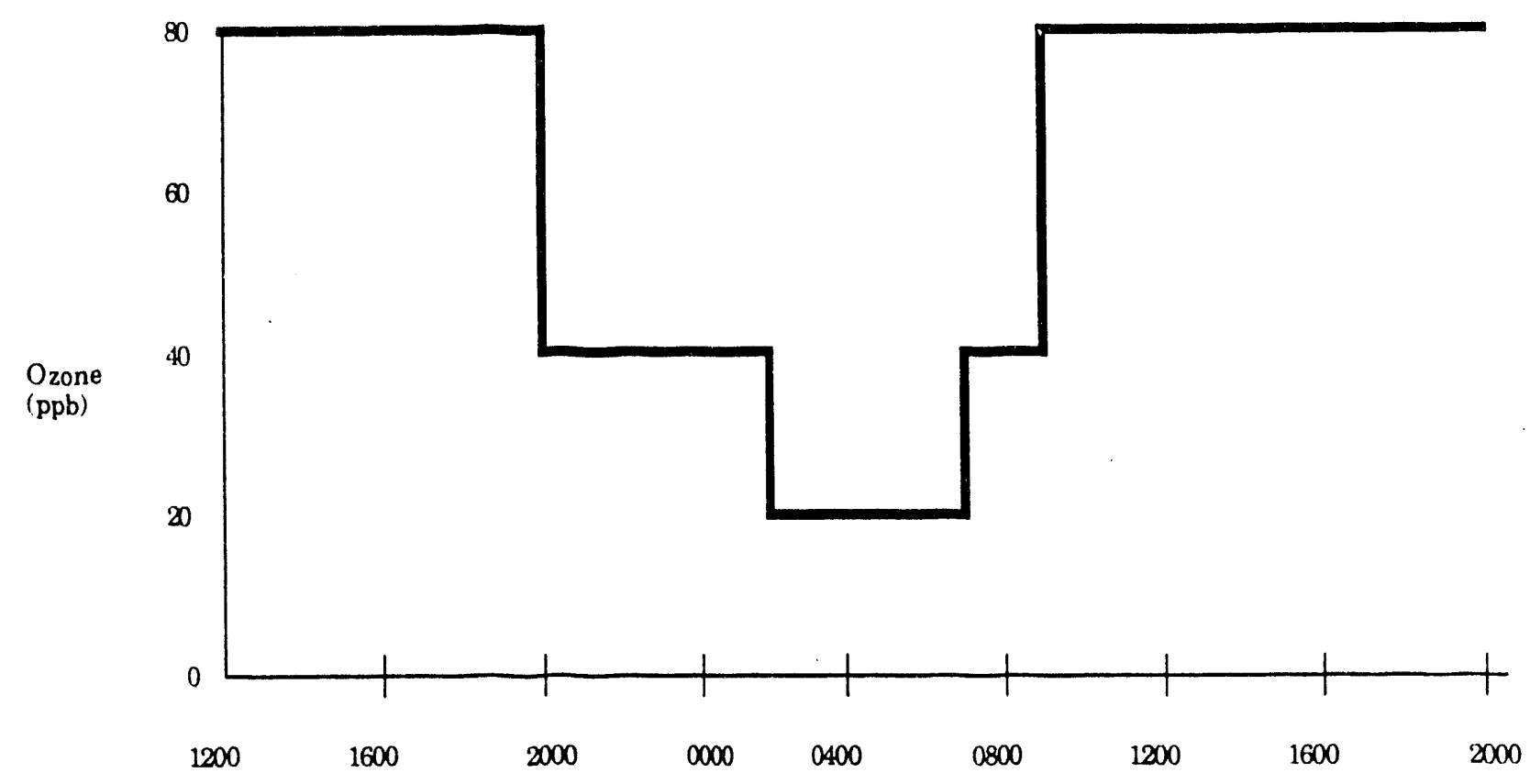

FIGURE 4 Ozone Boundary Conditions for Case A2 from 1200 LST on July 5, 1988, to 2000 LST on July 6, 1988

Varying the boundary conditions for ozone reduced ozone concentrations during the nighttime and early morning, as expected, but maxima were also lowered. Overall model performance improved, and the predicted patterns are more realistic, with maximum ozone being less determined by the high early morning values. Because these time-varying concentrations reflect the measured site data, they were included, as was the new biogenic emission factor, in other sensitivity runs. Statistical tests and site-specific changes for this run are compared to the previous base case in Sections 2.6 and 6.1.

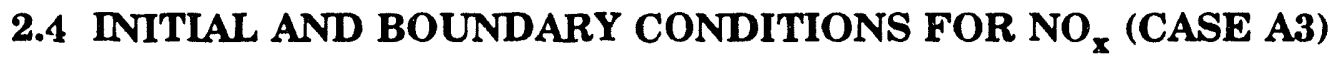

The sensitivity of UAM results to initial and boundary conditions for $\mathrm{NO}_{\mathrm{x}}$ emissions was tested by increasing both $\mathrm{NO}$ and $\mathrm{NO}_{2}$ concentrations by two to three times their previous values. Specifically, for lateral boundary conditions, $\mathrm{NO}$ and $\mathrm{NO}_{2}$ doubled from 0.5 and $1.5 \mathrm{ppb}$ to 1 and $3 \mathrm{ppb}$, respectively. At the top of the grid, $\mathrm{NO}$ and $\mathrm{NO}_{2}$ tripled from 0.5 and $1.5 \mathrm{ppb}$ to 1.5 and $4.5 \mathrm{ppb}$, respectively. As initial conditions, $\mathrm{NO}$ and $\mathrm{NO}_{2}$ were tripled from 1 and $3 \mathrm{ppb}$ to 3 and $9 \mathrm{ppb}$, respectively. A UAM run, designated Case A3, was made using these conditions, and the maximum ozone predictions were calculated. Case A3 also retained the time-varying ozone boundary conditions of Case A2 and the new emissions of Case A1. 


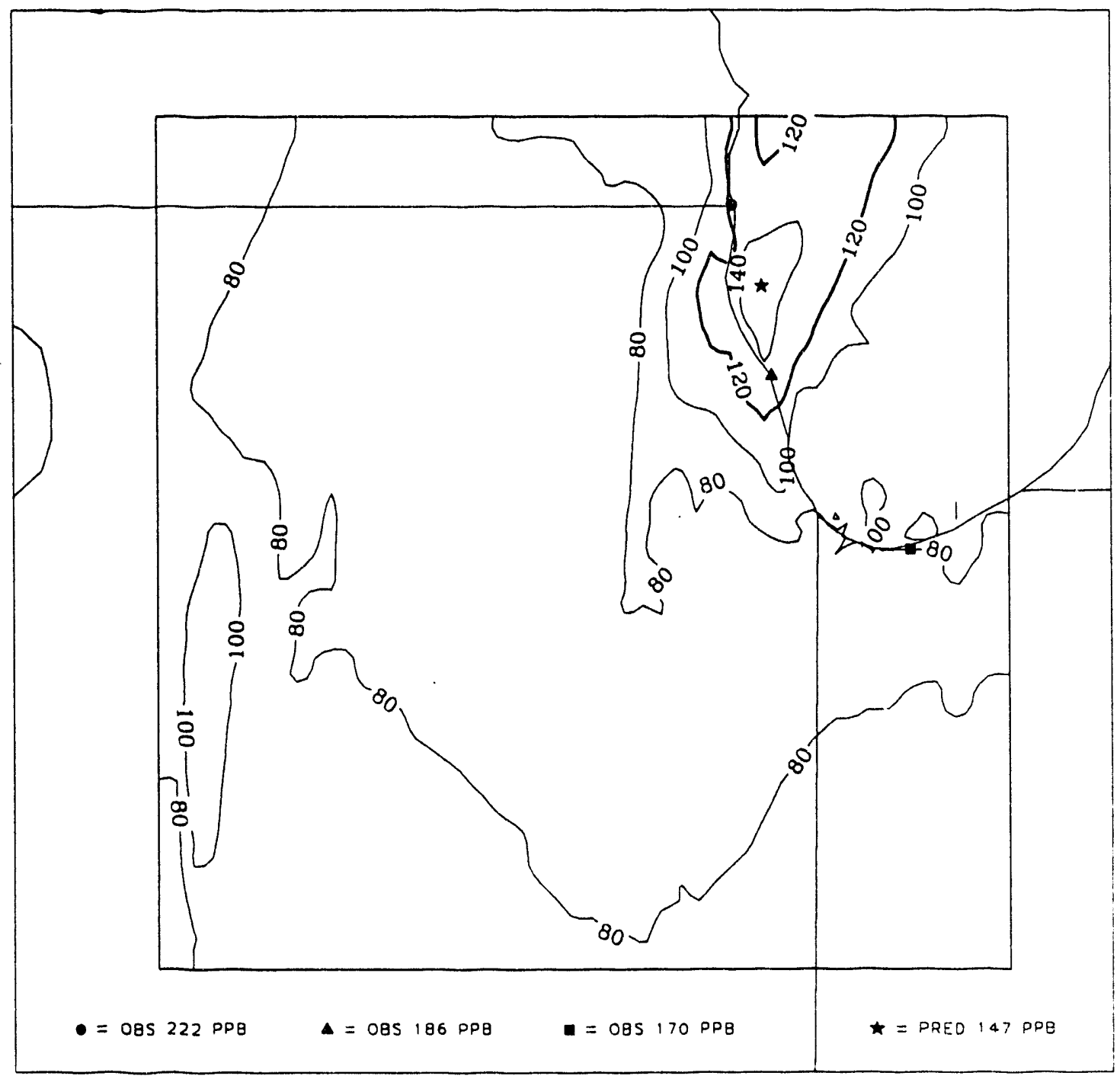

FIGURE 5 Predicted Maximum Hourly Ozone Concentrations for 1200 to 2000 LST on July 6, 1988: Varying Ozone Boundary Conditions Case (A2) (maxima are based on the period from 1200 to $2000 \mathrm{LST}$ )

The contour plot of maximum ozone predictions is shown in Figure 6. The predicted ozone maximum was $148 \mathrm{ppb}$, and it occurred close to the Case A2 maximum. Most sites have small increases in maximum ozone concentration (about 0 to $5 \mathrm{ppb}$ ) when compared with Case A2. Overall, Case A3 is not very different from Case A2. Statistical tests and sitespecific changes, see Sections 2.6 and 6.1.

\subsection{MIXING HEIGHTS (CASE A4)}

Ozone predictions are known to be sensitive to the mixing height field (EPA 1991b). The UAM preprocessors provide several methodologies for deriving mixing heights based on 


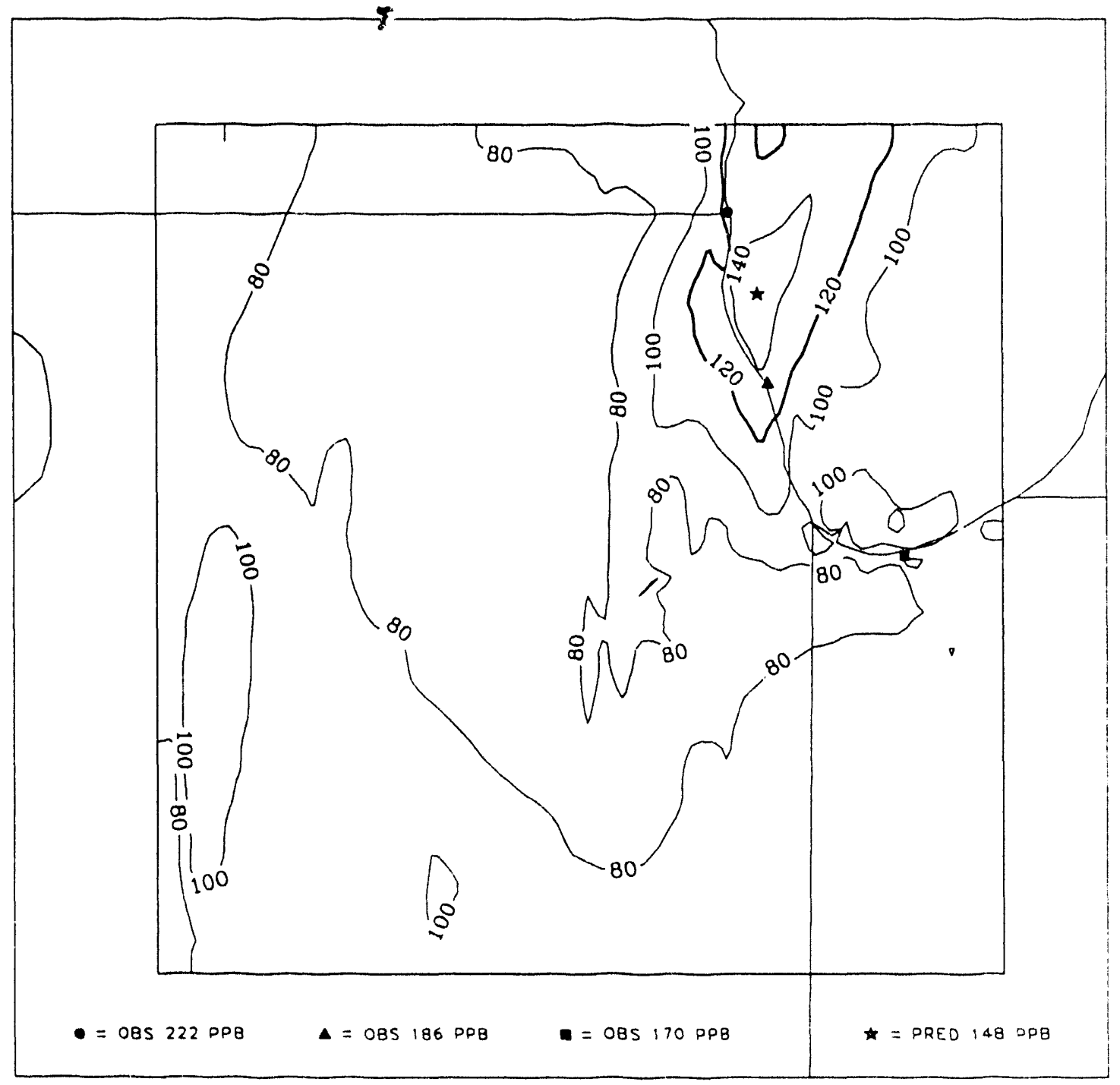

FIGURE 6 Predicted Maximum Hourly Ozone Concentrations for 1200 to 2000 LST on July 6, 1988: Increased NO Initial and Boundary Conditions Case (A3) (maxima are based on the period from 1200 to 2000 LST)

surface temperature, vertical sounding measurements of temperature and cloud cover. In UAM, the diffusion break or mixing height is either the height of the well-mixed layer (days) or the height of the inversion base (nights). The mixing height is calculated from meteorological inputs of surface temperature, pressure and upper air soundings.

The choice of mixing heights in the base-case UAM calculation performed in Phase 1 (Fernau et al. 1992) assumed an option that calculated the rate of growth of the mixing height as a function of temperature ("Option 2"). In the present sensitivity test, another option that accounts for the diurnal variation in mixing height (but not based on surface temperature) was used ("Option 0") (EPA 1990a, Vol. 2). Hourly mixing height data from five stations were used to calculate the mixing height field over the entire grid region. The 
change in mixing height options affects other preprocessor calculations. Specifically, the grid region top mixing height value was changed to $2,600 \mathrm{~m}$, about $58 \mathrm{~m}$ above the maximum mixing height, and the wind fields were recalculated. These changes require that the initial condition, point source plume rise, and biogenic emissions preprocessors be rerun. All of these modified input files were then used for a new UAM run. The new biogenic emission factor (A1) and time-varying ozone boundary conditions (A2) were included as part of the calculation.

The UAM results of this run, called Case A4, are shown in the form of a contour plot of maximum ozone predictions in Figure 7. The maximum ozone prediction increased from 147 (Case A2) to $156 \mathrm{ppb}$. The range between maximum and minimum predictions changed at all 31 measured sites, with 18 sites having a greater difference between maxima and minima (in better agreement with the measured data) and 13 having less range. However, 11 sites exhibited large increases in range ( $>20 \mathrm{ppb}$ ), while only 4 sites showed equivalent large decreases. Therefore, the new mixing height choice provided some improvement to time series fits to the ozone data. Compared with B1, however, there is still the trade-off of lower minima but also somewhat lower maxima. Statistical tests and site-specific changes for this run are compared in Sections 2.6 and 6.1.

\subsection{NEW COMBINED BASE CASE (CASE A5)}

On the basis of the sensitivity studies in this section (2.2-2.5), ANL conducted several statistical tests on the UAM-predicted ozone results to see how they compared with the base case B1 and with each other, so that the Phase 2 modeling would be based on the best case. The statistical tests most highly recommended by EPA (EPA 1991) for comparing predicted and observed ozone concentrations at measured sites include:

1. The Unpaired Highest Prediction Accuracy (UHPA) test, which is defined as the difference between the observed maximum and the predicted maximum relative to the observed maximum, unpaired in time or space. The EPA recommends $\pm 15-20 \%$ as good performance, although the model developers state that $\pm 30 \%$ was often seen in past studies.

$$
\text { UHPA }=\frac{\text { obsmax }- \text { predmax }}{\text { obsmax }} \times 100
$$

2. The Normalized Bias Test (NBT), which is defined as the normalized difference between all hourly prediction-observation pairs at all monitoring stations. The EPA recommends $\pm 5-15 \%$ as good performance. For calculating this statistic, all ozone observations below the Aerometric Information Retrieval System (AIRS)-stated detection limit of $5 \mathrm{ppb}$ were set to $5 \mathrm{ppb}$. Negative values indicate overprediction.

$$
N B T=\sum_{i=1}^{N} \frac{(\text { obs })-(\text { pred }) i}{(\text { obs }) i} / N \times 100
$$




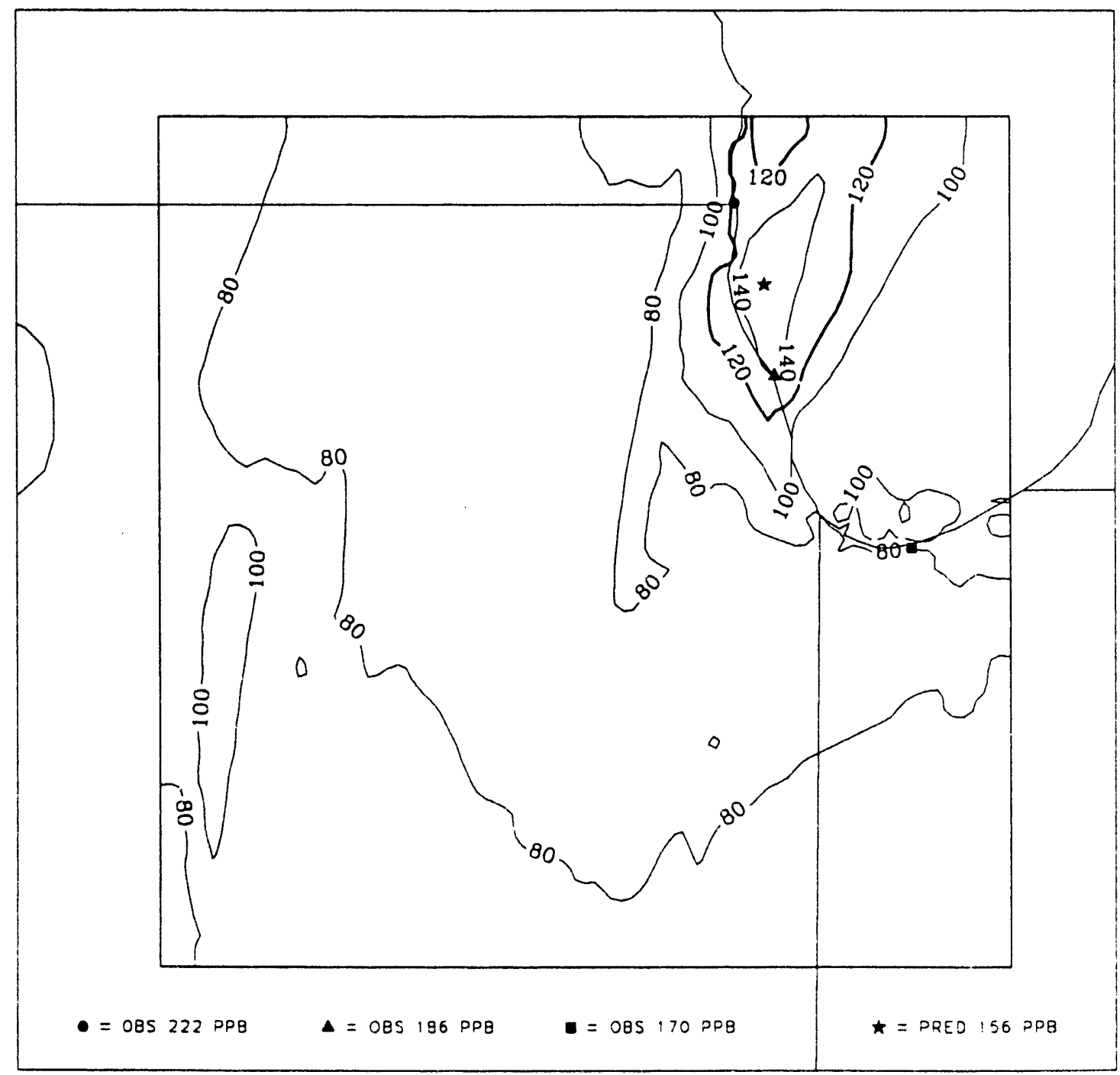

FIGURE 7 Predicted Maximum Hourly Ozone Concentrations for 1200 to 2000 LST on July 6, 1988: Mixing Height Sensitivity Case (A4) (maxima are based on the period from 1200 to 2000 LST)

3. The Gross Error of All Pairs > 60 ppb (GEAP > 60), which is defined as the normalized gross error for all hourly prediction-observation pairs for hourly observed values greater than $60 \mathrm{ppb}$. The EPA indicates a range of $30-35 \%$ is acceptable.

$$
\text { GEAP }>60=\sum_{i=1}^{N} \frac{(\text { obs })-(\text { pred }) i}{(\text { obs }) i} / N \times 100
$$

Another measure of performance is the following:

4. The Normalized Bias of All Station Peaks (NBASP), which is defined as the normalized bias from all prediction-observation pairs for peak 
observed values at each monitoring station. The formula is the same as NBT, but pairs are only summed over all sites, not all hours. Positive values indicate underprediction.

For these tests, the "predicted" value is obtained by weighted interpolation of the predicted concentrations at the four grid cells nearest to the station for the given hour. Alternate methods are discussed below.

Table 1 shows the values obtained for all three statistical measures for Case B1 and the various sensitivity tests $\mathrm{A} 1$ through $\mathrm{A} 4$. The statistics confirm that little difference exists between the $\mathrm{B} 1$ and the corrected $\mathrm{A} 1$ runs. There is a steady improvement in UHPA with the tests, but still none is as good as B1. GEAP > 60 and NBASP confirm the degradation at high observed values, with A3 doing better than A2 or A4. The improvement in NBT, reflecting the improved performance at night, is readily apparent with A1 through A4, all improving on B1.

On the basis of the results from A1 through A4, ANL determined that combining Case A1 (corrected biogenic emissions), Case A2 (realistic time varying ozone initial and boundary conditions), Case A3 (increased initial and boundary conditions for $\mathrm{NO}_{\mathrm{x}}$ ), and Case A4 (different mixing height algorithm) into one UAM run would provide a better, more realistic set of parameters and potentially an improved fit to the observations. Figure 8 shows the contour plot of maximum predicted ozone values for the resulting run (Case A5). The statistical test for unpaired highest prediction accuracy is $28.8 \%$, the gross error of all pairs greater than $60 \mathrm{ppb}$ is $21 \%$, and the normalized bias test is $-132 \%$. The reason for the large value is the consistent overprediction at lower observed concentrations. The UHPA is above EPA recommendations but in line with other modeling study results.

TABLE 1 Comparison of the Results of Several Statistical Tests for Cases B1 and A1-A5 ${ }^{\mathrm{a}}$

\begin{tabular}{lcccccc}
\hline Stat Test & B1 & A1 & A2 & A3 & A4 & A5 \\
\hline UHPA & +28 & +29 & +34 & +33 & +30 & +29 \\
NBT & -231 & -229 & -191 & -184 & -136 & -132 \\
GEAP $>60$ & 18 & 18 & 26 & 22 & 26 & 21 \\
NBASP & +15 & +16 & +34 & +29 & +33 & +28 \\
\hline
\end{tabular}

a Values are given in percent. 


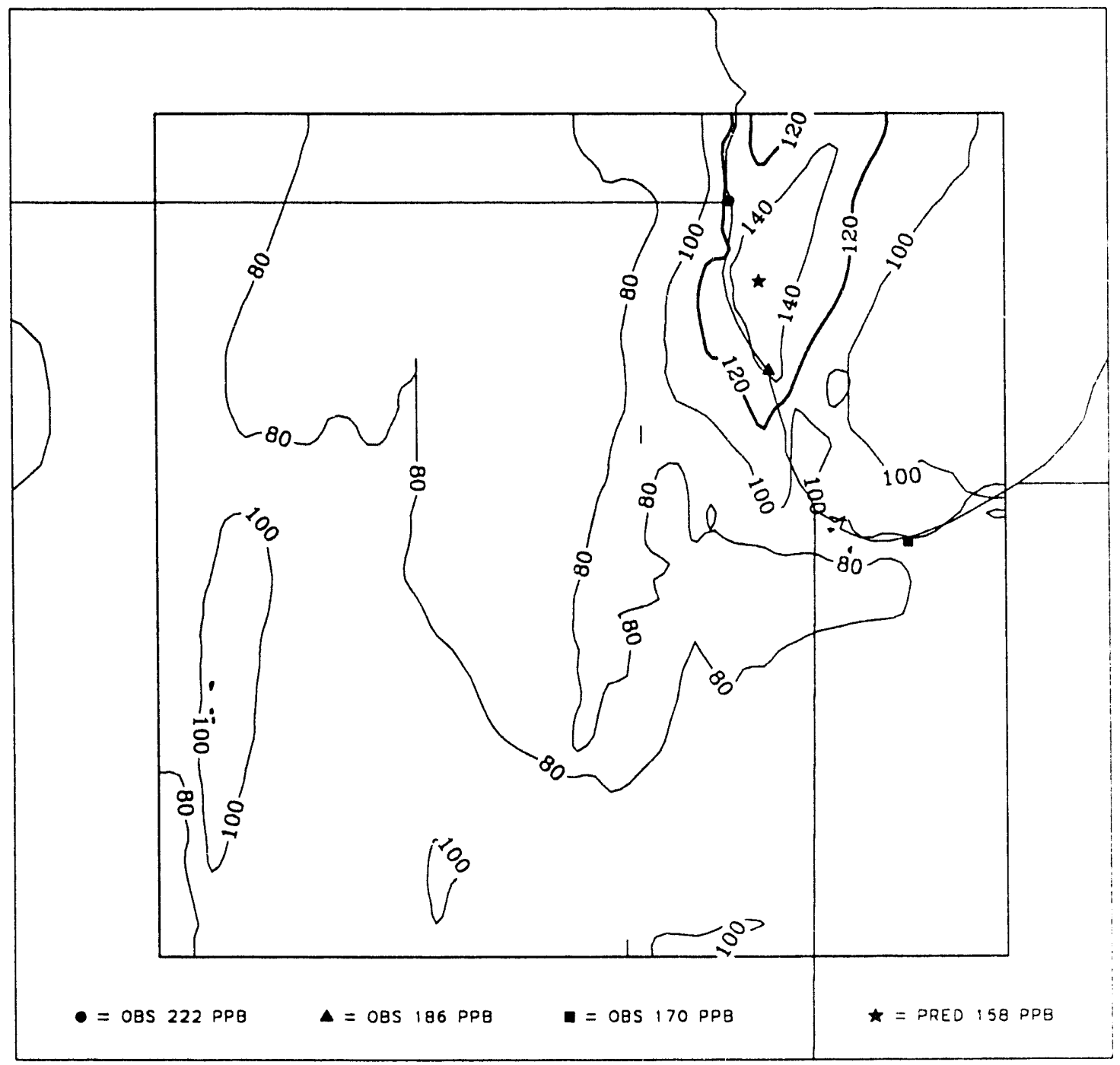

FIGURE 8 Predicted Maximum Hourly Ozone Concentrations for 1200 to 2000 on LST July 6, 1988: Combined Case (A5) (maxima are based on the period from 1200 to 2000 LST)

The GEAP > 60 is within EPA recommendations. Although greatly improved over B1 (from $-231 \%$ to $-132 \%$, a factor of about 2 ), NBT is well above EPA recommendations. This will be discussed further below.

On the basis of these results, ANL selected A5 as the base case for the Phase 2 modeling. Figure 9 is a percentile plot of both B1 and A5 vs. the observations. Points are plotted in increments of $5 \%$, with the leftmost point being the minimum, the rightmost point the maximum, and the middle point the median. The B1 curve shows the overprediction of observations less than about $60 \mathrm{ppb}$, better performance at higher observations, and underprediction of the highest $10 \%$ of values. The A5 curve is considerably improved at the lower values, although still overpredicting. This remaining overprediction may be due to the 


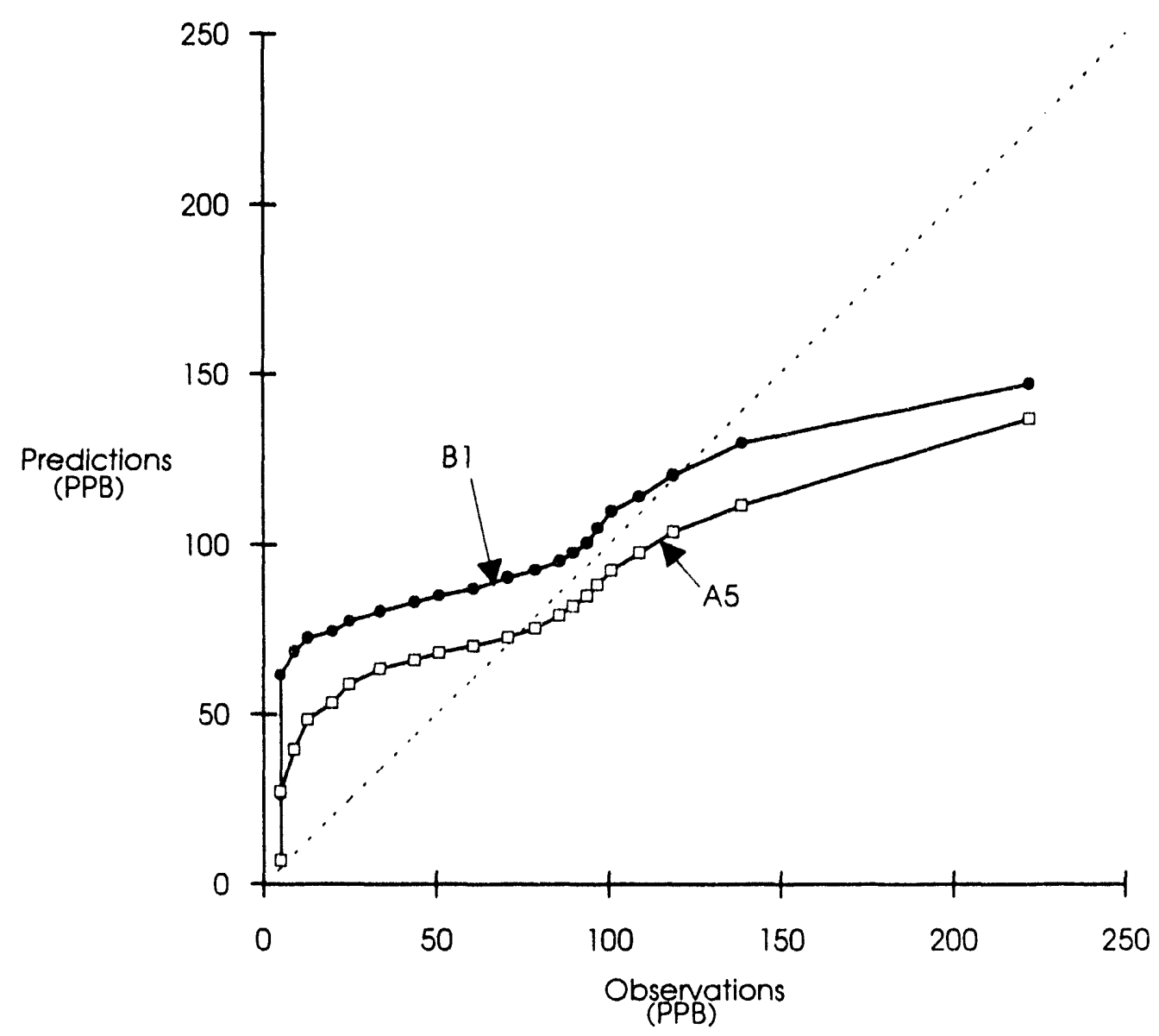

FIGURE 9 Percentile Plot of Cases B1 and A5 vs. Observations (percentile increment $=5 \%$ )

high initial conditions present on July 5. Future work could involve starting the model at midnight on day 1 to see if that improves performance. Performance remains good at middle percentiles; however, some degradation in performance at higher values is evident.

It will be shown later (Section 4.2.2) that doubling motor vehicle emissions gives much better performance at the high values. Combining doubled motor vehicle emissions with the A5 case yields very good statistics (Section 4.2.3), but its arbitrary nature precluded its use as the base case.

Regarding model performance, published UAM studies often exclude values less than $40 \mathrm{ppb}$ or even $60 \mathrm{ppb}$ in reporting bias results (Morris et al. 1992), something that would cover up poor performance at low values and improve the statistics. This could be justified because it is a normalized or relative statistic, so small absolute errors are magnified greatly in percentage terms. For instance, for Case A5, moving the cutoff from 0 to $20 \mathrm{ppb}$ improves 
NBT from -132 to $-18 \%$, close to the EPA guideline, and moving to $40 \mathrm{ppb}$ yields $+7 \%$, firmly within EPA guidelines. For the Phase 1 B1 base case, a 40-ppb cutoff also yields a value within EPA guidelines (-14\%).

Second, comparing observations at a point with values spread over a $25-\mathrm{km}^{2}$ grid cell is difficult. If the spatial pattern is correct but shifted somewhat in space (or even time), the statistics will indicate a poorer performance than is warranted. Alternate definitions of a "prediction" were defined as the value within a one- or two-cell radius of the observation that most closely matched the observation. For A5, this alternate definition improved GEAP > 60 from $21 \%$ to $12 \%$ and $9 \%$ for one and two cells, respectively. NBT improves from $-132 \%$ to $-103 \%$ and $-86 \%$ for one and two cells, respectively. Calculations were not done for the 20- and 40-ppb cutoffs, but one can assume performance with the new definitions would be improved over the numbers cited in the previous paragraph, yielding even better results within the EPA guidelines.

Finally, the inability to predict low enough minima or high enough maxima apparently is common in UAM applications. The Electric Power Research Institute (1992) reports average bias and error in the 10 to $40 \%$ range for an array of UAM studies. First results from a recent UAM study in the northeastern United States reported that UAM was biased toward overpredicting most hours while not necessarily predicting all of the peaks. Concentrations at night in the model do not go down to the low concentrations measured (Air Quality Week 1993).

A typical example of the difficulties in predicting observed maxima and minima is shown in Figure 10, a time series plot of hourly ozone predictions for cases B1 and A5 vs. observations at the Evanston site. The effect of new parameters from cases A1 through A4 is evident in the improved fit to the data before $1200 \mathrm{LST}$ on day 2. However, the fit to the data on the afternoon and evening of day 2 is worsened slightly. An analysis of time series plots at Evanston in terms of individual parameter changes (not shown), cases A1 through A4, indicates that most of the improvement comes from the choice of new ozone boundary conditions and new mixing height.

Time series plots at three other sites that compare cases B1, A5, and observations are shown in Figures 10 to 13 . At the Pleasant Prairie, Wisconsin, site, which had the highest observed ozone of any site on July 6, neither case gives good fits, and Case A5 is slightly worse than B1. This site is located near Lake Michigan, and it may be that the land/ lake breeze is not being modeled properly at that location so that elevated ozone over the lake is not being transported inland in the afternoon. At the Edgewater and North Ashland site in downtown Chicago, Case A5 significantly improves the fit before noon but at the expense of afternoon and evening hours. At a site in Peoria, Case A5 significantly improves predictions before 0700 , is much worse than B1 from 0800 to 1000 , and then is the same as B1. It is evident that Case A5 generally provides improved fits to maximum ozone time series data overall, but with some worsening of fits to the afternoon and evening data. This improvement is also evident in statistical tests. 


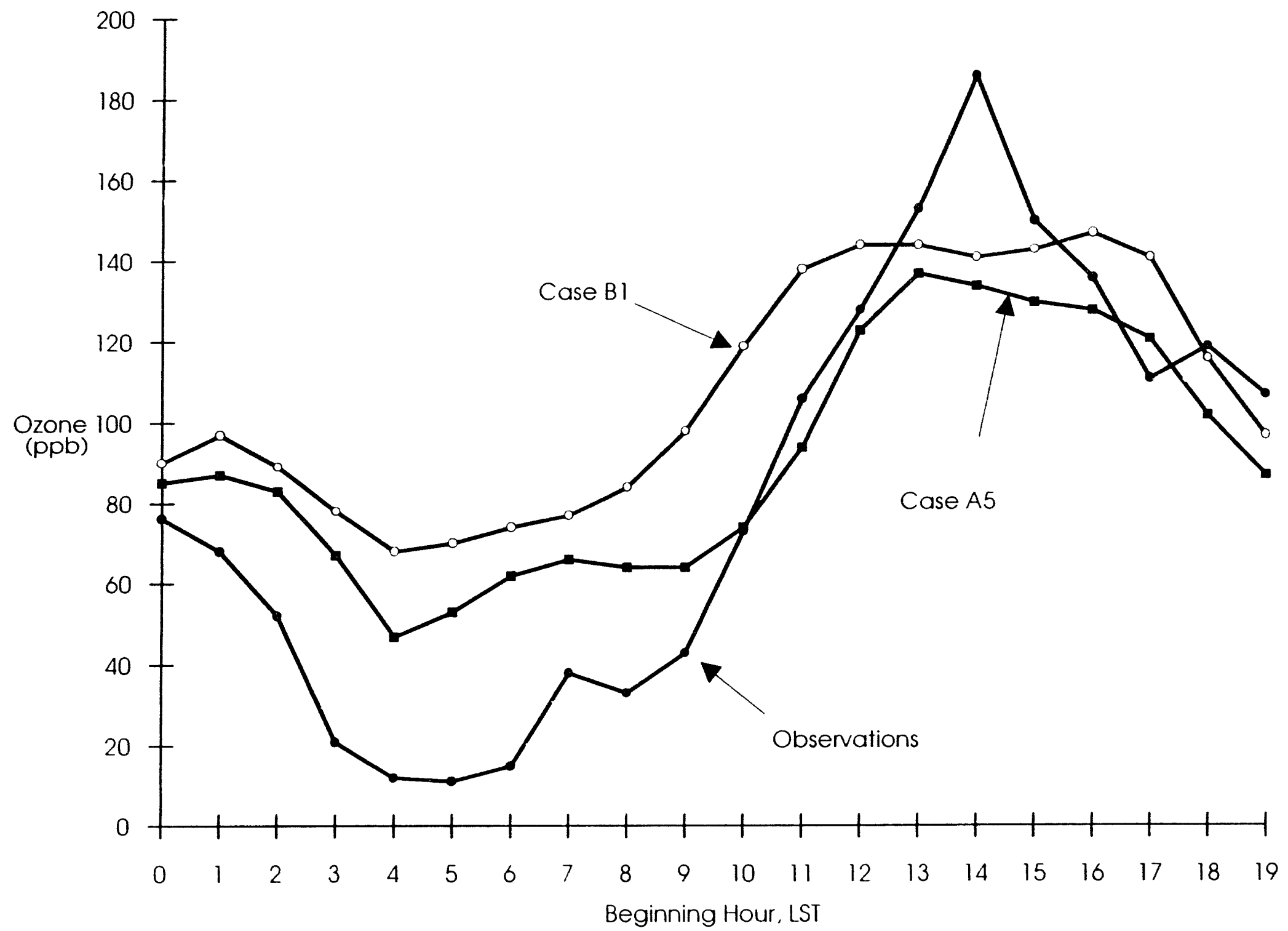

FIGURE 10 Time Series Plot of Hourly Ozone Concentrations for July 6, 1988, at Evanston, Illinois: Case B1, Case A5, and Observations 


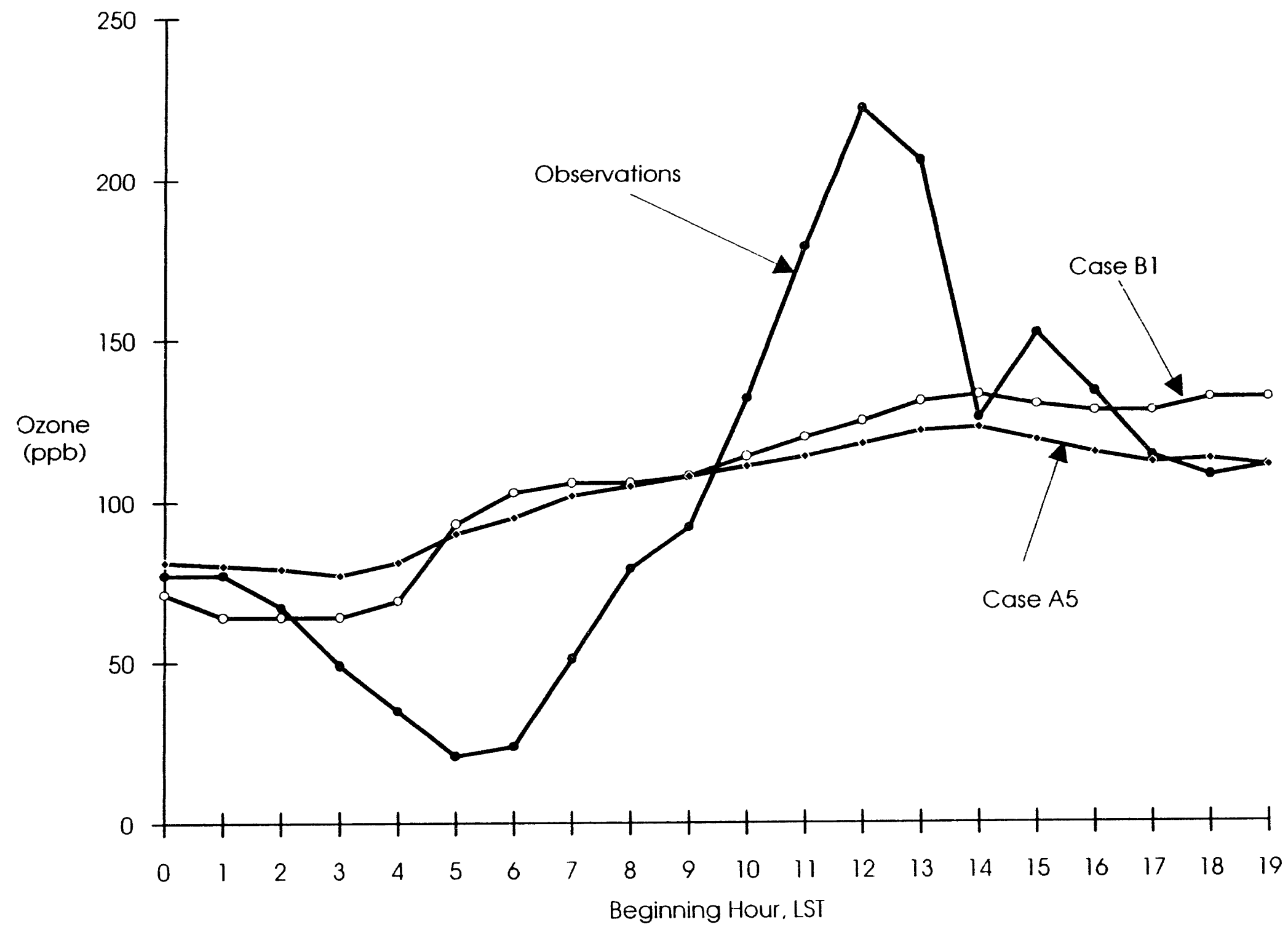

FIGURE 11 Time Series Plot of Hourly Ozone Concentrations for July 6, 1988, at Pleasant Prairie, Wisconsin: Case B1, Case A5, and Observations 


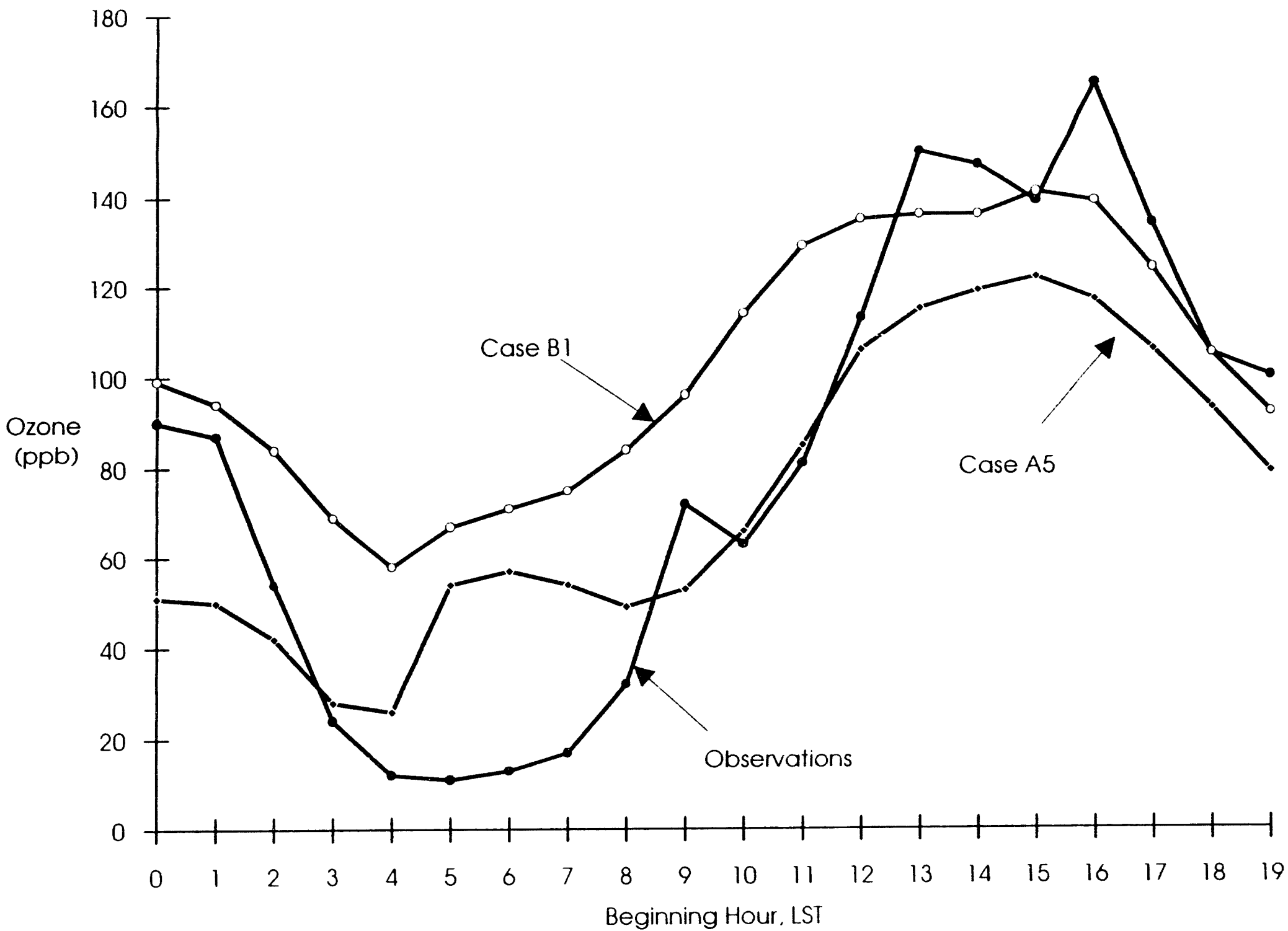

FIGURE 12 Time Series Plot of Hourly Ozone Concentrations for July 6, 1988, at North Ashland and Edgewater Chicago Site: Case B1, Case A5, and Observations 


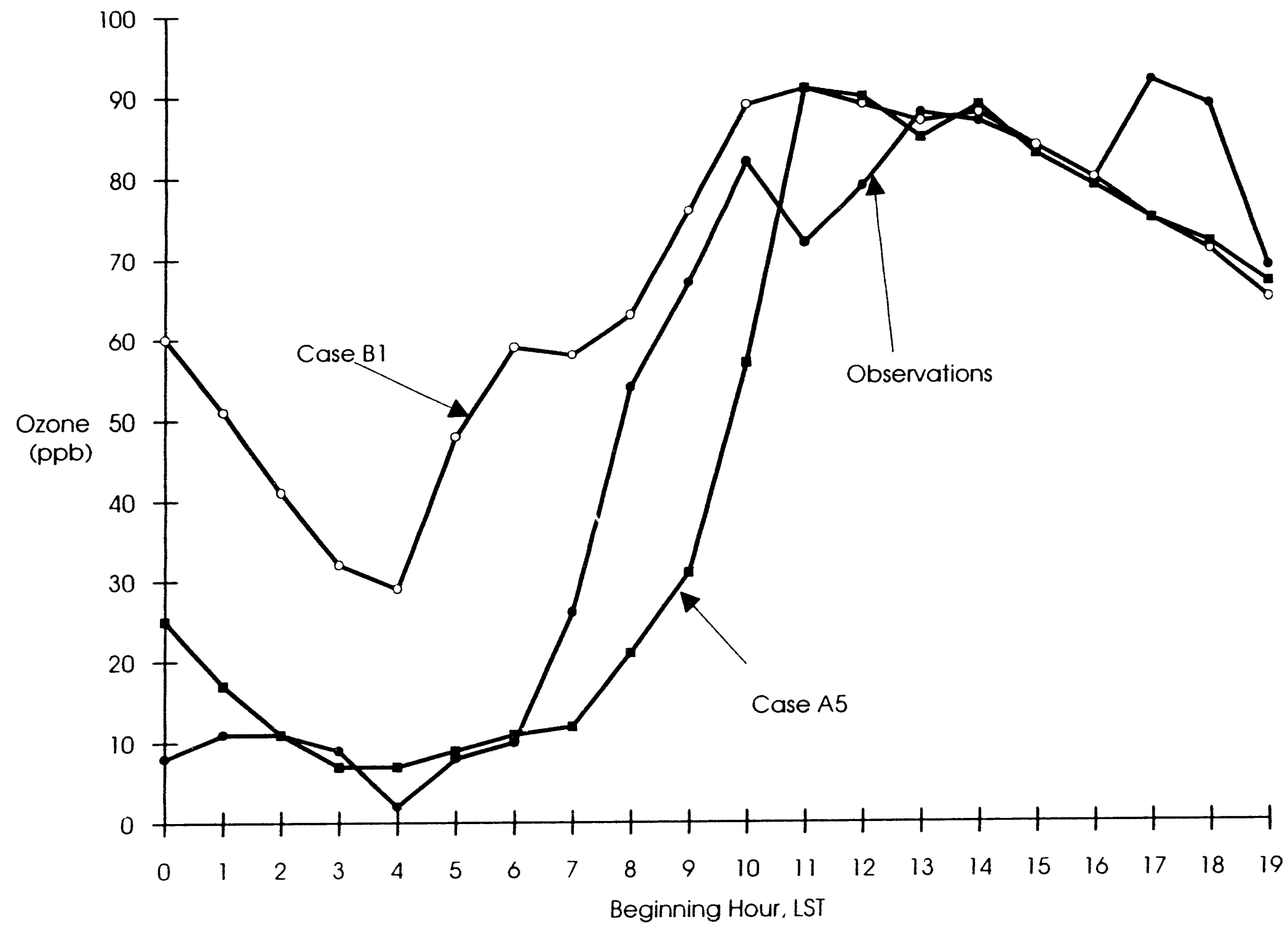

FIGURE 13 Time Series Plot of Hourly Ozone Concentrations for July 6, 1988, at Peoria, Illinois: Case B1, Case A5, and Observations 


\section{WIND FIELD INVESTIGATION}

The wind field is a major factor in determining the appearance of the ozone spatial distribution and magnitude. Thus, it is important to simulate a realistic wind field. This section investigates the sensitivity of the wind field to the number of stations used to determine the wind vector for each grid point. The overall consistency of the generated wind field, spatially and temporally, also is checked and verified. Wind fields are of particular importance in Chicago because of the presence of a small-scale land/sea breeze, caused by differential heating of the lake and the shore, during ozone episodes. This breeze can transport ozone up the coast but is not resolved easily by the routine monitoring networks (Lyons 1991).

\subsection{SENSITIVITY TO NUMBER OF STATIONS IN WEIGHTED AVERAGE}

The UAM generates three-dimensional wind fields by using the Diagnostic Wind Model (DWM), which combines the laws of physics and objective analysis techniques to extend measured meteorological data to the entire UAM grid at 20 vertical layers (EPA 1990a, Vol. 3). ANL's data consisted of hourly surface wind data at approximately $10 \mathrm{~m}$ above ground level from 28 sites, mostly from the urbanized area surrounding Lake Michigan; coverage over rural areas and Lake Michigan itself was sparse. In addition, twice daily upper air data from 3 sites and hourly meteorological tower data from 11 sites provided higher level wind information. (Appendix A gives details of wind field generation by UAM.)

For all UAM runs reported in this and the earlier Phase 1 work, the five closest stations or wind data collecting sites within $300 \mathrm{~km}$ were allowed to influence the wind field at a grid cell for the four lowest layers, and the three closest sites for the remaining layers. In this procedure, the contribution of each site is given a $1 /$ radius-squared weighting for the lowest layer and a $1 /$ radius weighting for elevated layers.

Argonne studied the sensitivity of the generated wind fields to the number of stations allowed to influence a grid cell by examining wind fields resulting from three different choices of station averaging. The wind preprocessor DWM was run three times, with either 1-, 5-, or 10-station sites allowed to contribute to each grid point. Wind vector plots were produced for July 6, 1988, at 9 a.m. for the lowest vertical layer for each choice of station averaging parameter. Figure 14 shows the case where only the nearest station determined the grid velocity. While the general pattern of flow was similar to the 5- and 10-station cases, the magnitudes and directions of the wind velocities showed marked shifts at the boundaries of grid areas where one side was influenced by one station and the other by a different station. These boundaries are clearly visible in Figure 14 and provide an unrealistic wind field. The wind fields resulting from 5- (Figure 15) and 10-station averages were identical and provided a much smoother and more realistic wind pattern. At the same time, these smoothed plots clearly were averaged from the existing data as both 1-station and multistation plots 


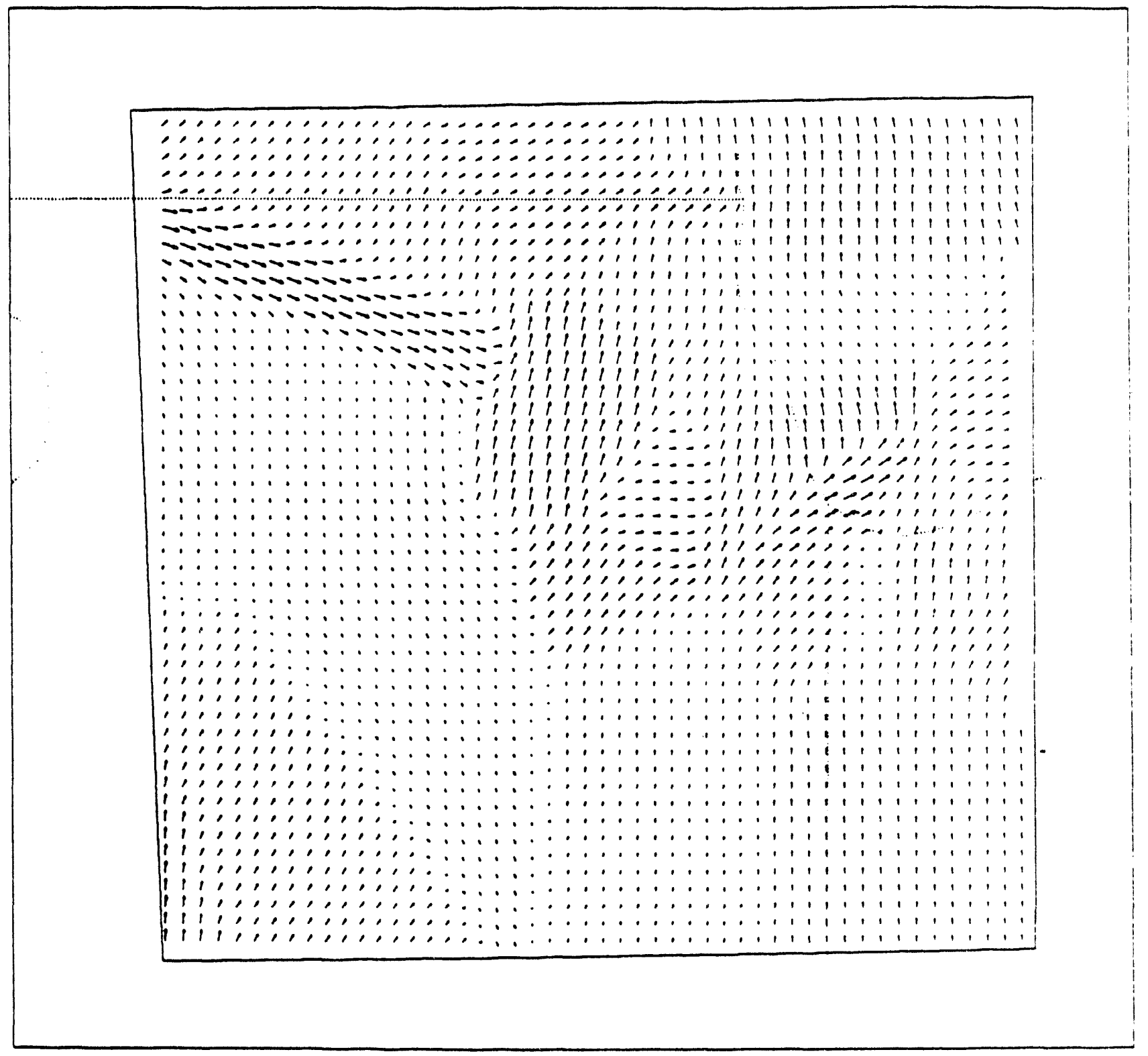

FIGURE 14 Wind Vector Grid Plot for 0900 LST on July 6, 1988, for the Lowest Vertical Layer, Using 1-Station Averaging

exhibited much the same directional flow pattern. Because the 5- and 10-station options were identical, ANL saw no need to perform UAM runs to determine ozone sensitivity to these different choices of parameters. The 1-station option was rejected as unrealistic.

\subsection{DIAGNOSTIC VERIFICATION}

Next, ANL made wind vector plots to see how the generated wind fields varied spatially and temporally compared with observations. Wind plots were made (1) at all five 


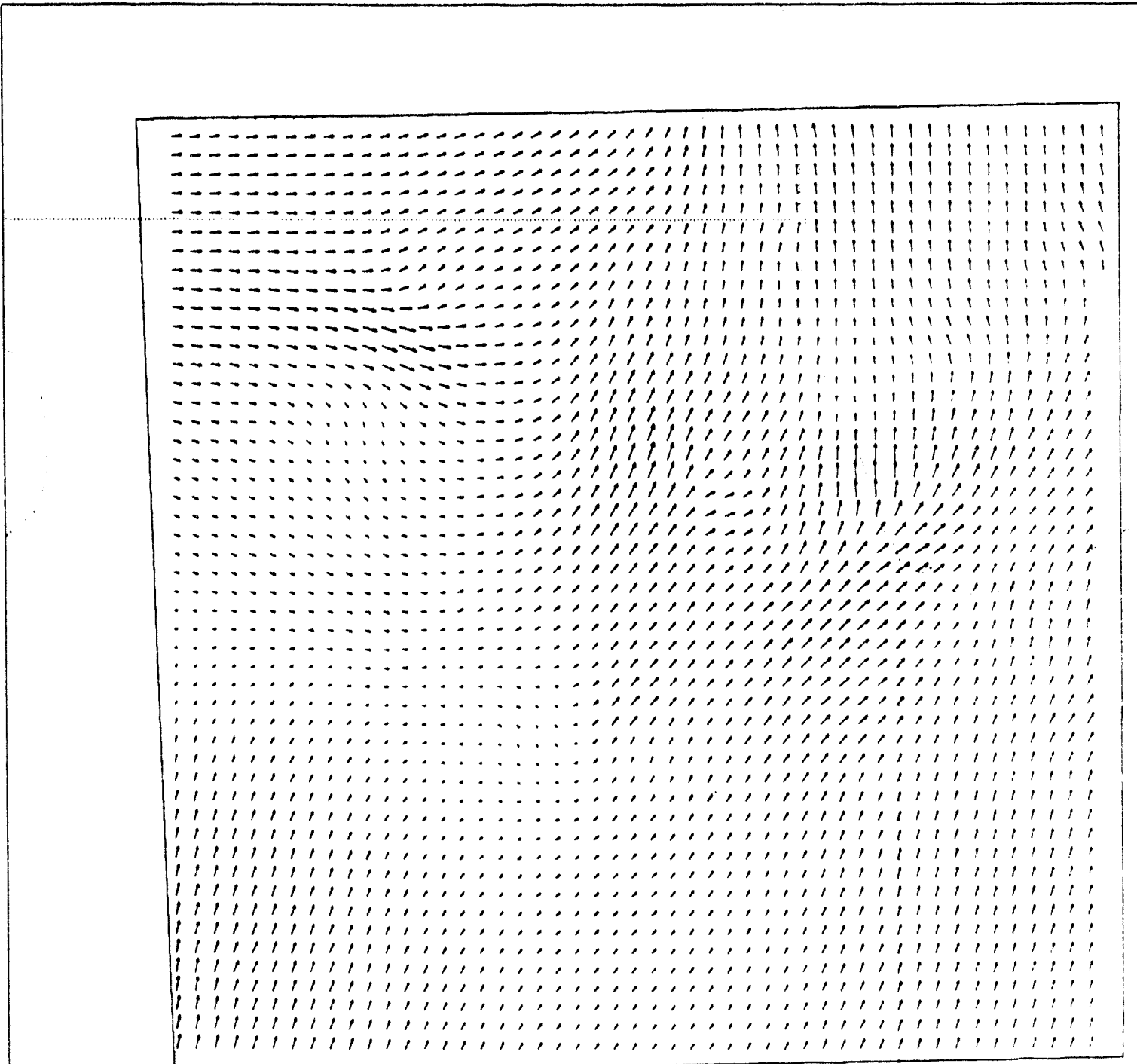

FIGURE 15 Wind Vector Grid Plot for 0900 LST on July 6, 1988, for the Lowest Vertical Layer, Using 5-Station Averaging

vertical levels at one particular time to see how the wind fields changed with height; (2) at the lowest level on an hourly basis for July 6,1988, to study wind field changes with time; and (3) at the top vertical layer to see how wind fields aloft changed with time.

In all cases, the wind vector plots are consistent with known meteorological inputs. For all levels beyond the lowest, and at all hours, the winds show a simple S-SE to S-SW flow from the grid bottom boundary to the grid top boundary. The lowest layer has a much more complex structure, temporally and spatially, that reflects the actual meteorological inputs. Figures 15 and 16 show typical plots over the grid at 0900 and 1600 LST, respectively, on 


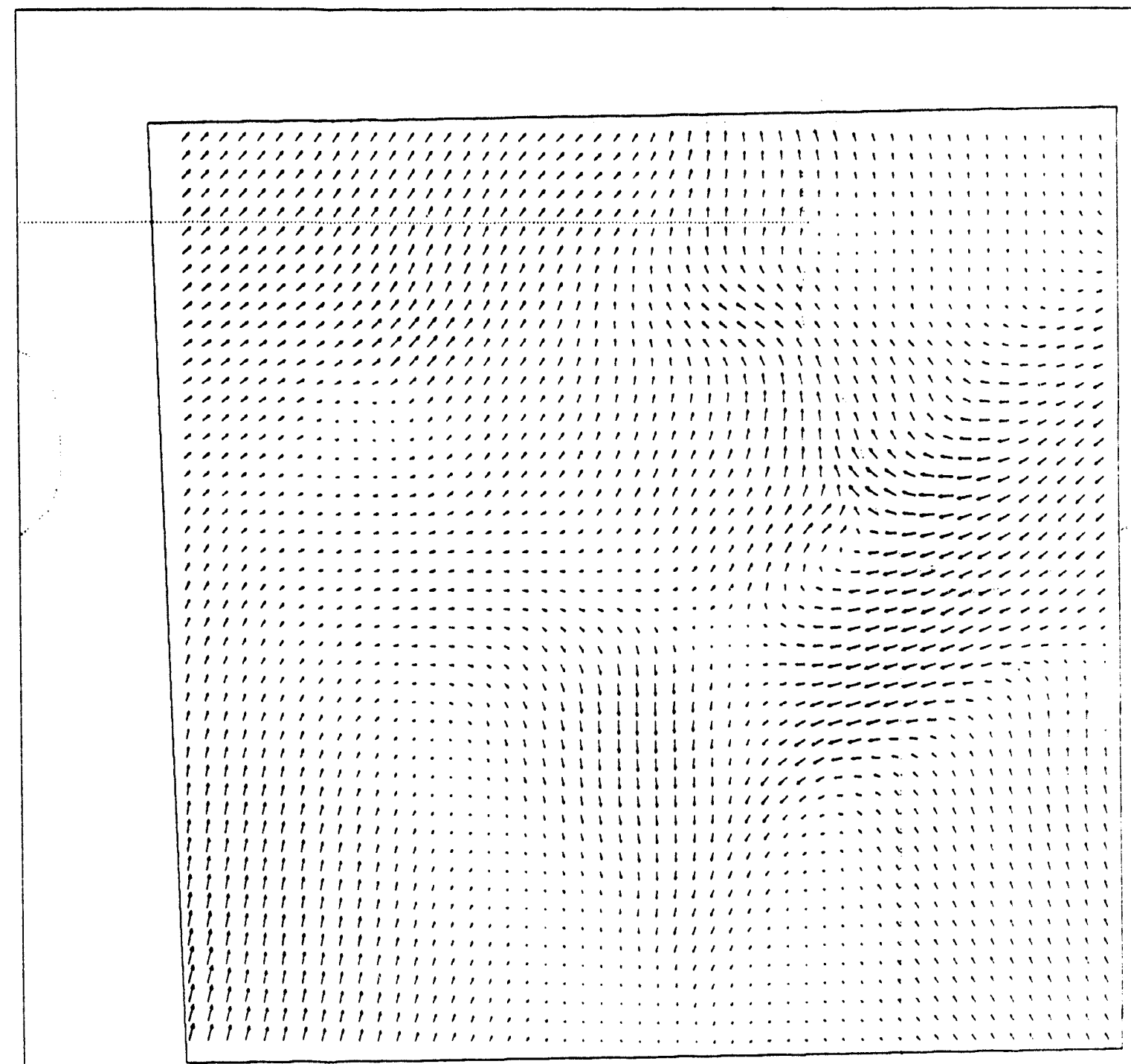

FIGURE 16 Wind Vector Grid Plot for 1600 LST on July 6, 1988, for the Lowest Vertical Layer

July 6, 1988. Changing directional patterns, particularly the reversal of winds over the southwestern coast of Lake Michigan due to the land/sea breeze effect, are evident. In all cases, wind speeds are relatively low, a characteristic of the high-pressure system associated with this high-ozone episode. The generated wind fields appear to be consistent with known data at measured sites, are appropriately smoothed, and exhibit expected behavior vertically, geographically, and temporally. For these reasons, other potential options for generating wind fields were not investigated further in this study. 


\section{GROSS SENSITIVITY TESTS AGAINST THE 1988 BASE CASE}

This section reviews earlier sensitivity tests that removed all emissions and all utility emissions. Additional sensitivity tests in the transportation and industrial sectors are also examined to assess their impact relative to utility emission controls.

\subsection{REVIEW OF PHASE 1 WORK}

\subsubsection{Complete Removal of Emissions (Case B3)}

Case B3 investigated the degree to which initial and boundary conditions influenced the model by removing all emissions, both natural and manmade. Ozone concentrations initially rose in the afternoon and evening of day 1 across the grid, but they dropped continuously, so that interior grid ozone concentrations were about $60-69 \mathrm{ppb}$ by the evening of day 2. The maximum day 2 afternoon ozone concentration in the grid ( $88 \mathrm{ppb}$ ) occurs on the southern border; this concentration represents a reduction of $45 \%$ from the 159 -ppb base case. Over the entire grid, the reduction in maximum ozone was $17 \%$, although two sites - Pleasant Prairie, Wisconsin, and the Porter County water treatment plant - showed insufficient percentage reductions to reach attainment, most likely reflecting the influence of high initial and boundary conditions.

The failure of ozone values to drop to background levels of several tens of parts per billicn with no emissions indicated that initial (high) ozone and $\mathrm{NO}_{\mathrm{x}}$ from day 1 and the boundary conditions, which, for ozone, were set at $80 \mathrm{ppb}$ and held constant over time, influenced model predictions. As explained earlier, the results of this UAM run necessitated the use of the maximum ozone concentrations occurring after noon on day 2 in order to remove the unrealistic influence of initial conditions on ozone behavior. Starting the day 1 modeling at midnight might alleviate much of this problem, but that has not yet been tried.

\subsubsection{Removal of Utility Emissions (Case B2)}

Case B2 tested the sensitivity of air quality to utility emissions by removing utility point source emissions and performing a UAM run. The resulting analysis used day 2 noon to $8 \mathrm{p}$.m. maxima (Section 4.1.1). The maximum predicted ozone concentration over the grid was $145 \mathrm{ppb}$, a decrease of $9 \%$ from the base case (B1). Complete removal of utility emissions did not result in attainment and only improved air quality by $20-25 \%$ of that gained by removing emissions from all sources (case B3), even though utilities provided approximately $50 \%$ of $1988 \mathrm{NO}_{\mathrm{x}}$ emissions. 


\subsection{MOBILE SOURCES}

The mobile source scenarios focus on the transportation sector. First, ANL conducted a gross sensitivity test of the effects of all motor vehicle emissions by removing them from the emissions inventory. Second, ANL examined the level of mobile source emissions because estimates show that actual motor vehicle emissions may be at least twice the values contained in most emission inventories (National Research Council 1991). Finally, ANL examined a scenario that assumes some electric vehicle penetration into Chicago, based on the work of the Argonne Center for Transportation Research.

Argonne was unable to run EPA's MOBILE5a model specifically. The preliminary or test version released by EPA contained coding errors and other problems. The EPA has recommended discarding any results obtained with the test model. While they recently made the "final" version available on their computer bulletin board, the time and resources available for this study prevented ANL from incorporating a MOBILE5a run.

\subsubsection{Removal of Motor Vehicle Emissions (Case MV1)}

In this sensitivity test, ANL removed all motor vehicle emissions, dropping total anthropogenic $\mathrm{NO}_{\mathrm{x}}$ from area sources by two-thirds and VOC by one-half. The resulting emissions file was merged with the new biogenic emission file, inputted to UAM, and designated Case MV1. Because this run was to be compared to Phase 1 cases B2 and B3, initial and boundary conditions and mixing heights were kept the same as in those runs. However, the new biogenic emissions file was included because the Phase 1 file was in error. The associated contour plot of maximum predicted ozone concentrations is shown in Figure 17. The predicted ozone maximum was reduced from the base case $\mathrm{A} 1$ (158 $\mathrm{ppb})$ to $132 \mathrm{ppb}$ for Case MV1. The biggest change to the time series predicted ozone concentrations at measured sites occurred in the afternoon of day 2, when maxima of sites with higher predicted ozone levels were decreased considerably. For sites in attainment with lower predicted ozone levels, removing all motor vehicles had little effect. Site-specific comparisons between various cases are given in Section 6.2.

\subsubsection{Doubling of Motor Vehicle Emissions (Case MV2)}

Motor vehicle emissions could be considerably underestimated in current emission inventories (National Research Council 1991). Therefore, ANL performed a sensitivity test in which all motor vehicle emissions were doubled from base case values. Total manmade $\mathrm{NO}_{\mathrm{x}}$ emissions increased by two-thirds, and total VOC increased by one-half compared with base-case values. The emission file was merged with the new biogenic emission file and inputted to UAM.

The resulting contour plot of maximum ozone concentrations is shown in Figure 18. The predicted ozone maximum was increased from the base case A1 (158 ppb) to $181 \mathrm{ppb}$ for 


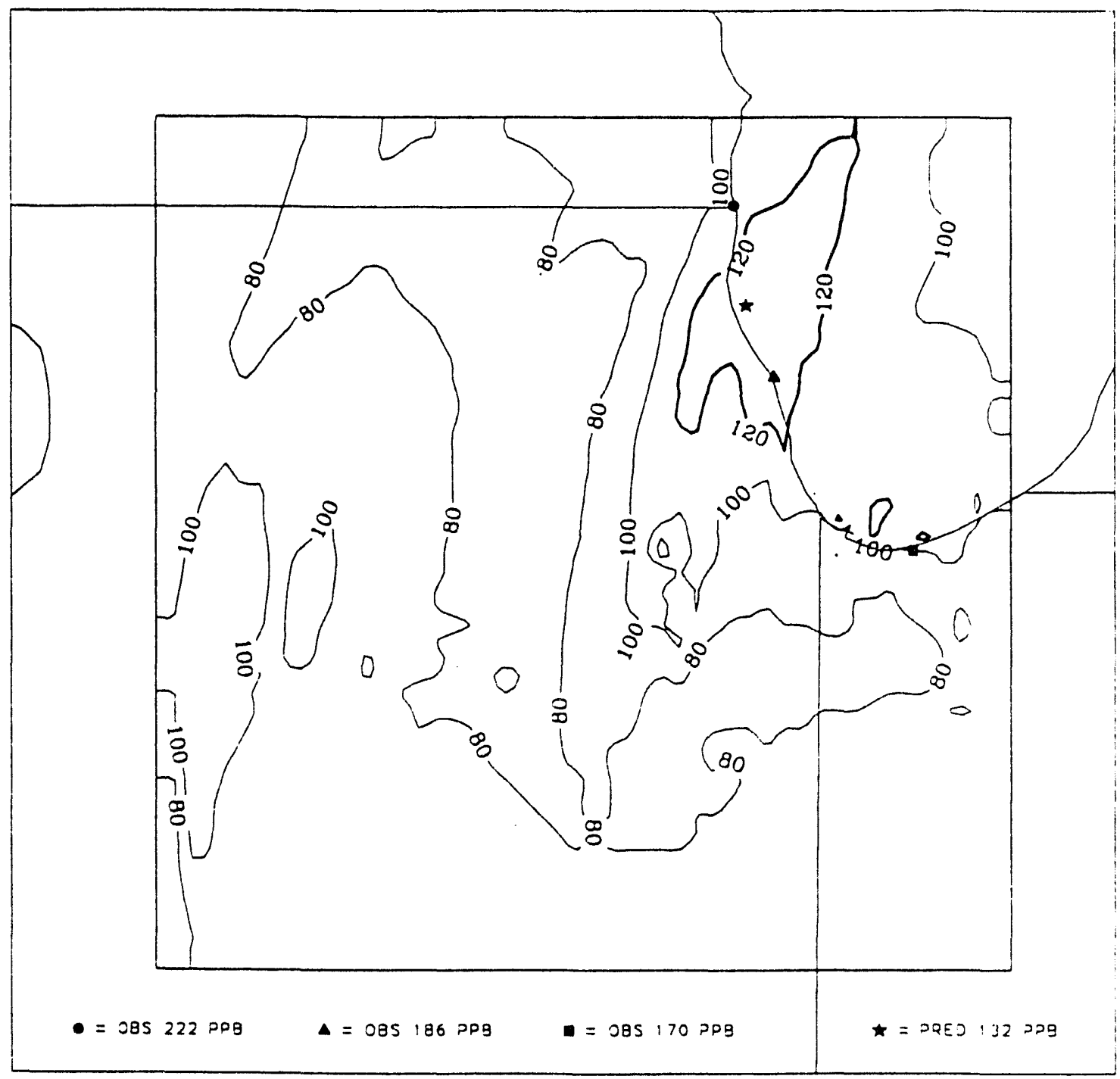

FIGURE 17 Predicted Maximum Hourly Ozone Concentrations for 1200 to 2000 LST on July 6, 1988: No Motor Vehicle Emissions Sensitivity Case (MV1) (maxima are based on the period from 1200 to 2000 LST)

this case (MV2). The major change to the time series ozone predictions compared with the base case was to increase the maxima in the afternoon of day 2 and to decrease slightly the minima in the early morning hours for about one-third of the sites. Doubling motor vehicle emissions improved the correspondence with maximum measured values over most of the grid. However, the predictions at many sites, particularly those without pronounced maxima in the afternoons, changed only slightly. The UHPA and GEAP > 60 are 19\% for MV2, NBT is $-221 \%$, and NBASP is an underprediction of $10 \%$. These statistics compare favorably with B1 and are better than B1 for the highest observations. Site-specific comparisons between various cases are given in Section 6.2. 


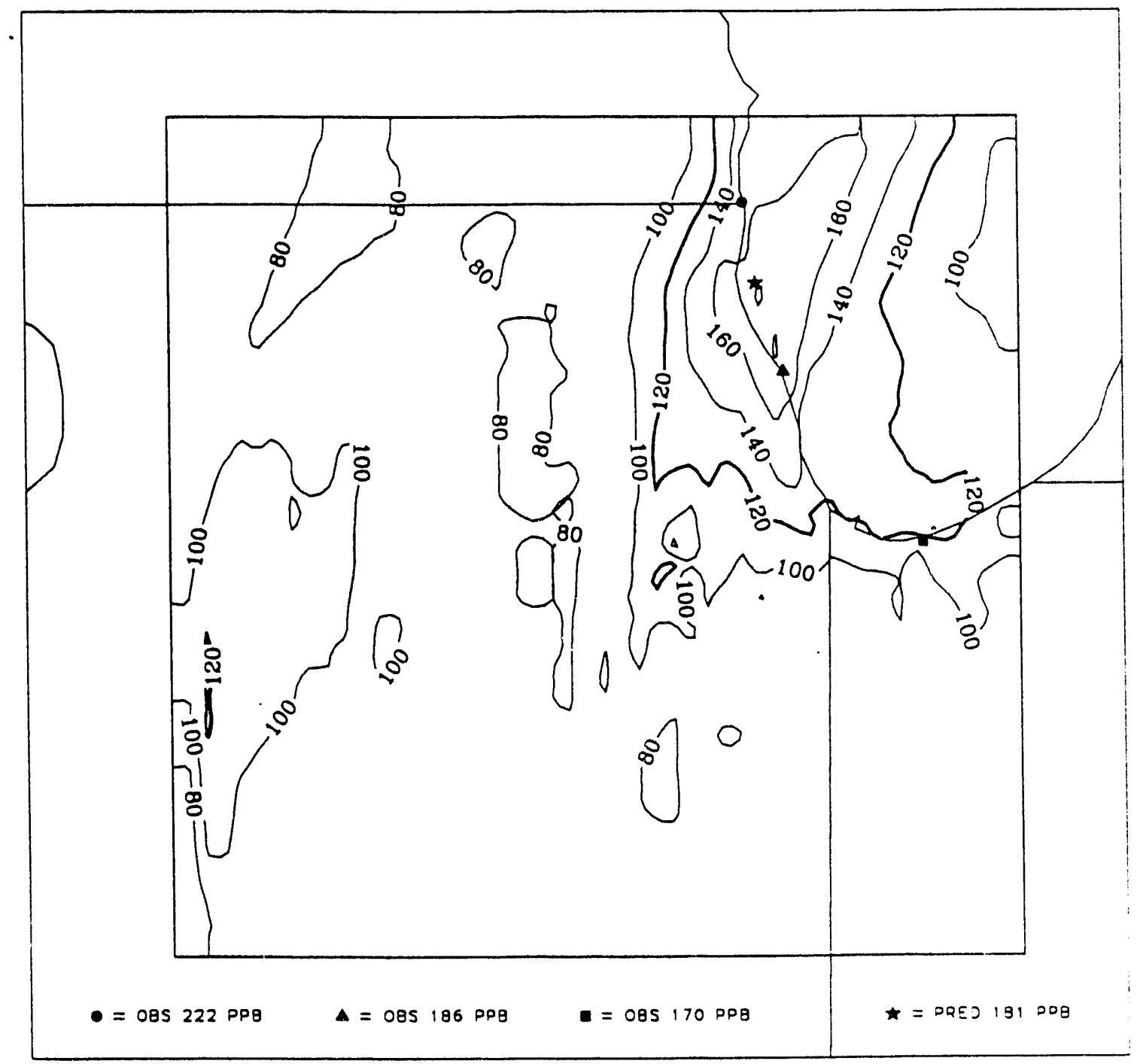

FIGURE 18 Predicted Maximum Hourly Ozone Concentrations for 1200 to 2000 LST on July 6, 1988: Doubled Motor Vehicle Emissions (Case MV2) (maxima are based on the period from 1200 to 2000 LST)

\subsubsection{Doubled Motor Vehicle Scenario (MV2) with New Base Case (A5)}

The improvement in the maximum ozone predictions found in Section 4.2.2 by doubling motor vehicle emissions, together with the changes in parameters examined in Section 2, motivated a sensitivity test to see whether the data fit could be improved if both changes were incorporated. As noted in Section 2, it is reasonable to choose more realistic ozone and $\mathrm{NO}_{\mathrm{x}}$ initial and boundary conditions, a new corrected biogenic emissions factor, and an alternative mixing height algorithm. As noted in Section 4.2.2, doubled motor vehicle emissions are plausible and perhaps even likely, although there is no specific evidence or measurement that would justify this choice in this study. Nonetheless, such a choice would indicate how well the data could be fit with new base-case parameters, given the 
uncertainties inherent in motor vehicle emissions. Thus, new base-case parameters and doubled motor vehicles were combined in a UAM run (Case A6).

A contour plot of maximum ozone values for Case A6 is shown in Figure 19, while site predictions and other measurements of performance are found in Section 6.2. The grid maximum ozone is $182 \mathrm{ppb}$, the highest of any case examined. Unpaired highest prediction accuracy is improved to give the lowest value of any UAM run (18\%), while the normalized bias test is $-116 \%$, again the best value of any UAM run. The gross error of all pairs $>60 \mathrm{ppb}$ is $19 \%$, a relatively low value that is comparable to B1 and MV2.

Time series plots that compare cases B1, A5, and A6 and observations at two sites are shown in Figures 20 and 21. At the Edgewater and North Ashland site in downtown Chicago, Case $A 6$ retains and improves on the better early morning fit of Case 5 and gives a fit equivalent to B1 during the afternoon maximum. The Evanston site (Figure 21) shows similar results, with the afternoon fit being better than that of Case B1. Figure 22 shows observations vs. predictions by percentile for $\mathrm{B} 1$ and $\mathrm{A} 6$ for all sites. Comparison with Figure 9 shows that the improved fit at low values is retained and high observations are simulated as well as they are in B1. Thus, Case A6 is actually the best "base case" of any of the ones tried, but it was not used because of the difficulty providing proof that the emissions inventory is valid.

\subsection{INDUSTRIAL SOURCES: REMOVAL OF INDUSTRIAL EMISSIONS (Case I1)}

Many industries contribute point and area source emissions in the Chicago area. To investigate these contributions relative to other sectors, ANL conducted a gross sensitivity test in which all industrial emissions were removed (Case I1). This sensitivity test involved removal of all industrial emission categories from both area and point sources. Industrial emissions included all sources, except utilities, motor vehicles, commercial, residential, institutional, or governmental. The modified emission files were merged with the new biogenic emission file. Manmade point source $\mathrm{NO}_{\mathrm{x}}$ dropped $30 \%$, and point source VOCs decreased by $96 \%$, confirming that utilities are not a significant source of VOCs. Manmade nonmotor vehicle area source $\mathrm{NO}_{\mathbf{x}}$ decreased $23 \%$, and area source VOCs decreased 73\%. A UAM run, with all other input files the same as Case A1, resulted in output designated as Case I1.

The associated contour plot of maximum ozone predictions is shown in Figure 23, the maximum ozone prediction was reduced to $148 \mathrm{ppb}$ for this case compared with the base case A1 prediction of $158 \mathrm{ppb}$. The major change to the predicted time series plots compared with Case A1 was to drop the maxima occurring in the afternoon of day 2. Only minor changes were noted in predicted time series plots that did not have a pronounced afternoon peak. A site-specific analysis of changes is given in Section 6.2. 


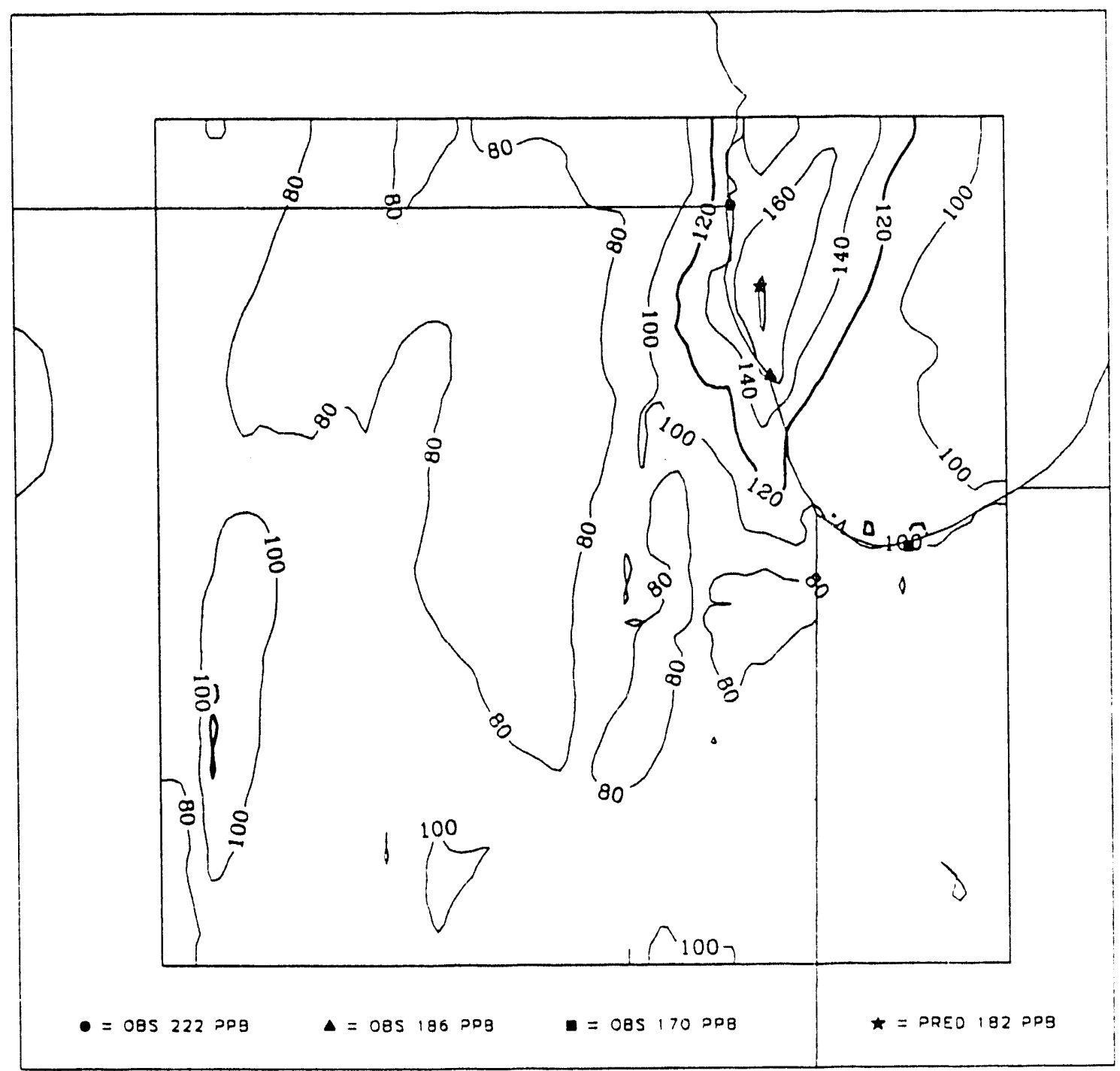

FIGURE 19 Predicted Maximum Hourly Ozone Concentrations for 1200 to 2000 LST on July 6, 1988: Doubled Motor Vehicle Emissions Combined with Case A5 (Case A6) (maxima are based on the period from 1200 to 2000 LST) 


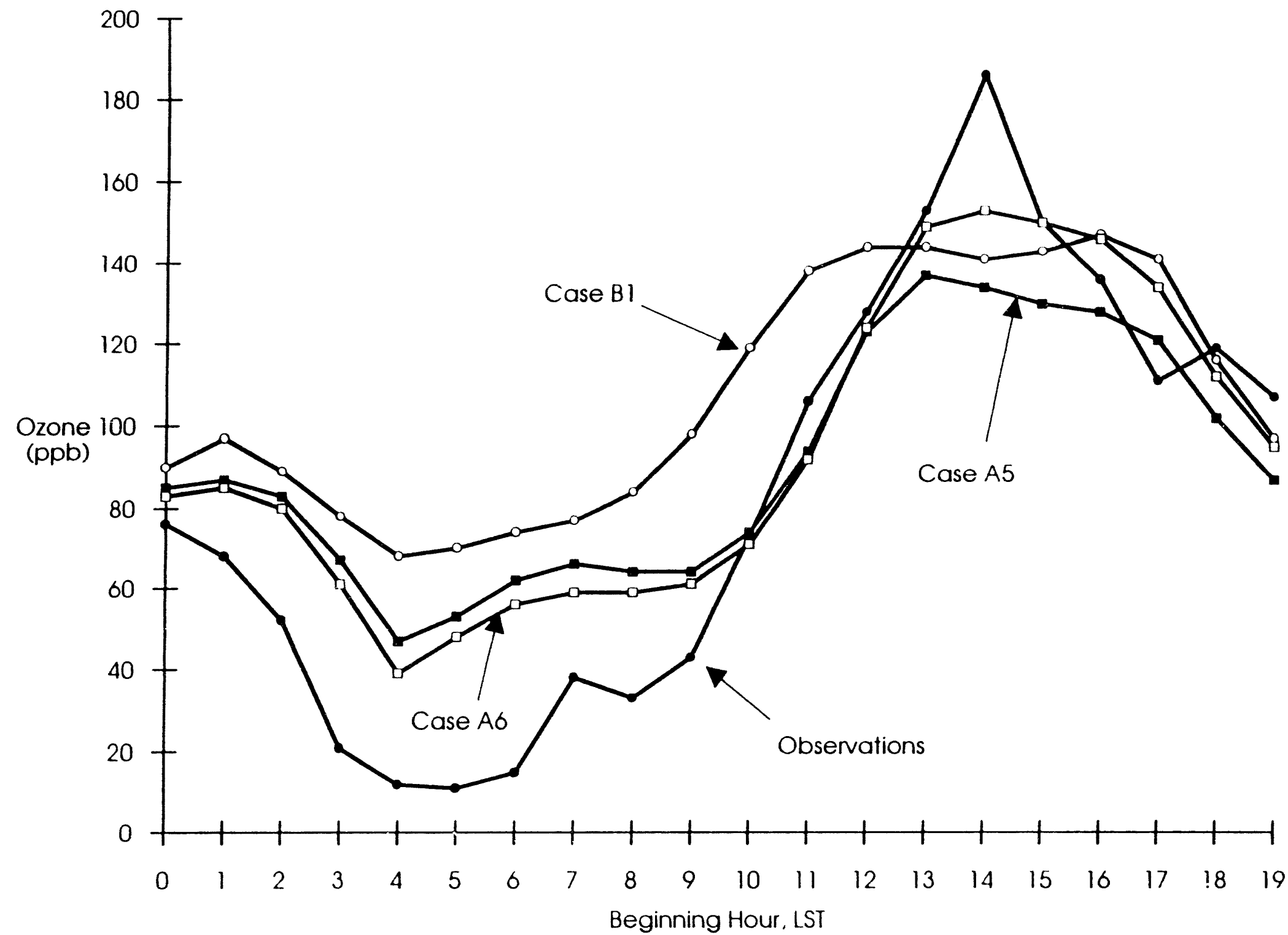

FIGURE 20 Hourly Ozone Concentrations for Edgewater and North Ashland Site, Chicago, on July 6, 1988: Cases B1, A5, and A6 and Observations 


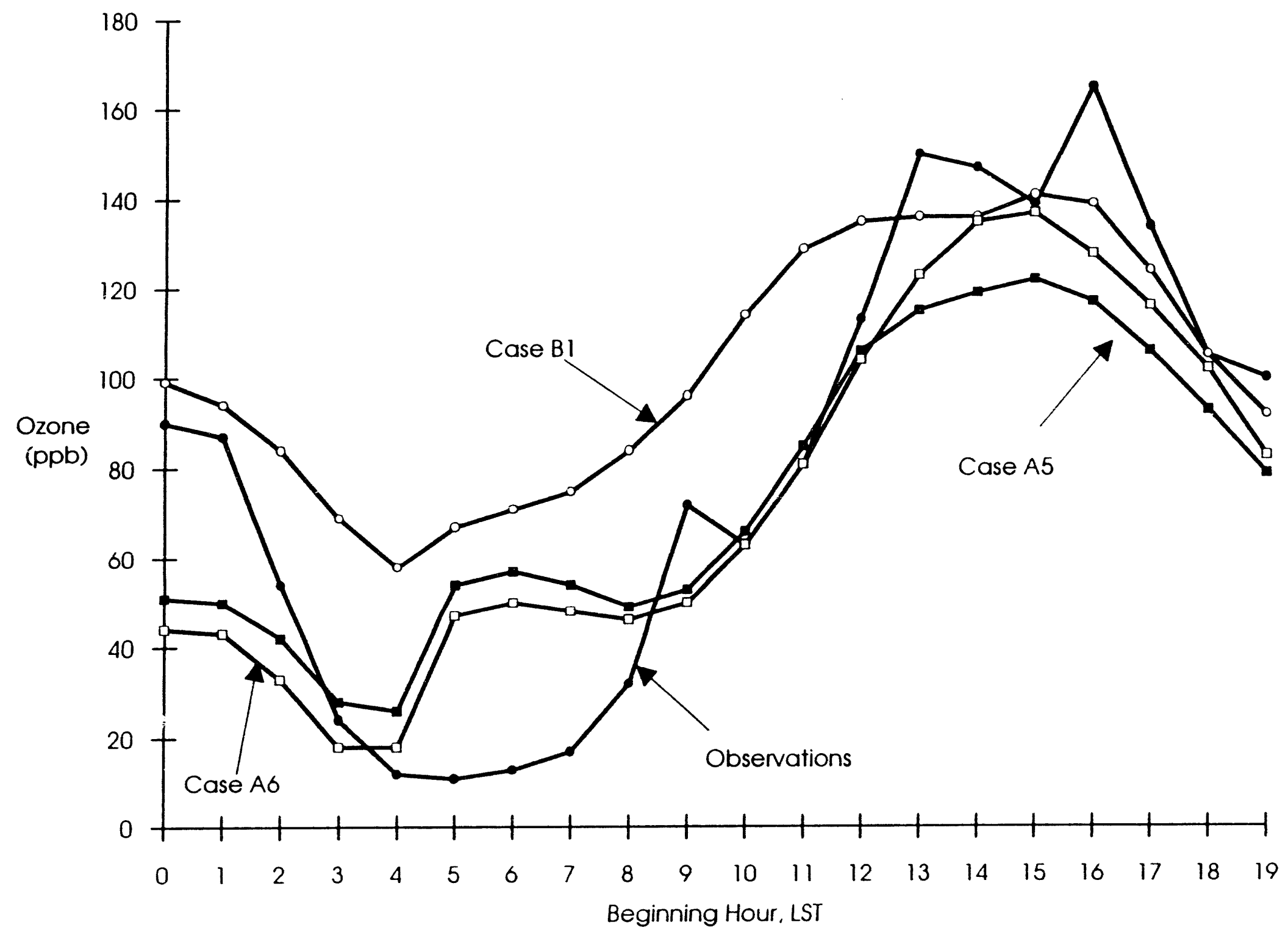

FIGURE 21 Hourly Ozone Concentrations for Evanston Site, Chicago, on July 6, 1988: Cases B1, A5, and A6 and Observations 


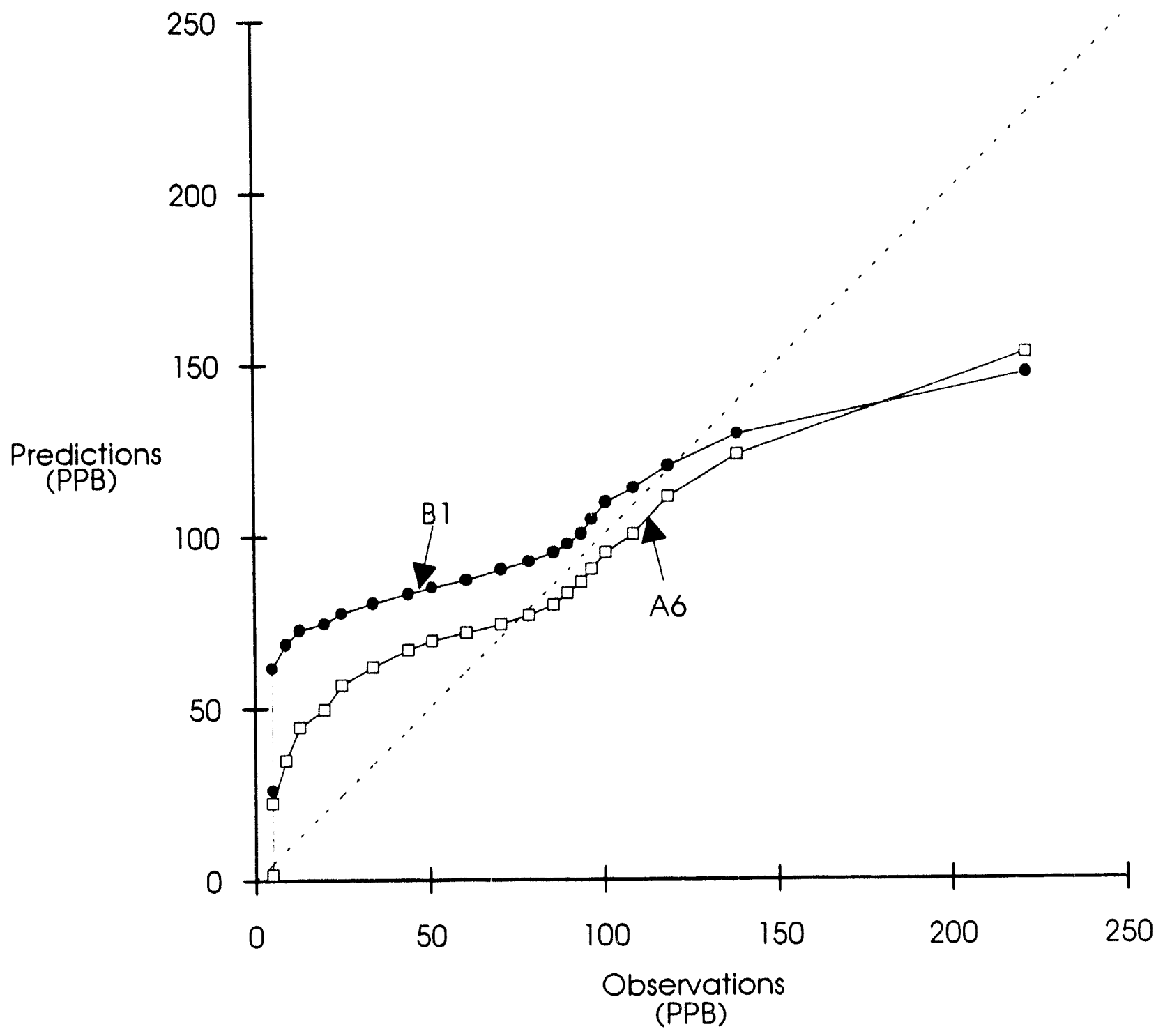

FIGURE 22 Percentile Plot of Cases B1 and A6 vs. Observations (percentile increment = 5\%; compare with Figure 9) 


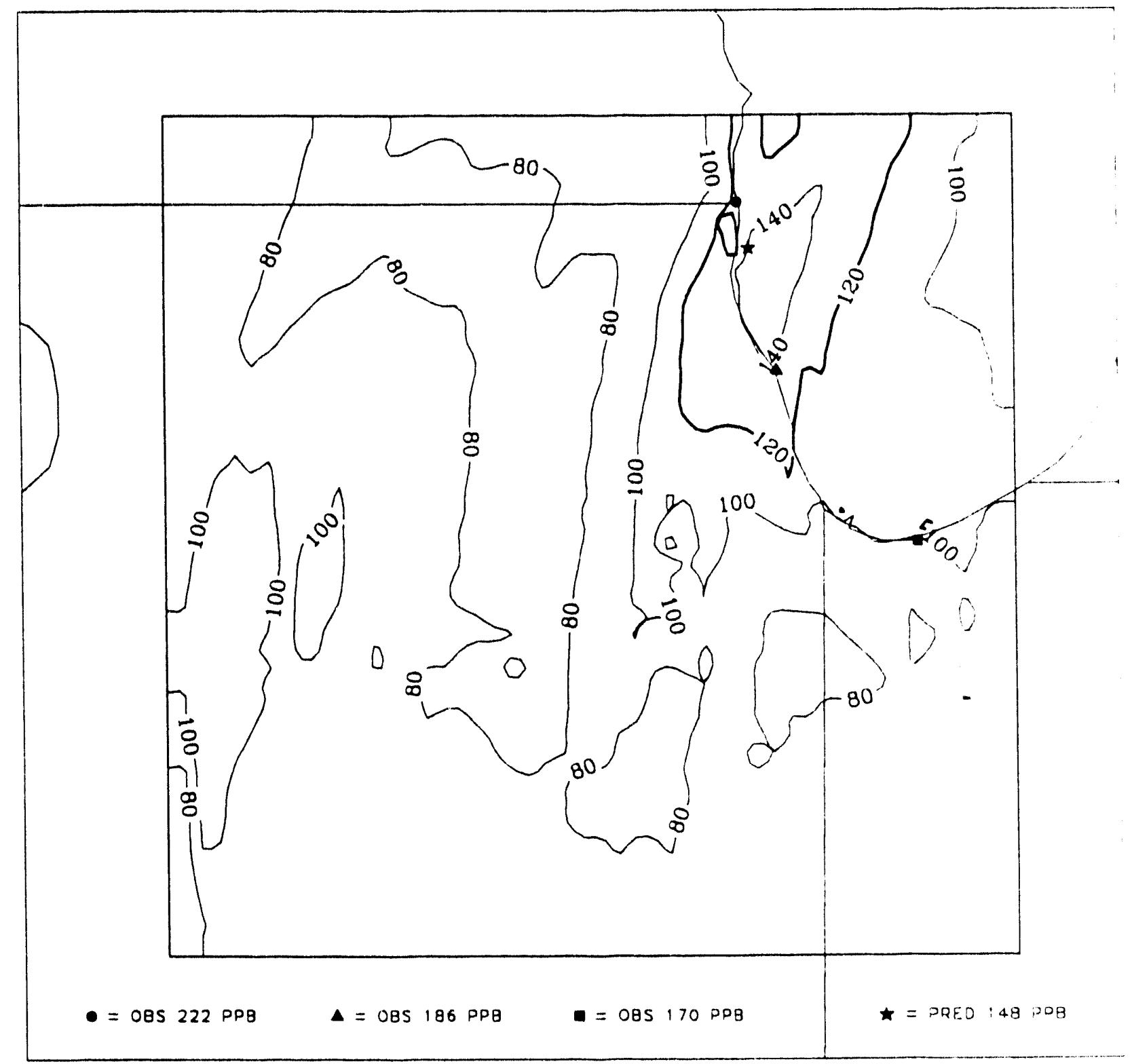

FIGURE 23 Predicted Maximum Hourly Ozone Concentrations for 1200 to 2000 LST on July 6, 1988: No Industrial Emissions Case (I1) (maxima are based on the period from 1200) to 2000 LST) 


\section{FUTURE EMISSIONS CASES}

\subsection{REVIEW OF PHASE 1 WORK}

\subsubsection{Base Case 1996 New Nuclear (N1)}

Case $\mathrm{N} 1$ is a future base case for 2010, in which Title IV $\mathrm{SO}_{2}$ and $\mathrm{NO}_{\mathrm{x}}$ controls are applied to utilities and the other emissions sources are projected, as described in Fornau et al. (1992) and Appendix B. New nuclear capacity is allowed beginning in 1996. Com Ed $\mathrm{SO}_{2}$ and $\mathrm{NO}_{x}$ emissions decrease from 1988 in this case. Peak maximum ozone decreases $3 \%$ of that achieved when all emissions are removed, and only 1 of the 14 sites in nonattainment in 1988 came into attainment on a percentage basis. The three most polluted sites achieved only 6 to $16 \%$ of the percentage decrease needed to reach attainment. The air quality at four sites west of Chicago worsened. The spatial plot of maximum ozone for this case is similar to the 1988 base case shown in Figure 2.

\subsubsection{Base Case 2000 New Nuclear (N2)}

Argonne developed an alternative case (N2) in which nuclear capacity could not be added until the year 2000 because that date was considered to be more realistic than the NES date of 1996. It gave similar UAM results to the $\mathrm{N} 1$ case, although Com Ed $\mathrm{NO}_{\mathrm{x}}$ emissions were higher.

\subsubsection{High Fossil Fuel Use (F1)}

Another UAM scenario, high fossil fuel use (F1), is similar to the future base case, except that no nuclear relicensing or new capacity is allowed. Com Ed NO emissions were higher than in 1988 because use of fossil fuel increased. Despite the $\mathrm{NO}_{\mathrm{x}}$ differences, the UAM ozone results were not very different from the future base case (N1). Peak ozone increased slightly from the 1988 case, and 2 of 14 sites reached attainment on a percentage basis. The Evanston monitoring site, which had the second worst air quality, showed an increase in peak ozone.

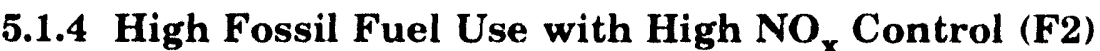

Another UAM scenario, high fossil fuel use with high $\mathrm{NO}_{\mathrm{x}}$ control (F2), provided for $95 \% \mathrm{NO}_{\mathrm{x}}$ control on all utility sources. Com Ed NO $\mathrm{x}_{\mathrm{x}}$ emissions were substantially reduced from 1988. Grid peak ozone decreased by $24 \%$ of that achieved when all emissions were removed, but this decrease was not enough to reach attainment on a percentage basis. Only 1 of 14 sites reached attainment on a percentage basis, and the three most polluted sites achieved about $20 \%$ of the reduction needed to reach attainment on a percentage basis. Within a few kilometers of power plants, ozone decreased less than in the other scenarios or 
even increased. This increase may reflect ozone scavenging by $\mathrm{NO}_{\mathrm{x}}$ in the power plant plume. One grid cell downwind of the Com Ed Collins plant increased $40 \%$ in maximum ozone. Compared with Figure 2, the area with concentrations greater than $140 \mathrm{ppb}$ decreased considerably, and the area above $120 \mathrm{ppb}$ decreased slightly.

\subsubsection{Removal of Utility Emissions (N3)}

Another scenario, designated N3, in which all utility emissions were removed (i.e., complete conversion to nuclear power) gives results similar to those from the $95 \%$ control scenario, except that overall ozone levels were lower, and 2 of 14 sites came into attainment. Increased ozone was observed in the vicinity of power plants. The spatial maximum ozone pattern is very similar to that of F2, but the area of $140-\mathrm{ppb}$ concentrations is no longer present.

\subsection{SENSITIVITY OF PREVIOUS RESULTS TO NEW BASE CASE (A5)}

As seen in Section 2.6, overall comparison to observations improved on the basis of incorporating (1) the new biogenics factor, (2) new and more realistic ozone and $\mathrm{NO}_{\mathrm{x}}$ initial and boundary conditions, and (3) a different mixing height calculation, although maximum prediction values were reduced. To test whether use of a new base case affects previous results and whether previous results can be compared with new results, ANL repeated several of the Phase 1 scenarios with the new base case.

Argonne conducted a sensitivity test by rerunning two of the previously investigated 2010 scenarios. One (N2 = new nuclear in 2000) showed only minor changes from the base case $\mathrm{B} 1$, and another (F2 = high fossil fuel with $95 \% \mathrm{NO}_{\mathrm{x}}$ control) showed larger changes. In this test, ANL applied the new biogenics factor only to the no utility emissions scenario because time constraints precluded running the emissions preprocessor suite again for all three scenarios. However, as shown in the previous section, UAM results are very insensitive to this factor (maximum ozone changed by $1 \mathrm{ppb}$, and $<0.5 \%$ totaled over the grid). New ozone and $\mathrm{NO}_{x}$ initial and boundary conditions and mixing height were incorporated into new scenario runs for N2 and F2, which were designated N2A and F2A. The previous results and the output of these new runs are compared below.

\subsubsection{Base Case 2000 New Nuclear (N2A)}

The maximum ozone concentration plot for N2A is shown in Figure 24. The N2A case can be compared with the contour plot for N2 on page 54 of Fernau et al. (1992). While the maximum predicted ozone value drops from $157 \mathrm{ppb}$ for $\mathrm{N} 2$ to $153 \mathrm{ppb}$ for N2A, its position on the grid is essentially unchanged. However, the extent of the 120-ppb contour is less in the N2A case. This lowered ozone reflects the difference in maximum ozone be:ween the two base cases (B1 and A5). Changes in the maximum ozone prediction, total 


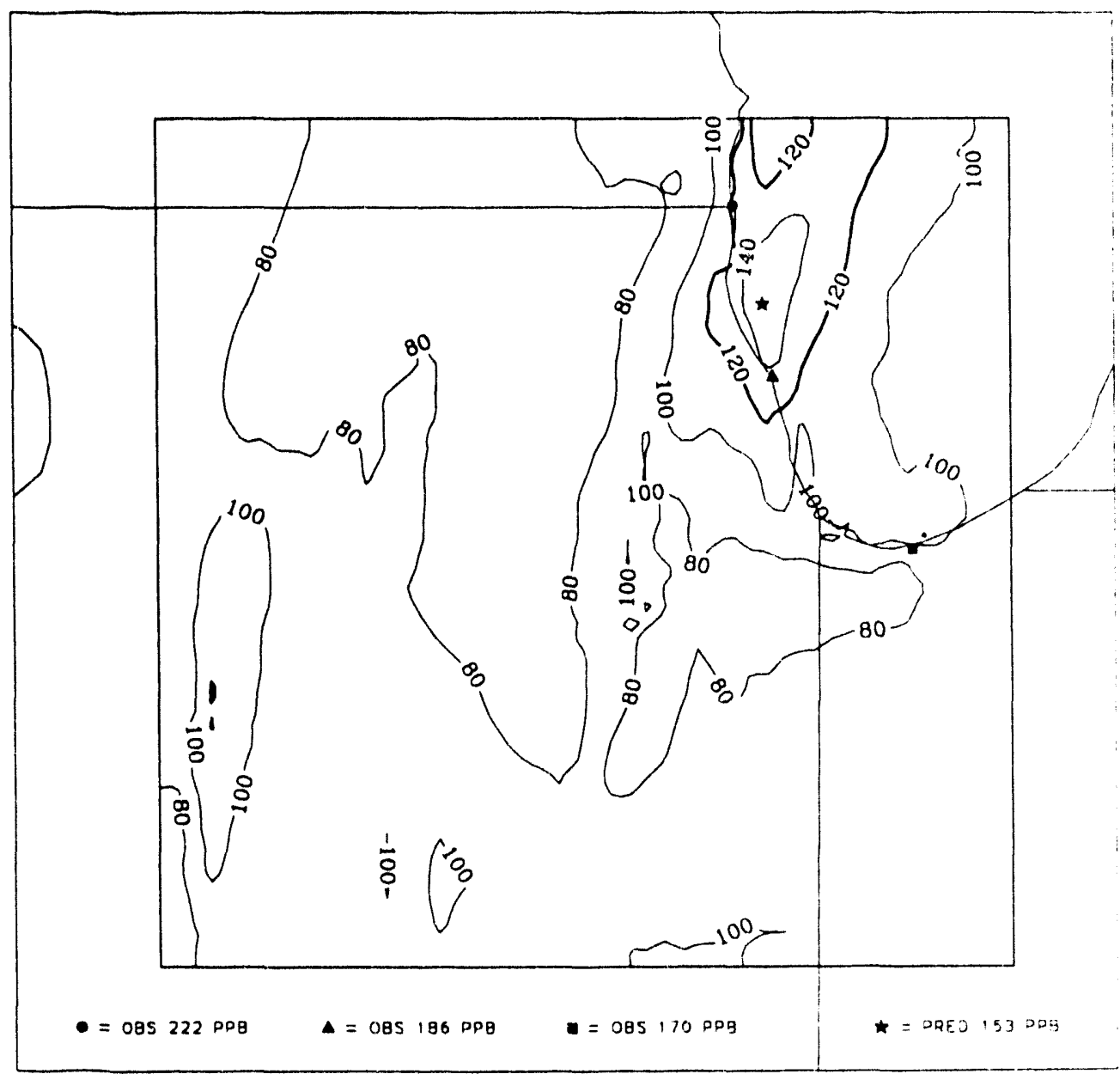

FIGURE 24 Predicted Maximum Hourly Ozone Concentrations for 1200 to 2000 LST on July 6, 1988: N2 with New Base Case A5 (N2A) (maxima are based on the period from 1200 to 2000 LST)

ozone in the grid, and total ozone in nonattainment counties are similar for Case N2A compared with Case N2. Most individual sites in N2A showed decreases in air quality compared with $\mathrm{N} 2$, either less of an improvement, more of a deterioration, or even a change in the sign of the change. The number of sites in nonattainment remains at 13 for both cases. Compared with A5, Case N2A showed little change in air quality.

\subsubsection{High Fossil Use with High NO $\mathrm{N}_{\mathrm{x}}$ Control (F2A)}

The maximum ozone concentration plot for F2A is shown in Figure 25. Case F2A can be compared with the contour plot for F2 on page 58 of Fernau et al. (1992). While the maximum predicted ozone value drops from $142 \mathrm{ppb}$ for F2 to $140 \mathrm{ppb}$ for F2A, its location is essentially unchanged. Again, the extent of the 120-ppb contour is less for Case F2A, reflecting the underlying differences in the base case. Ozone is considerably reduced relative 


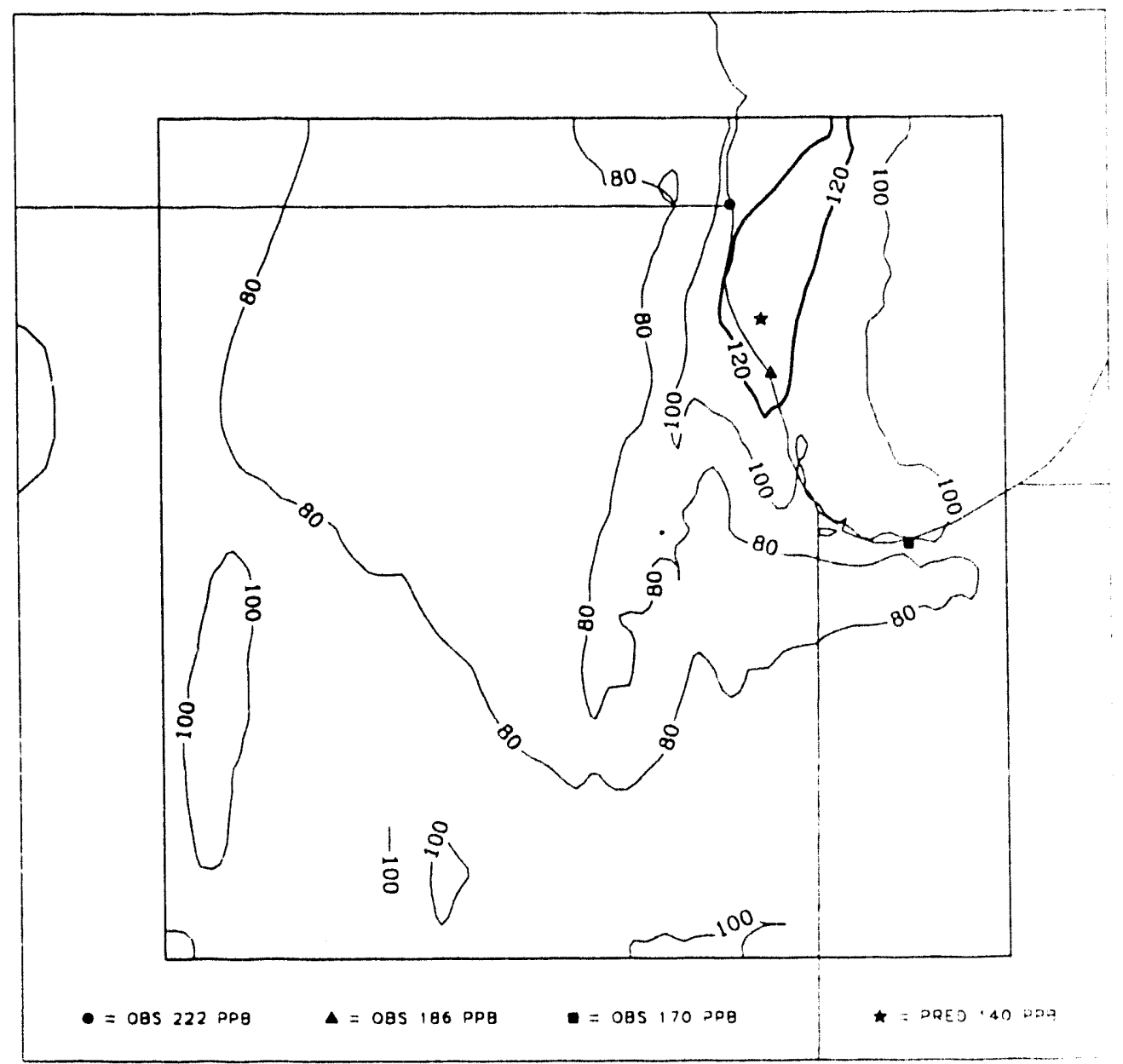

FIGURE 25 Predicted Maximum Hourly Ozone Concentrations for 1200 to 2000 LST on July 6, 1988: F2 with New Base Case A5 (F2A) (maxima are based on the period from 1200 to 2000 LST)

to N2A. Changes in the maximum ozone prediction, total ozone in the grid, and total ozone in nonattainment counties are similar for Case F2A compared with Case F2. Plots of the percentage change in ozone maximum between the base case and the scenario (not shown) show areas with increased deterioration of air quality, both in magnitude and spatial extent, in the vicinity of utilities. Deterioration in air quality is evident at the Lisle monitor, where instead of improving by $4 \%$ (F2), the ozone maximum increased by $23 \%$. This increase is not enough to put the site into nonattainment, however. The number of sites in nonattainment remains at 13 for both cases.

\subsubsection{No Utility Emissions (N3A)}

The maximum ozone concentration plot for Case N3A is shown in Figure 26. Case N3A can be compared with the contour plot for N3 on page 59 of Fernau et al. (1992). 


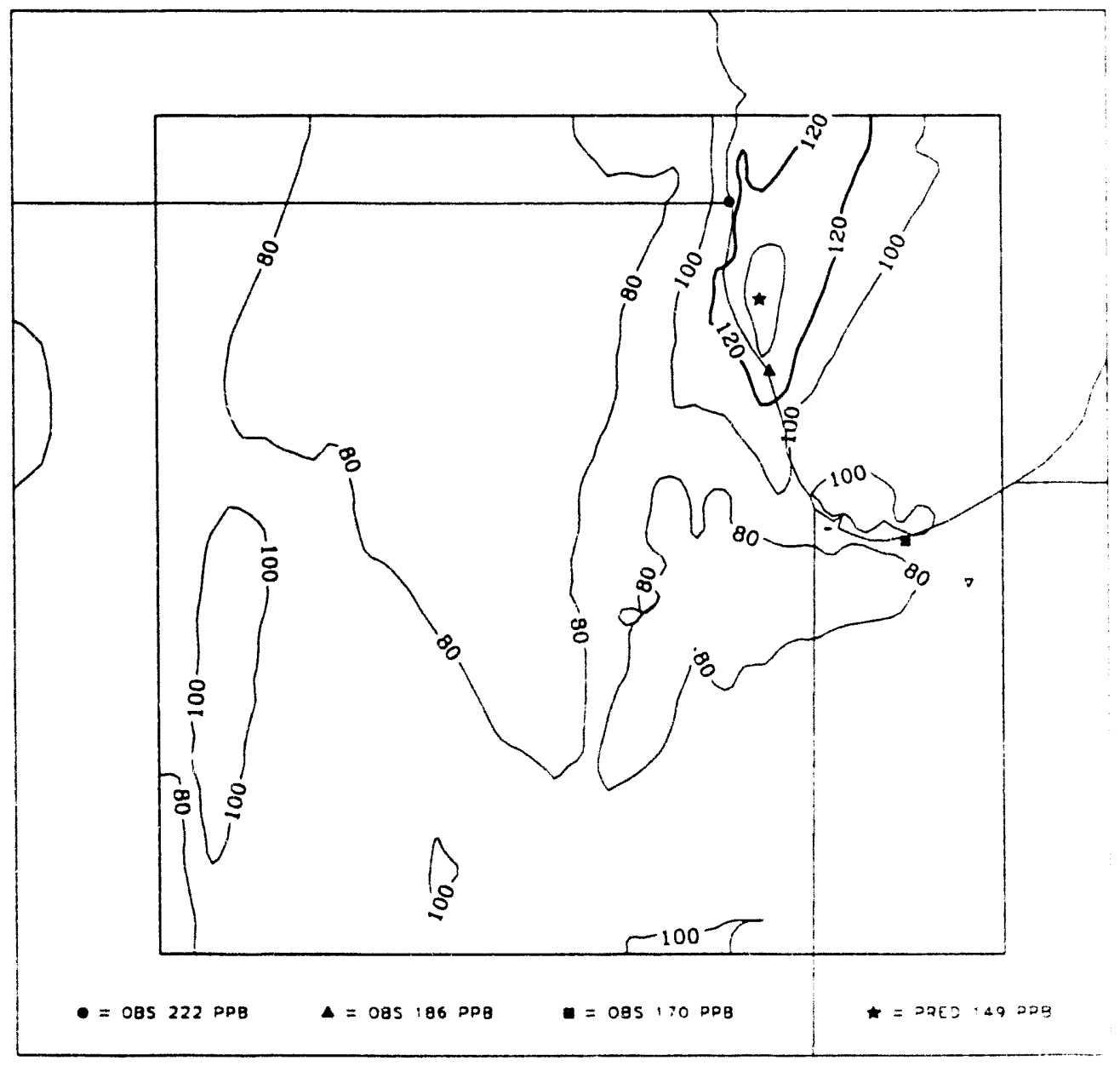

FIGURE 26 Predicted Maximum Hourly Ozone Concentrations for 1200 to 2000 LST on July 6, 1988: N3 with New Base Case A5 (N3A) (maxima are based on the period from 1200 to 2000 LST)

The maximum predicted ozone value increases from $140 \mathrm{ppb}$ for $\mathrm{N} 3$ to $149 \mathrm{ppb}$ for N3A, and its position is essentially unchanged. Again, the extent of the 120-ppb contour is less for Case N3A, reflecting the underlying differences in the base case. Changes in the maximum ozone prediction, total ozone in the grid, and total ozone in nonatiainment counties are a few percentage points smaller for Case N3A compared with Case N3. Plots of the percentage change in ozone maximum between the base case and the scenario (not shown) show areas with increased deterioration of air quality, both in magnitude and spatial extent, in the grid; however, they are spatially different from Case F2A. A large area of ozone increases over Chicago in F2A is not present in N3A, while N3A has a large area of increased ozone in the center of the grid that is not present in F2A. Since the changes in power plant emissions between F2A and N3A are not too large, the deterioration may be an artifact of Case N3A having the new biogenic emissions; however, at this point the mechanism cannot be explained. Similar to the F2 case, most sites showed worse air quality in Case N3A compared with Case N3. The number of sites in nonattainment remains at 12 for both cases. 
Overall, some relative differences from using the new base case and/or the new biogenic emissions factor for scenario examination are noted relative to the previous numbers. These differences manifest themselves in changes in the amount and direction of air quality changes in the scenarios. They may, to some extent, modify the conclusions reached in Phase 1.

\subsection{PHASE 2 SCENARIOS}

Two new scenarios were run in Phase 2 - an electric vehicle scenario and an improved industrial control scenario. These runs used Case A5 as the base case.

\subsubsection{Electric Vehicle Penetration (MV3)}

On the basis of work done by the Argonne Center for Transportation Research (CTR) (Wang and Santini 1993; Saricks 1993), an electric vehicle penetration scenario was developed for the Chicago area. Overnight charging was assumed because the penetration consists mostly of fleet vehicles. ARGUS runs for the changed demand in load due to recharging showed that the entire demand could be handled by existing nuclear plants, so no increase in stationary emissions was assumed. The Argonne CTR projects that electric light-duty trucks may comprise 3 to $4 \%$ of vehicle-miles traveled in that category, and lightduty electric autos would comprise 1 to $2 \%$ of vehicle-miles traveled. The decrease in emissions may be proportionately larger because most of the emissions displaced would occur at low highway speeds. Argonne assumed an optimistic penetration scenario of $10 \%$ of lightduty truck emissions and 5\% of light-duty autos, based on the more conservative CTR estimates. Electric vehicle use was assumed to be limited to urban roads in Cook County, with no use on limited-access highways or outside of Cook County.

The overall change in mobile source emissions from this scenario between 1988 and 2010 was less than $1 \%$ for $\mathrm{NO}_{\mathrm{x}}$ and $1 \%$ for VOCs. Figure 27 shows that the area of maximum ozone greater than $140 \mathrm{ppb}$ has shrunk relative to Case A5. For Case A5, the maximum ozone decreased by $5 \%$ from $158 \mathrm{ppb}$ to $150 \mathrm{ppb}$, ozone over the grid decreased by $1 \%$, and two sites came into attainment. Thus, very limited emissions decreases from electric vehicles located downtown seem to affect air quality.

\subsubsection{Improved Industrial Growth and Controls (I2)}

In Phase 1, ANL left some industrial emissiuns source categories unchanged from 1988 to 2010 because of uncertainty in various projections (Fernau et al. 1992). In this scenario, ANL used modeling for the NES to correct these emissions. The VOCs from energy processes were doubled based on the actions case. Based on the NES Clean Air Act Amendments case, industrial boiler total suspended particulate was reduced by $25 \%$, carbon monoxide from energy processing was increased by $33 \%$, and VOC from energy transport was 


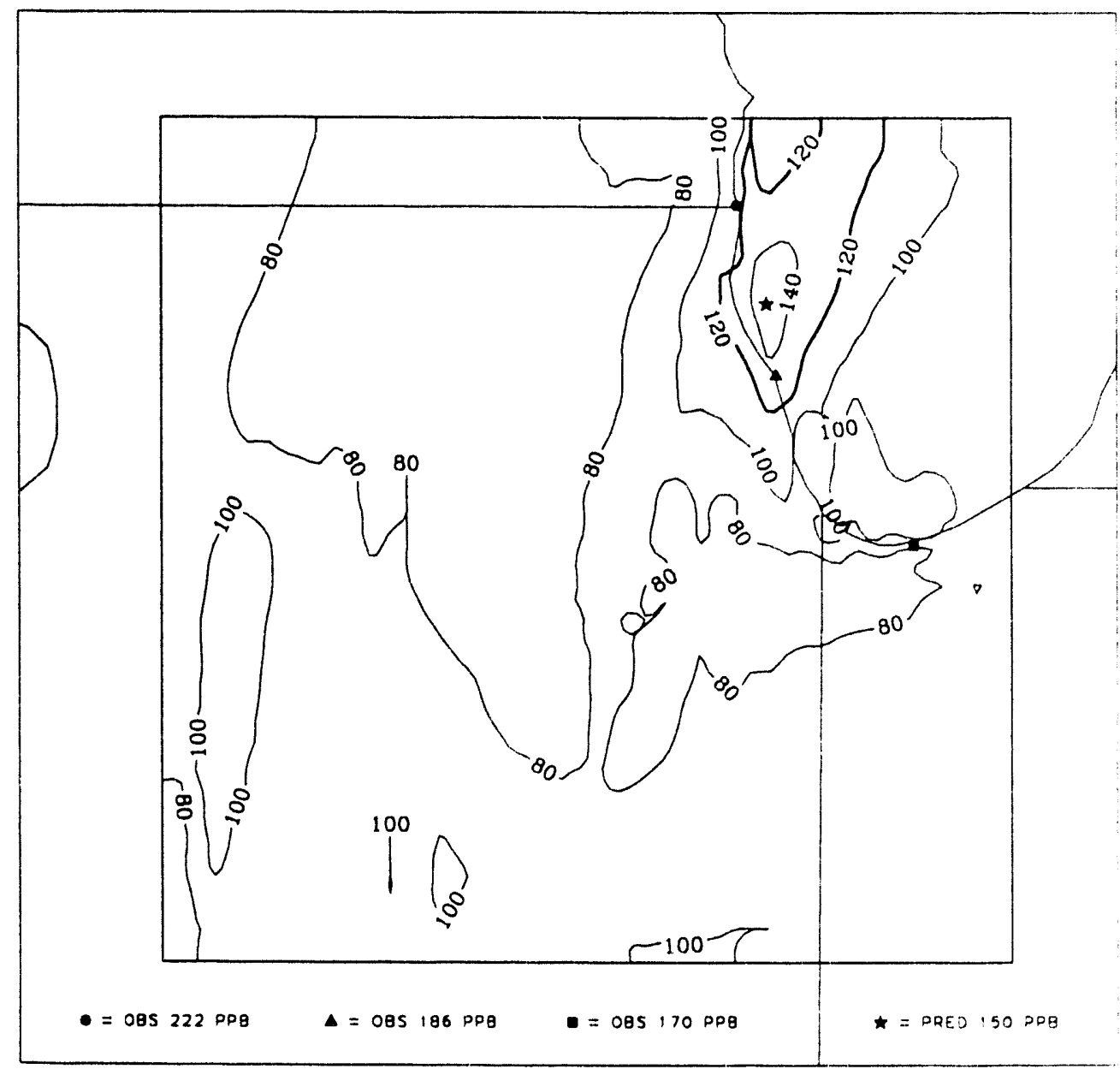

FIGURE 27 Predicted Maximum Hourly Ozone Concentrations for 1200 to 2000 LST on July 6, 1988: Electric Vehicle Penetration Scenario (MV3) (maxima are based on the period from 1200 to 2000 LST)

increased by $32 \%$. Based on declining usage and off-highway engine control regulations, railroad emissions of $\mathrm{NO}_{\mathrm{x}}, \mathrm{VOC}$ and carbon monoxide were reduced by $25 \%$. Also, $\mathrm{NO}_{\mathrm{x}}, \mathrm{VOC}$, and carbon monoxide from industrial boilers and processes were reduced by $25 \%$ to reflect tightening and tuning of reasonably available control technology and implementation of market incentive programs such as trading, taxes, and open-ended incentives in the Chicago area.

The change in point source emissions from this scenario between 1988 and 2010 was $22 \%$ for $\mathrm{NO}_{\mathrm{x}}$ and an increase of $5 \%$ for VOCs. For nonmobile area sources, $\mathrm{NO}_{\mathrm{x}}$ decreased $13 \%$, and VOCs decreased $5 \%$. Figure 28 shows that the area of maximum ozone greater than 140 and $120 \mathrm{ppb}$ decreased relative to Case A5. Maximum ozone decreased by 5\% from 158 to $147 \mathrm{ppb}$, ozone over the grid decreased by $2 \%$, and two sites came into attainment. 


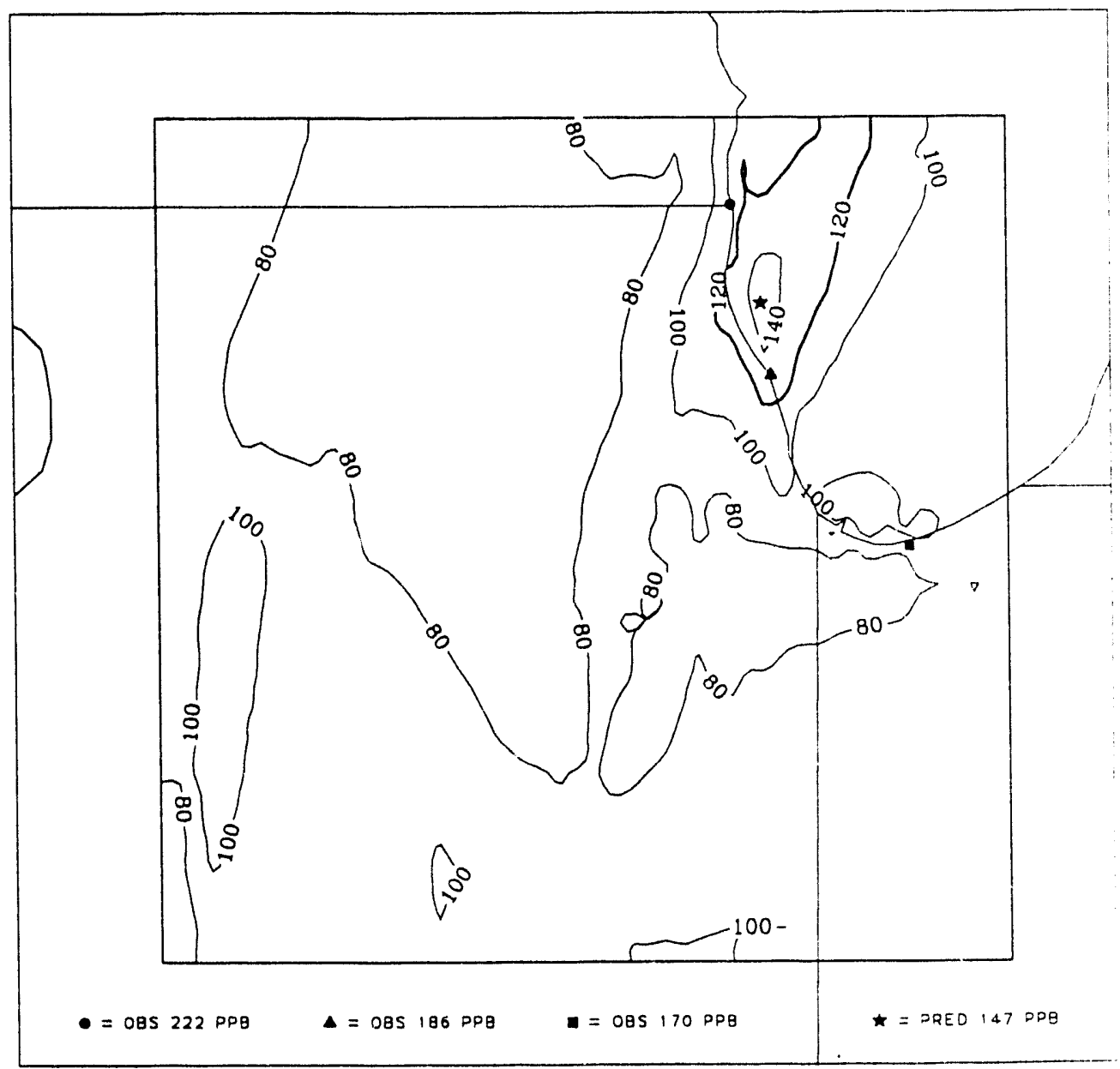

FIGURE 28 Predicted Maximum Hourly Ozone Concentrations for 1200 to 2000 LST on July 6, 1988: Improved Industrial Control Scenario (I2) (maxima are based on the period from 1200 to 2000 LST) 


\section{SUMMARY OF MODEL RUNS}

\subsection{COMPARISON OF INPUT PARAMETER SENSITIVITY RUNS}

The UAM input parameter sensitivity runs were performed to see how sensitive predicted ozone concentrations would be to "reasonable" changes such as an improved biogenic emissions factor, more realistic time-varying ozone initial and boundary conditions, increased values for $\mathrm{NO}_{\mathrm{x}}$ initial and boundary conditions, and different methods of calculating the mixing height grid predictions. The base case for these changed parameters is B1. The detailed choice of parameters for each case and the resulting contour plots and statistical results are given in Section 2. To determine the sensitivity of each change separately, each change must be compared with the run in which all parameters the same, except the one of interest. Case A1 should be compared with base case B1, Case A2 with Case A1, Case A3 with Case A2, Case A4 with Case A2, and Case A5 with either Case A.3 or A4.

The predicted maximum ozone for the new biogenic factor (Case A1) changed from 159 to $158 \mathrm{ppb}$, and the percent in maximum ozone, totaled over grid and nonattainment counties, changed less than $1 \%$. Since VOC emissions were reduced considerably, the reason for this insensitivity appears to be that the grid region is $\mathrm{NO}_{\mathrm{x}}$ limited. Since the new biogenic emissions factor is believed to be the correct one, it is used in all the UAM runs performed in this report. Use of this factor alone does not seem to change the results presented in Fernau et al. (1992). Case A1 and the previous base case (B1) are used interchangeably when making comparisons.

Adding time-varying initial and boundary conditions for ozone drops the maximum ozone concentration from 158 to $147 \mathrm{ppb}$ and lowers the maximum ozone concentrations, totaled over the grid by $14 \%$, and totaled over nonattainment counties by $21 \%$. However, the new ozone boundary conditions led to a larger range between maxima and minima at many more sites than they led to a lower range, showing that low ozone observations were simulated better. Increasing initial and boundary conditions for $\mathrm{NO}_{\mathrm{x}}$ increases maximum ozone by $1 \mathrm{ppb}$ relative to A2 and slightly improves the model bias relative to A2. Adding mixing height parameter changes increases the maximum ozone by $9 \mathrm{ppb}$ relative to A2 although the percent change in ozone, totaled over both grid and nonattainment counties scarcely is changed relative to A2. Bias is reduced considerably. Finally, the last case (A5) includes all four changes (A1-A4). The maximum ozone prediction is $158 \mathrm{ppb}$, the same as the new biogenic emission case, and percent changes in maximum ozone relative to A1, totaled over the grid and nonattainment counties, are $5 \%$ and $13 \%$, respectively. These changes may be thought of as resulting from combining cases A3 and A4.

In summary, the new corn emissions factor had little effect on the accuracy of the simulation. Mixing height changes reduce bias considerably by improving simulation of low diurnal ozone concentrations. Time-varying ozone boundary conditions also reduce bias significantly, but harm performance at higher observed ozone concentrations. $\mathrm{NO}_{\mathrm{x}}$ changes in boundary and initial conditions improve bias marginally and mitigate somewhat the 
decrease in performance in simulating high ozone concentrations induced by the other changes. A combination of all four cases yields the best improvement in the simulation, but performs less well than the Phase 1 base case B1 at high ozone concentrations.

A final case that combined Case A5 with doubled motor vehicle emissions yielded the best performance of all the cases - it was very good in absolute terms, with a maximum of $182 \mathrm{ppb}$ and good statistics relative to EPA guidelines. However, it was not adopted as the new base case because of the arbitrary increase of emissions.

\subsection{COMPARISON OF VARIOUS SENSITIVITY RUNS}

The UAM was run for an ozone episode that occurred on two days (July 5-6) in 1988 in the Chicago region and surrounding areas (B1). The sensitivity of the model and air quality to complete removal of emissions (B3) and to selective removal of emissions from the utility (B2), motor vehicle (MV1), and industrial (I1) sectors, respectively, was tested. Doubled motor vehicle emissions (MV2) also were tested. The only difference other than the sector emissions in these cases is that B2 and B.3 do not contain the new biogenic emissions. In the following summary, attainment is defined on a percentage basis relative to the percent change needed at each site to bring the observed maximum at that site on July 6 down (or up) to $120 \mathrm{ppb}$. Absolute concentrations are not used because of the underprediction bias at the highest ozone concentrations.

To reach attainment, maximum grid ozone must be reduced by $46 \%$. Case B3 reduced it by $45 \%$. In other words, complete removal of emissions, including natural emissions, failed to bring the area into attainment. This result points out the influence of the initial and boundary conditions on the episode. Case B2 reduced the maximum by $9 \%$, MV1 reduced the maximum by $21 \%$, and $\mathrm{I} 1$ reduced the maximum by $7 \%$.

Based on observations for July 6, 14 sites were in nonattainment. When all emissions are removed (B3), two sites are in nonattainment. For B2, it remains at 14. For MV1, it is 11. Twelve sites remain in nonattainment for I1. For B1 on July 6, there are 254 grid cells with absolute maxima above $120 \mathrm{ppb}$. Under B3, there are none. The numbers for B2, MV1, and I1, respectively are 159,100 , and 161 .

When motor vehicle emissions were doubled (Case MV2), the maximum ozone prediction over the grid was $181 \mathrm{ppb}$ compared with the base case B1 concentration of $159 \mathrm{ppb}$. An analysis of predictions at the 31 measuring sites found that for 22 sites the maximum prediction moved closer to the observed maximum, at eight sites it worsened, and at one it remained unchanged. As discussed earlier, there is some evidence that motor vehicle emissions may be substantially underestimated in current emission inventories. While one cannot point to any data for this region that would give the magnitude of this underestimation, doubling the motor vehicle emissions provides considerable improvement between predicted ozone maxima and observations. 
In summary, the transportation sector clearly makes the largest contribution to high ozone concentrations; removing its emissions reduces the number of predicted grid cells greater than $120 \mathrm{ppb}$ by $61 \%$, while the same procedure for either the utility or industrial sector reduces it about $37 \%$. The utility and industrial sectors provide comparable contributions to the ozone concentrations.

\subsection{COMPARISON OF FUTURE SCENARIOS}

The future scenarios (N2A, F2A, MV3 and I2) can be compared relative to the new base case A5. Since N1 was almost identical to N2, it is reasonable to assume that N2A is representative of $\mathrm{N} 1$ run with base case $\mathrm{A} 5$. $\mathrm{F} 1$ was similar to $\mathrm{N} 2$, and $\mathrm{N} 3$ was similar to F2. Thus, N2A and F2A should be representative of Phase 1 scenarios. Relative to A5, cases N2A, MV3, I2, and F2A reduced maximum grid ozone by $3,5,7$, and $11 \%$, respectively, nowhere near the attainment goal of $46 \%$. The number of nonattainment sites changed in all future scenario runs, from a base case A5 value of 14, to 13 for cases N2A and F2A, and 12 for cases MV3 and I2. The number of cells on.July 6 with ozone maxima above $120 \mathrm{ppb}$ is $119,101,86,77$, and 64 for $\mathrm{B} 1, \mathrm{~N} 2 \mathrm{~A}, \mathrm{MV} 3, \mathrm{I} 2$, and F2A, respectively. The sites located in downtown Chicago and in Indiana seemed to benefit most from the electric vehicle scenario MV3; they showed more improvement in air quality in Case MV3 than they did from the high $\mathrm{NO}_{\mathrm{x}}$ reduction scenario, Case F2A.

The relative changes between $\mathrm{N} 2-\mathrm{N} 2 \mathrm{~A}$ and F2-F2A were similar with the two base cases despite the changes. There did appear to be an increased tendency for $\mathrm{NO}_{\mathrm{x}}$ reductions to make air quality worse downwind of utilities. Since these two runs did not include the new biogenic emissions, poor air quality may be related to the changes in the $\mathrm{NO}_{\mathrm{x}}$ initial or boundary conditions. A N3A case was run in which N3 was rerun with the new base case A5 and biogenic emissions, but the results did not make sense intuitively. They fell midway between the MV3 and I2 scenarios; emissions should have been reduced relative to those scenarios. The case was expected to be similar to F2A, but it was not. It has not been determined yet whether an error was made during preprocessing or if the result is legitimate, possibly resulting from the biogenic emissions change or the increased $\mathrm{NO}_{\mathrm{x}}$ sensitivity.

In summary, a realistic industrial scenario made the NES/CAAA future base case more effective in reducing ozone, but not as effective as increasing utility $\mathrm{NO}_{\mathrm{x}}$ controls to 95\%. However, there is still much uncertainty surrounding the future levels of VOC and $\mathrm{NO}_{\mathrm{x}}$ emissions from industry. The modest electric vehicle scenario was unexpectedly effective in improving air quality in the immediate vicinity of downtown Chicago but was not as effective further downwind. The results from Phase 1 appear to be robust, but more research is needed to investigate questions involving $\mathrm{NO}_{\mathbf{x}}$ contributions to ozone and the N3A results. 


\section{MAJOR FINDINGS AND FUTURE DIRECTIONS}

This study investigated the role of utilities in contributing to urban air quality with respect to ozone and studied the relative effects of different emissions control strategies on ozone concentrations. Results yielded some information on the role of utilities and other sectors in determining air quality. This section outlines these findings, which apply to the region (Greater Chicago) and limited meteorological conditions (July 5-6, 1988, and similar episodes) examined in this study.

Phase 1 of this study found that, for the episode modeled, compliance with Title IV regulations for utility $\mathrm{NO}_{\mathrm{x}}$ emissions did not significantly affect air quality. Also, completely removing utility emissions did not lead to attainment, because it only improved air quality by $20-25 \%$ of the improvement that is predicted from removing all emissions, which illustrates that nonutility sources contribute to the ozone problem in that region.

A major finding of Phase 1 was that the region appears to be $\mathrm{NO}_{\mathrm{x}}$-limited, except for a very limited area in the vicinity of large power plants. Thus, reductions in $\mathrm{NO}_{\mathrm{x}}$ emissions should not lead to deterioration in air quality over most of the area.

This study (Phase 2) answered some of the questions that remained after Phase 1 and prevented firm conclusions from being drawn from these findings. However, because of the complex nature of photochemical modeling, uncertainties still remain. These uncertainties remain because certain issues specific to this study require specification of boundary and initial conditions and because generic uncertainty is associated with this type of work (e.g., difficulty in characterizing fully anthropogenic and natural emissions, lack of complete knowledge of the chemistry, and inability to depict the exact wind field). The emissions projections also contain uncertainties because it is difficult to anticipate all possible structural changes in the use of energy that could occur in the next 20 years.

The states will be using UAM to determine control strategies, although the state of the science lags behind the needs of the policy makers, and the current generation of models may be inadequate for firm regulatory decisions. Given the uncertainties associated with photochemical modeling even when a high-quality data set is used for model inputs and testing, the models should be regarded as tools that can guide decision making but that cannot provide precise answers.

This study resulted in the following findings:

- The four order-of-magnitude error in the VOC emissions factor for corn present in the old EPA biogenic emissions moael does not affect this ozone episode and thus does not weaken the findings of Phase 1 (Case A1).

- Initial and boundary condition specifications of atmospheric pollutant concentrations are improved on the basis of observations. Alternative 
mixing height calculations enhance nighttime mixing. These changes significantly improve the base case, making it more credible as a starting point for cases. However, prediction of the highest $10 \%$ of observations deteriorates slightly, making it necessary to continue use of relative rather than absolute changes to examine nonattainment issues (cases A2 through A5).

- Doubling motor vehicle emissions (Case MV2) gives a better fit to observations, especially when combined with the other changes in the base case (Case A6). Although the arbitrary nature of the emissions change precludes its use in the new base case, it does support the widespread evidence that motor vehicle emissions inventories are underestimated substantially in ozone nonattainment areas.

- The mobile source sector (Case MV1) contributes more to high ozone concentrations than do the utility (Case B2) or industrial (Case I1) sectors, based on selective removal of emissions. The utility and industrial sectors appear to contribute equally to ozone concentrations. Attainment cannot be achieved by eliminating any one sector's emissions.

- An industrial control strategy (Case I2) that is more realistic than that used in Case N2 lowers ozone relative to the Phase 1 future base case (Case N2A) but still is not as effective as $95 \%$ control on utility sources (Case F2A). None of the emission reduction strategies examined contributed significantly to achieving attainment, except for complete removal of emissions.

- Electric vehicles effectively reduce downtown ozone relative to the amount of emissions reductions gained from them, but the absolute amount of penetration projected in 2010 is not large enough to make a significant difference in air quality (Case MV3).

- Although some areas of uncertainty remain in the treatment of initial and boundary conditions and in the projection of emissions to 2010 , the results from Phase 1 are not contradicted by additional work and remain valid. Some evidence exists that the specification of the base case can affect the extent to which $\mathrm{NO}_{x}$ controls are effective, but this fact needs to be investigated further.

Given these findings and the large reductions in precursor emissions that will be necessary to achieve attainment in the Chicago area, it seems likely that $\mathrm{NO}_{\mathrm{x}}$ emissions reductions, perhaps beyond Title $I V$, will be required - although the cost-effective combination of sectional strategies is yet to be determined. The Lake Michigan Ozone Control Program, which will be implemented by the regional authorities, will add additional evidence to confirm or weaken this finding. 
Some uncertainties remain to be investigated. Some of these areas of concern are described here, as are Argonne's plans for reducing the remaining uncertainties.

- Argonne did not specifically examine the effects of initial conditions on the model results. The base case could possibly be improved by beginning the model run earlier, for example, at 0000 LST on July 5. Starting the model run earlier might prevent the very high initial conditions from significantly influencing overnight ozone values. This change would be relatively easy to implement.

- Changing the boundary conditions for ozone to time-varying values improves overall model performance, but it causes the secondary ozone maximum modeled on the south shore of Lake Michigan to dissipate. Because this feature is present in the observations, it may be tied to transport into the eastern boundary of the grid. Additional boundary condition tests (e.g., a separate value for the eastern boundary or higher daytime values) could be investigated to see if the feature can be resolved.

- Switching to the improved base case appears to make the model more sensitive to ozone scavenging by $\mathrm{NO}_{x}$ downwind of large $\mathrm{NO}_{x}$ sources. The effect is still localized, but the spatial extent spread by several tens of kilometers and the magnitude of air quality deterioration increase. Additional cases or sensitivity studies could be conducted to investigate this fact further to identify the exact conditions causing the phenomenon.

- The VOC projections used in Phase 2 can be refined by using new VOC modeling. New VOC modeling uses the latest interpretations of the impacts of the CAAA on VOC emissions and incorporates market-based incentives such as trading schemes, the form of which are better known than when previous NES and National Acid Precipitation Assessment Program work was done.

- The Lake Michigan Ozone Study, a $\$ 13$ million project to develop new models and databases to help the states to achieve attainment, is nearing completion. The data are being readied for public access and could be used to model additional time periods with better data or at least to improve boundary conditions and other inputs.

- Argonne has gained much experience with UAM in the last year and has improved the base case to the point where cost-effectiveness issues of various control strategies could be examined. Individual UAM runs can now be developed, modeled, and analyzed in less than a week, once the case is defined. 


\section{REFERENCES}

Air Quality Week, 1993, Urban Airshed Models Found Less Than Perfect, April 26.

DOE: See U.S. Department of Energy.

Electric Power Research Institute, 1992, The Use of Photochemical Air Quality Models for Evaluating Emission Control Strategies: A Synthesis Report, EPRI TR-101918, Electric Power Research Institute, Palo Alto, Calif.

EPA: See U.S. Environmental Protection Agency.

EPRI: See Electric Power Research Institute.

Fernau, M.E., K.A. Guziel, and D.W. South, 1992, Potential Impacts of Title I Noncttainment on the Electric Power Industry: A Chicago Case Study, internal report available from the authors, Argonne National Laboratory, Argonne, Ill.

Fernau, M.E., K.A. Guziel, and D.W. South, 199.3a, An Examination of Utility Emissions Contributions to Elevated Ozone Concentrations in the Chicago Area, paper 93-TA-37A.07, presented at the 86th Annual Meeting of the Air and Waste Management Association, Denver, Colo., June 14-18.

Fernau, M.E., D.W. South, and K.A. Guziel, 1993b, Ozone Nonattainment: Implications for NO ${ }_{x}$ and VOC Compliance by the Electric Power Industry, presented at the 54th Annual American Power Conference and scheduled for publication in the proceedings, Chicago, Ill, April 13-15.

Fisher, R.E., G.A. Boyd, J.C. Molburg, G. Pandola, and C.L. Saricks, 1991, unpublished information, Argonne National Laboratory, Argonne, Ill.

Kohout, E.J., D.J. Miller, L.A. Nieves, D.S. Rothman, C.L. Saricks, F. Stodolsky, and D.A. Hanson, 1990, Current Emission Trends for Nitrogen Oxides, Sulfur Dioxide, and Volatile Organic Compounds by Month and State: Methodology and Results, ANL/EAIS/TM-25, Argonne National Laboratory, Argonne, Ill.

Lyons, W.A., 1991, The Use of a Mesoscale Prognostic Meteorological Model for the LMOS, presented at the 1991 Conference on Lake Michigan Ozone and the Clean Air Act, Air and Waste Management Association, Lincolnshire, Ill., October 17-18.

Morris, R.E., A.K. Pollack, D.P. Chock, A.M. Dunker, and C.H. Schleyer, 1992, Methodology for Trajectory and Grid Modeling to Determine the Impact of Different Vehicle/Fuel Systems on Air Quality - Auto/Oil Air Quality Improvement Research Program, paper 92-119.05, presented at the 85th Annual Meeting of the Air and Waste Management Association, Kansas City, Mo., June 21-26. 
National Research Council, 1991, Rethinking the Ozone Problem in Urban and Regional Air Pollution, published by National Academy Press, Washington, D.C.

Saricks, C.L., 1993, unpublished information, Argonne National Laboratory, Argonne, Ill.

Sharkey, T., 1992, Biogenic Hydrocarbon Emissions, presented at the 1992 Conference on Lake Michigan Ozone and the Clean Air Act, Schaumburg, 1ll., October 22-23.

South, D.W., K.A. Bailey, and K.A. McDermott, 1992, Emissions Trading and Compliance: Regulatory Incentives and Barriers, paper presented at the 1992 Air Emissions and Waste Management Conference, Lake Michigan States Section of the Air and Waste Management Association, Chicago, Jan. 30.

Streets, D.G., J.A. Fox, D.A. Hanson, L.G. Jones, J.P. Weyant, N. Bhatti, G.A. Boyd, C.L. Saricks, and J.K. Wagner, 1990, Methods for Modeling Future Emissions and Control Costs, report 26 contained in Volume IV of the Acidic Deposition: State of Science and Technology series, National Acid Precipitation Assessment Program, available from Superintendent of Documents, Government Printing Office, Washington, D.C.

U.S. Department of Energy, 1991, Integrated Analysis Supporting the National Energy Strategy: Methodology, Assumptions and Results, DOE/S-0086/P, Technical Annex 2 of the National Energy Strategy, Washington, D.C.

U.S. Environmental Protection Agency, 1990a, User's Guide for the Urban Airshed Model, EPA-450/4-90-007A through D (4 volumes), Office of Air Quality Planning and Standards, Research Triangle Park, N.C.

U.S. Environmental Protection Agency, 1990b, Urban Airshed Model Study of Five Cities: A Low-Cost Application of the Urban Airshed Model to the New York Metropolitan Area and the City of St. Louis, EPA-450/4-90-006e, Office of Air Quality Planning and Standards, Research Triangle Park, N.C.

U.S. Environmental Protection Agency, 1991a, Regional Ozone Modeling for Northeast Transport (ROMNET) Project Final Report, EPA-450/4-91-002a, Office of Air Quality Planning and Standards, Research Triangle Park, N.C.

U.S. Environmental Protection Agency, 1991b, Guideline for Regulatory Application of the Urban Airshed Model, EPA-450/4-91-013, Office of Air Quality Planning and Standards, Research Triangle Park, N.C. (available from NTIS as document number PB92-108760).

U.S. Environmental Protection Agency, 1991c, National Air Pollutant Emission Estimates 1940-1990, EPA-450/4-91-026, Office of Air Quality Planning and Standards, Technical Support Division, Research Triangle Park, N.C. 
Veselka, T.D., J.C. VanKuiken, G.D. Parker, and K. Rose, 1990, Introduction to the Argonne Utility Simulation (ARGUS) Model, ANL/EAIS/TM-10, Argonne National Laboratory, Argonne, Ill.

Wang, Q., and D.L. Santini, 1993, Magnitude and Value of Electric Vehicle Emissions Reductions for Six Driving Cycles in Four U.S. Cities with Varying Air Quality Problems, Transport. Res. Record, accepted for publication. 
APPENDIX A:

NONEMISSIONS MODEL INPUT DATA PREPARATION 


\section{APPENDIX A:}

\section{NONEMISSIONS MODEL INPUT DATA PREPARATION}

This appendix presents the details and assumptions involved in generating the meteorological and air quality input data for the Urban Airshed Model (UAM).

\section{A.1 PREPARATION OF METEOROLOGY INPUTS}

Several different types of meteorology data are required to run UAM, in. mixing height data, wind fields, temperature fields, radiation data, and other met variables. This subsection describes how those fields were derived.

\section{A.1.1 Mixing Height Information}

A diffusion break file must be created to define the daytime height of the well-mixed layer and the height of the inversion break at night. To do this, three programs must be run. The first uses surface and upper air meteorological data from a radiosonde to determine the morning and afternoon maximum mixing heights. The second program uses these mixing heights to calculate hourly mixing heights at one or more sites. The third program interpolates these mixing heights to the entire UAM grid.

The first program is a mixing height program supplied by the U.S. Environmental Protection Agency (EPA). Twice-daily Peoria sounding data (height, pressure, temperature) were obtained from the National Climatic Data Center (NCDC) and were used to determine the morning and afternoon maximum mixing heights, based on the potential temperature vertical gradients. If a $0-\mathrm{m}$ mixing height was calculated for the morning sounding, the height was set at $250 \mathrm{~m}$.

The second program, also developed by EPA, was run for five different sites, the airports in Rockford, Peoria, DuPage County, Chicago-Midway, and Chicago-O'Hare, using surface measurements of temperature and wind speed at these sites, obtained from the $\mathrm{NCDC}$, and the mixing height information along with sunrise and 2 p.m. LST temperature from Peoria. The program uses temperature and calculated Pasquill-Gifford stability class to calculate hourly mixing heights. The program produces both a rural and an urban mixing height time series. The urban time series was used for input to the next preprocessor.

The program can be run in three different option modes. The first mode is the original EPA program, which tends to have a rapid decrease to a minimum specified mixing height. The second cption incorporates surface information at the sites. The third option also includes surface temperature information from Peoria to allow changes in the surface temperature field to influence the mixing height. 
The final step in the mixing height preprocessing was to run a program that uses the results from the selected options at the five sites to interpolate mixing heights to each grid cell in the UAM grid. Option 2 was used in Phase 1 because it is the most sophisticated of the three options, but it led to large mixing heights at night, and subsequent UAM runs had too much surface ozone because of this. In Phase 2 (this report) the sensitivity of UAM to which option is used was tested by using the option 0 mixing heights instead.

Another preprocessor assigned a constant value to each grid cell to represent the top of the modeling domain. As recommended by the user's guide, this value was chosen to be about $100 \mathrm{~m}$ above the maximum mixing height that occurred in the grid.

\section{A.1.2 Wind Fields}

The UAM needs a three-dimensional wind field to transport pollutants through the grid. Four preprocessor programs perform this task. The first two convert raw wind speed and direction data into $u$ and $v$ components, interpolate vertically to a fixed number of layers, and interpolate temporally to create a time series, for the surface and upper air data. The third program uses these data to interpolate in space on the dense vertical grid and produce a physically consistent wind field. The final program interpolates the output from the third program to the smaller number of layers used in UAM.

Hourly surface wind data measured at approximately $10 \mathrm{~m}$ above ground level were obtained at 7 airport sites and 21 pollution monitoring sites. The airport data came from NCDC, and the data from the monitoring sites were obtained from EPA's Aerometric Information Retrieval System (AIRS). Most of these sites are located in the urban and suburban Chicago area, with some near Rockford and Peoria; coverage over the rural areas and Lake Michigan was almost nonexistent. Wind speed and direction were converted to vectors.

Twice-daily ( 6 a.m. and 6 p.m. CST) upper air data were available from NCDC at the three National Weather Service sites located closest to the grid: Peoria, Illinois; Green Bay, Wisconsin; and Flint, Michigan. Hourly meteorological tower data were obtained for several levels from Argonne National Laboratory and 10 different utility measuring sites. The wind speed and direction and the height information were used to convert to $u$ and $v$ components and interpolate vertically to 20 layers and temporally.

From the above data, three-dimensional wind fields were generated using the Diagnostic Wind Model (DWM), which combines the laws of physics and objective analysis techniques to extend the site data to the entire UAM grid at 20 vertical layers. Alternatively, a mesoscale weather model could be used, but this was not feasible under the budget of this project. Another alternative is to use wind fields from the Regional Oxidant Model as a basis for the UAM winds.

The DWM has two parts. In the first part, a domain mean wind field is produced from simplified meteorological assumptions and is adjusted to reflect underlying terrain. In 
the second part, the observations are used to adjust the field generated in step one. The final field will reflect the observations where they are present and will use the domain wind in data-sparse regions. If observations are sufficiently dense, step one can be omitted.

In this study, step one was omitted because of time constraints and technical difficulties. The measurement network is sufficiently dense in the high emissions and ozone part of the grid that this omission should not be a problem. In the objective analysis, any site within $300 \mathrm{~km}$ was allowed to influence the wind field at a grid cell, except that only the five closest sites were used in the four lowest layers, and the three closest sites in the remaining layers. A 1 radius weighing is used for the elevated layers, and $1 /$ radius-squared weighing is used for the lowest layer. Time constraints did not allow testing of the sensitivity of the ozone and wind fields to the number of sites allowed to influence a grid cell.

Finally, the DWM wind field at fixed vertical layers must be converted to the UAM grid, in which the layer definitions can change with time and space. The mixing height data

are used at this stage. Pasquill-Gifford stability classes derived from the meteorological data are used to determine the extent to which the surface wind field is allowed to influence tho data-poor upper layers.

\section{A.1.3 Other Meteorological Fields}

The UAM requires several other meteorological parameters derived from measurements.

\section{A.1.3.1 Temperature}

The seven airport sites were used to interpolate hourly surface temperature data to the UAM grid. Sites within $100 \mathrm{~km}$ of a grid cell influence the temperature value in that grid cell. Weighing is inverse with distance from the grid cell for these sites.

\section{A.1.3.2 Meteorological Scalars}

The UAM needs several different hourly meteorological variables that are considered to be constant across the grid. Atmospheric pressure was set from the DuPage County Airport values because it is located in the center of the grid. O'Hare Airport data were used to calculate the concentration of water vapor in parts per million by volume. The ClausiusClapeyron equation yields the saturation vapor pressure from surface temperature. The saturatior: vapor pressure and the atmospheric pressure are used to obtain the saturation mixing ratio, which is then used with the relative humidity to yield the mixing ratio. Multiplying by a million and dividing the numerator and denominator by the molecular weights of wet and dry air, respectively, gives the desired water vapor concentration. 
A program calculates both the nitrogen dioxide $\left(\mathrm{NO}_{2}\right)$ photolysis rate, which is used in the chemistry module, and the solar zenith angle, which is combined with cloud cover data at $\mathrm{O}^{\prime} \mathrm{Hare}$ to give a measure of stability known as the exposure class.

Temperature gradients above and below the diffusion break were calculated from the Peoria soundings according to guidance provided in the user's guide. These values are somewhat subjective.

\section{A.2 PREPARATION OF AIR QUALITY INPUTS}

The UAM requires specification of the initial chemical concentrations over the grid and at the horizontal and top boundaries during the run.

\section{A.2.1 Initial Conditions}

Initial chemical concentrations over the grid must be specified at each level of the model. For this study, initial conditions were based on EPA guidance and air quality measurements from the AIRS database. In addition to the approximately 40 measurement sites (mostly clustered around the south end of Lake Michigan, Peoria, and Rockford), three "pseudo sites" near the corners of the grid were specified to aid the interpolation algorithm.

Table A.1 lists the default initial conditions used in this study. The values are taken from EPA (1991b), with slight modification as mentioned below. At each measuring site for which observed hourly concentrations of ozone, $\mathrm{NO}_{2}$, and carbon monoxide (CO) for the initial hour were present, the measurements were used; for all other species and for missing data, the default values were assigned to the sites. Horizontal interpolation using the measuring sites yielded spatially varying fields for ozone, $\mathrm{NO}_{2}$, and $\mathrm{CO}$ and constant fields for the other volatile organic compounds (VOCs). Vertical interpolation was done by using the initial surface fields, values specified at the top of the model domain (described below) and a step function to describe the vertical distribution. For VOC, this resulted in a constant vertical distribution because the top values are identical to the surface values. For ozone, $\mathrm{NO}_{2}$, and $\mathrm{CO}$, the surface value applies up to the mixing height, and then the value for the top of the domain was used from the top of the mixing height to the top of the model domain.

Several changes to the EPA-recommended values were made. The default ozone concentration was doubled from 40 to 80 parts per billion ( $\mathrm{ppb}$ ) based on observations. The EPA-recommended defaults for $\mathrm{NO}_{2}$ and $\mathrm{NO}$ are 2 and $0 \mathrm{ppb}$, respectively. This was changed to a $3 / 4-1 / 4$ split for $\mathrm{NO}_{\mathrm{x}}$ (i.e., $1.5 \mathrm{ppb}$ for $\mathrm{NO}_{2}$ and $0.5 \mathrm{ppb}$ for $\mathrm{NO}$ ) as recommended in the UAM documentation, and these two values were then doubled to reflect the observations. The initial conditions were not altered for the future scenario modeling runs. In Phase 2, some sensitivity analyses were done with increase $\mathrm{NO}_{\mathrm{x}}$ concentrations. 
TABLE A.1 Default Initial Conditions for Chicago Case Study (units are parts per million carbon for VOC [paraffins and below] and parts per million for the others)

\begin{tabular}{lcc}
\hline \multicolumn{1}{c}{ Species } & UAM Abbreviations & Concentration \\
\hline Ozone & $\mathrm{O}_{3}$ & 0.08 \\
Nitrogen dioxide & $\mathrm{NO}_{2}$ & 0.003 \\
Nitric oxide & $\mathrm{NO}$ & 0.001 \\
Carbon monoxide & $\mathrm{CO}$ & 0.350 \\
Paraffins & $\mathrm{FAR}$ & 0.01494 \\
Formaldehyde & $\mathrm{FORM}$ & 0.0021 \\
Toluene & $\mathrm{TOL}$ & 0.00126 \\
Higher aldehydes & $\mathrm{ALD} 2$ & 0.00111 \\
Ethene & $\mathrm{ETH}$ & 0.00102 \\
Xylene & $\mathrm{XYL}$ & 0.00078 \\
Olefins & $\mathrm{OLE}$ & 0.0006 \\
Isoprene & $\mathrm{ISOP}$ & 0.0001 \\
Methanol & $\mathrm{MEOH}$ & 0.0001 \\
Ethanol & $\mathrm{ETOH}$ & 0.0001 \\
Cresol, higher phenols & $\mathrm{CRES}$ & 0.00001 \\
Methyl glyoxal & $\mathrm{MGLY}$ & 0.00001 \\
Aromatic ring fragment acid & $\mathrm{OPEN}$ & 0.00001 \\
Peroxynitric acid & $\mathrm{PNA}$ & 0.00001 \\
Total nitrogen compounds & $\mathrm{NXOY}$ & 0.00001 \\
Peroxyacyl nitrate & $\mathrm{PAN}$ & 0.00001 \\
Nitrous acid & $\mathrm{HONO}$ & 0.00001 \\
Hydrogen peroxide & $\mathrm{H} \mathrm{O}_{2}$ & 0.00001 \\
Nitric acid & $\mathrm{HNO}{ }_{3}$ & 0.00001 \\
\hline
\end{tabular}

\section{A.2.2 Horizontal and Vertical Boundary Conditions}

Boundary concentrations must also be specified to reflect the amount of pollutant entering or leaving the domain. Boundary conditions on all four sides of the grid were set at the defaults listed in Table A.1 and were held constant with time. The only exception is that $\mathrm{NO}_{2}$ and $\mathrm{NO}$ were set to 1.5 and $0.5 \mathrm{ppb}$, respectively. The values in Table A.1 were also used to specify the concentrations at the top of the domain, with ozone set to $40 \mathrm{ppb}$ and $\mathrm{NO}_{2}$ and $\mathrm{NO}$ set to 1.5 and $0.5 \mathrm{ppb}$, respectively. The fields are constant across the domain. For computational reasons, the horizontal boundaries were defined to be one row or column in from the actual boundary of the grid. In Phase 2, some sensitivity studies were done involving diurnally varying ozone concentrations and elevated $\mathrm{NO}_{\mathrm{x}}$ values.

\section{A.3 PREPARATION OF OTHER NECESSARY FIELDS}

In addition to the files described above, several other files must be generated for the UAM preprocessors. 


\section{A.3.1 Terrain Heights and Land Use}

Several of the preprocessor programs need as input gridded terrain height and/or land use information. The land use information is used to produce a UAM input file of gridded surface roughness and surface deposition factor and also is used by the biogenic emissions preprocessor. Terrain heights are used by the DWM preprocessor.

The terrain heights and land use were assigned to the UAM grid from global ten-minute (about 20-km spacing) data obtained from the National Center for Atmospheric Research (NCAR). Each UAM grid cell was given the value of the closest NCAR data point. Only the dominant land use for each grid point was used. The files were visually inspected and manually adjusted to reflect more accurately the Lake Michigan boundary and the extent of the urban areas in Rockford, Peoria, and the Chicago suburbs. Three land use categories were used: urban, agricultural, and water.

\section{A.3.2 Chemical Reaction Rates}

A file that specifies information regarding the chemical reaction properties must be provided to UAM. It includes information on whether a given reaction is photolysis, temperature-dependent, or neither. It also has reaction rates, activation energies, and reference temperatures. EPA provides the input for this file and per the documentation no changes were made to it for this study.

\section{A.3.3 Simulation Control}

A file was created that gives start and end date and time, several print and simulation options, and some other controls and default values. Except for the time limits, this file was identical to that provided by EPA. 
APPENDIX B:

PREPARATION OF PRESENT AND FUTURE EMISSIONS INPUT 


\section{APPENDIX B:}

\section{PREPARATION OF PRESENT AND FUTURE EMISSIONS INPUT *}

\section{B.1 PROJECTION OF ANNUAL 1985 EMISSIONS TO SUMMER 1988 EMISSIONS}

The version of the Urban Airshed Model (UAM) used in this study is designed to use the National Acid Precipitation Assessment Program (NAPAP) 1985 inventory of emissions. Since the base case episode was in 1988, the 1985 emissions must be projected to 1988. For nitrogen oxides $\left(\mathrm{NO}_{\mathrm{x}}\right)$, volatile organic compounds (VOCs), carbon monoxide (CO), and total suspended particulate (TSP), UAM needs point source emissions, area source emissions (defined as point sources below a certain cutoff and disperse emissions), and mobile source emissions.

For point and area source emissions of $\mathrm{NO}_{\mathrm{x}}$ and VOCs, 1985-1988 growth rates were taken from Argonne National Laboratory's (ANL's) Month and State Current Emissions Trends (MSCET) database (Kohout et al. 1990), which provides state-specific growth rates for 68 emissions categories. For CO and TSP, annual national growth rates as reported by EPA were used (EPA 1991c). The 1985 NAPAP emissions for each category and pollutant were adjusted by the ratio of the 1988 MSCET numbers to the 1985 MSCET values.

Mobile sources were calculated by use of a different method. The 1985 NAPAP annual emissions were replaced with July 1988 state-level data (times 12), and shares of the state-level data were allocated by county using the 1985 NAPAP county percentage shares. The MSCET emissions are calculated using EPA's MOBILE4 emissions factors. MSCET uses state- and month-specific average temperatures and diurnal temperature ranges. These are important to capture nonlinear relationships between temperature and pollutant emission rates. MSCET also uses improved on-highway vehicle speed data provided over four speed classes and five vehicle types.

\section{B.2 FUTURE YEAR EMISSIONS}

The scenario analyses required emissions projection to a future year; 2010 was chosen because the Chicago region must be in attainment by 2007 . Future Commonwealth Edison (Com Ed) emissions growth rates were projected using the Argonne Utility Simulation Model (ARGUS) (Veselka et al. 1990). Other utility growth was based on the 1988-2010 ARGUS Com Ed growth rates. Growth in other sectors was based on modeling done by ANL for both the National Energy Strategy (NES) and NAPAP, using the NES Environmental Analysis Model (NESEAM) and other models developed at ANL (Streets et al. 1990; Fisher et al. 1991). Emissions from railroads and VOC emissions from industrial processes initially were not modeled, thus making the implicit assumption that growth and controls cancel,

* Full citations for the references called out in this appendix are provided in Section 8. 
leading to no change in emissions. In Phase 2, a scenario incorporating more realistic values was examined.

\section{B.2.1 ARGUS Analysis for Utilities}

ARGUS typically uses one or more composite groups of utilities known as power pools in its analysis, and this analysis was made simpler because Com Ed exclusively makes up one power pool. AFiGUS was run in this study using only the Com Ed power pool. ARGUS operates on a five yesr time step. ARGUS has the capability of simulating utility power production, simulating coal markets, minimizing the cost of expanding electric power capacity, estimating related atmospheric emissions from utilities, and computing a least-cost emissions reduction strategy. It consists of three major modules that were used in this study. The first adds new units in dynamic response to load growth and capacity changes. The second calculates unit-level capacity factors and provides the previous module with information on the expected operation of the system. The third determines the least-cost strategy to meet emission control regulations as outlined in Title IV of the Clean Air Act Amendments of 1990. Coal prices were kept static through the period, but a variety of coals were available from which new and compliance units could select.

The Com Ed power pool includes the large Kincaid plant that was included in the ARGUS analysis but is not located in the UAM grid. Also some non-Com Ed plants that are located in the UAM grid are omitted from the ARGUS analysis. Present and future fuel prices and peak loads were obtained from various sources. The amount of new capacity additions was based on a $20 \%$ reserve margin, as identified in the Com Ed current least-cost plan. The following new capacity additions were allowed, depending on the requirements of a particular scenario: gas combustion turbine, natural gas-fired combined cycle, nuclear (advanced light water reactor), integrated gasification combined cycle, pressurized fluidizedbed combustion, and pulverized coal with flue-gas desulfurization. New capacity was assumed to be built at existing sites, including Kincaid. To satisfy UAM input needs, the operating schedule and stack characteristics for new sources were defined using existing source characteristics.

The cost of an emission allowance was set at $\$ 300 /$ ton in 1995 and was assumed to increase by four percent annually. ARGUS initially chose fuel-switching over flue gas desulfurization for control of $\mathrm{SO}_{2}$ at all existing coal units. Based on state regulatory concerns, and after a review of the Com Ed coal units effected by Phase II compliance, it was decided to force a scrubber onto two of the Com Ed Powerton units to insure use of Illinois high sulfur coal (South et al. 1992).

Three scenarios were examined with ARGUS in Phase 1. A future base case assumed nuclear plant relicensing and new nuclear capacity. To maintain the NES assumptions, new nuclear units were allowed to become operational in 1996 . Another scenario delayed new nuclear capacity until 2000. Relicensing did not affect the Com Ed power pool during the period 1990-2010. All technologies were allowed to compete in these two scenarios. A third, high fossil fuel use, scenario did not consider nuclear units for new 
capacity additions. An existing ARGUS run was used to determine the effect of electric vehicle charging on electricity production. $\mathrm{NO}_{\mathrm{x}}$ emissions in these scenarios were assumed to be reduced by 50 to $60 \%$ through installation of low $\mathrm{NO}_{\mathrm{x}}$ burners.

All three scenarios added approximately the same amount of new capacity to meet the target reserve margin. The preferred technologies were nuclear reactor, integratedgasification combined cycle, and/or natural gas combustion turbine. The two nuclear scenarios added significantly more nuclear capacity. All scenarios showed a significant increase in gas capacity, indicative of the system need for peaking capacity. All scenarios added 4,500 to 5,000 MWe of gas turbine units along with base load coal or nuclear (4,800-6,000 MWe). The high fossil and delayed nuclear scenarios each built four natural gas combined cycle units. The pressurized fluidized-bed combustion and pulverized coal with flue gas desulfurization technologies were not chosen in any of the scenarios.

The 1988 Com Ed utility emissions were adjusted to 2010 using the ARGUS calculated growth rates. A small number of peaking units that were present in ARGUS but not in the 1988 database were omitted. Their emissions decreased from 1988 to 2010 . Emissions from new builds in ARGUS were added into the 2010 database. No units were retired in the scenarios examined. Growth rates based on existing Com Ed plants also were applied to non-Com Ed plants present in the UAM grid.

\section{B.2.2 Nonutility Emissions}

All nonutility emissions sources had to be projected using the results of other Argonne emissions models. This was accomplished by using results from previous Argonne work to obtain growth factors for different emissions categories. In most cases, NESEAM was used to compute emissions by applying emissions factors appropriate to energy consumption under the NES Actions case (DOE 1991; Fisher et al. 1991). Because NESEAM only models emissions from energy consumption, in some cases its results are not appropriate. For cases where NESEAM was not appropriate, various emissions models developed for NAPAP were used (Streets et al. 1990). Some categories were held to constant emissions because of conflicting modeling results. In Phase 2, these sectors were modeled more appropriately.

\section{B.3 PREPARATION OF EMISSIONS INPUTS}

The NAPAP emissions for 1985 for the Chicago area were obtained and were projected to 1988 or any of the future scenarios. A series of emissions preprocessors then were executed. This exercise was very time-consuming and computer-intensive. UAM uses three types of emissions: biogenic area sources, anthropogenic point sources, and anthropogenic area sources. The last are further divided into motor vehicle and all other area sources. Emissions were obtained for sulfur dioxide $\left(\mathrm{SO}_{2}\right), \mathrm{NO}_{\mathbf{x}}, \mathrm{CO}$, TSP, and total hydrucarbons (THC). UAM does not use the NAPAP volatile organic compounds emissions category, and the Chicago study also did not use the $\mathrm{SO}_{2}$ emissions. For convenience, the 
THC emissions are referred to as VOC in this report. After the major emissions types were preprocessed, a series of programs tallied them by sector, merged the different types of area emissions, and formatted them for input into UAM.

\section{B.3.1 Biogenic Emissions}

Trees and other vegetation are major sources of several VOCs and also emit $\mathrm{NO}_{\mathbf{x}}$. EPA has developed a model (the Biogenic Emissions Inventory System) that estimates emissions from natural sources. The program uses a combination of data supplied by EPA and the user to determine biomass and meteorological conditions and the consequent natural emissions. The user can supply information regarding canopy area and biomass if desired, but for this study the EPA-supplied county-level values were used.

The program uses the wind and temperature fields that were created for input to UAM (Section A.1 in Appendix A). One additional meteorological file was created in which relative humidity and cloud cover information for O'Hare Airport were listed. In addition, a file with the percent of each grid cell contained in a given county was prepared. For instance, one grid cell might be $100 \%$ contained in Cook County, but another one might have half its area in Cook Ccunty, 25\% in DuPage County, and 25\% in Will County. This information was used to allocate the county-level canopy data.

The biogenic emissions preprocessor was run twice, for July 5 and 6,1988 . The output was merged with the manmade area source emissions by grid cell. In Phase 2 , the model was run twice more to account for altered emissions factors and different mixing heights.

\section{B.3.2 Point Source Emissions}

If the initial point source inventory is to be altered for a particular control strategy: one or more steps are applied to it. Programs written by ANL staff do tasks such as removing all emissions from a particular sector from the inventory or applying growth/control factors to the non-Com Ed inventory, applying ARGUS growth factors to the Com Ed inventory, and then merging the two data sets.

The Emissions Processing System supplied by EPA has three computer programs that process point source emissions. The first takes the point source inventory and removes any sources that are off the specified grid, identifies sources that are missing latitude or longitude information, converts latitude and longitude to coordinates used by UAM, reports in-grid emissions by pollutant and two-digit standard industrial classification (SIC) code, and identifies which of the sources will be considered to be elevated sources and which are to be treated as ground-level emissions, based on the calculated plume rise. This program was run for each day of the simulation period. 
The second program does the major part of the point source processing. Minor point sources are assigned to the appropriate grid cell. Through use of standard or user-supplied profiles and information from the inventory that account for the behavior of individual point sources or industrial classes, the program converts the emissions of major point sources to hour-by-hour values, adjusts for day of the week and season of the year, and speciates VOC into the species needed for the UAM chemical mechanism. A glossary file that matches pairs of SIC codes and source classification codes or NAPAP (area) source category (NSC) with a set of activity, process, control, and source category codes is used to prepare emissions totals by code category for output by a later preprocessor. An additional preprocessor program converts the raw glossary file to a direct-access file to improve input/output performance. ANL had to make extensive additions to the glossary file to cover all the source pairs found in the Chicago inventory. This program was applied for both days of the simulation period. The low-level point source grid was later merged with area and biogenic emissions.

The major point source emissions were run through a third preprocessor for both days of the study. This program uses the UAM input meteorology files to distribute each point source's emissions vertically through the grid, based on stack height and plume rise calculations. The output from this program was input to UAM.

\section{B.3.3 Area Source Emissions}

Area source emissions also were run through three preprocessor programs. The first program reformats the emissions inventory for entry into the next processor. In the process, it removes emissions from those counties not in the UAM grid, assigns temporal allocation factors to the motor vehicle categories based on weekday vs. weekend; disaggregates motor vehicle VOC emissions into exhaust, evaporative, refueling, and running losses; and tallies the area source emissions by NSC and pollutant and the motor vehicle emissions by NSC, pollutant, and the various VOC subcategories.

To run the first preprocessor, a motor vehicle factor file derived from Mobile 4 results must be provided as input and the percentage allocation of vehicle-miles traveled (VMT) among automobiles, light trucks, and heavy trucks must be provided. For VMT percentages, the values provided by EPA for the Atlanta test case were used. Several of the motor vehicle factors were designed to reflect control strategies, but ANL used NES and NAPAP growth factors that already account for these strategies so the factors were set to 1.0. These strategies include alternative fuels, changes in Reid vapor pressure, changes in fleet composition, stage II controls, and growth in VMT. Factors to break VOC emissions down into exhaust, evaporative, and running loss fractions were taken from the Atlanta test case values. The adjustment factors for aldehydes (which are missing from the NAPAP inventory) were taken from those used in the EPA Five Cities Study (EPA 1990b). To adjust for the difference in evaporative and other emissions caused by the temperature difference between the Chicago study and the climatic temperature used to derive the NAPAP motor vehicle emissions, the ratio of the MSCET Illinois motor vehicle emissions for July 1988 to the 1988 annual motor vehicle emissions was used as the adjustment factor. The Mobile 4 runs used to derive the MSCET estimates took into account the temperature differences among months. 
The second area source preprocessor program allocates the county emissions for area and motor vehicle sources to the UAM grid cells, according to the spatial distribution of surrogate data such as county land area percentages or population distributions. It also assigns monthly and diurnal distribution factors by NSC for the nonmotor vehicle area sources. It was run twice, once for motor vehicle sources and once for the other area sources.

The spatial allocation is done in one of two ways, depending on NSC. Limited-access highway categories for different vehicle types, railroads, shipping, and airplane emissions are assigned to grid cells by creating a link file that defines line segments that represent highways, rail lines, shipping canals, and airport locations within counties. County-level emissions for these categories are redistributed along these links. The second method uses surrogates such as population distribution, land area distribution, water distribution, vegetation type distribution, etc., to represent the emissions distributions for various NSCs. For instance, residential heating or suburban automobile emissions would use population as a surrogate, while gasoline vessel emissions would be represented by the distribution of water area.

For the Chicago study, both a link file and a gridded surrogate data file were created. This task was extremely tedious and time-consuming. The link file was obtained by overlaying the UAM grid on a map of the area and determining the UTM coordinate end points of major highways, airports, rail lines, rivers, lakes, and the shipping canals, by county.

For the surrogate file, 1990 census tract data for population were obtained. The UTM coordinates of the centroid of each tract were determined, and the fraction of the county population that resided in that tract was assigr This method is recommended by EPA and wi where many tracts were located in a given grid he grid cell in which the centroid fell. 11 in the urban parts of the domain wwever, in the rural parts of the grid, this method resulted in the population being concentrated in a small number of grid cells with many grid cells having zero population fraction. This likely will lead to some error in calculating ozone from the precursor pollutant distribution.

The fraction of each county's land area falling in each grid cell also was entered into the surrogate file. For grid cells located entirely within a county, th: :s value was just $25 \mathrm{~km}^{2}$ divided by the total area of the county. For grid cells straddling the border of a county, a weighted value was used, based on the fraction of the grid cell falling into the county. The land area fractions were summed by county after the initial assignment and adjusted to equal unity.

Some NSCs use urban tr rural land area fractions as their surrogate. Argonne lacked detailed land use data so it was assumed that the urban fractions were equivalent to the population distribution fractions and the rural fractions were equivalent to the land area fractions, as described above. These as jumptions likely will not introduce too much error because NSCs common in rural areas will have low emissions near Chicago, and the large sources found near the city that use urban land area as a surrogate will have low emissions in the rural areas. 
The third preprocessor used for area sources is identical to that described as the second point source preprocessor. That is, it applies the temporal factors to derive hourly emissions and speciates the VOC emissions. The emissions are totaled by activity code, control code, etc. The processor is run four times, twice each for motor vehicles and other area sources to cover the two days of the simulation. Again the output from this step is tallied, merged with the natural emissions, and formatted for input into UAM. 


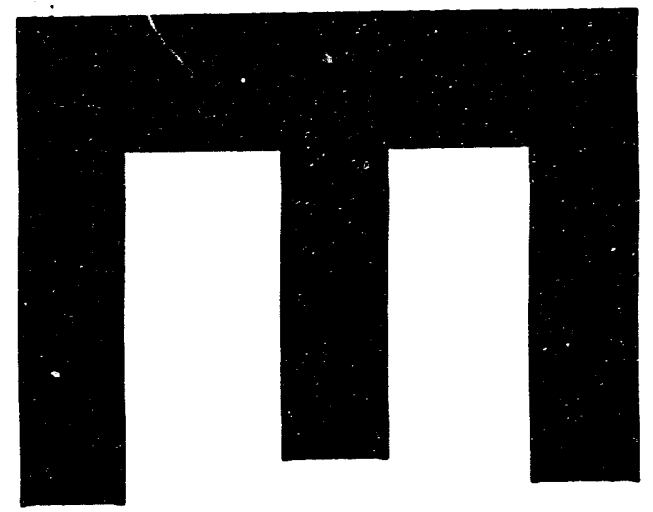

$\omega$
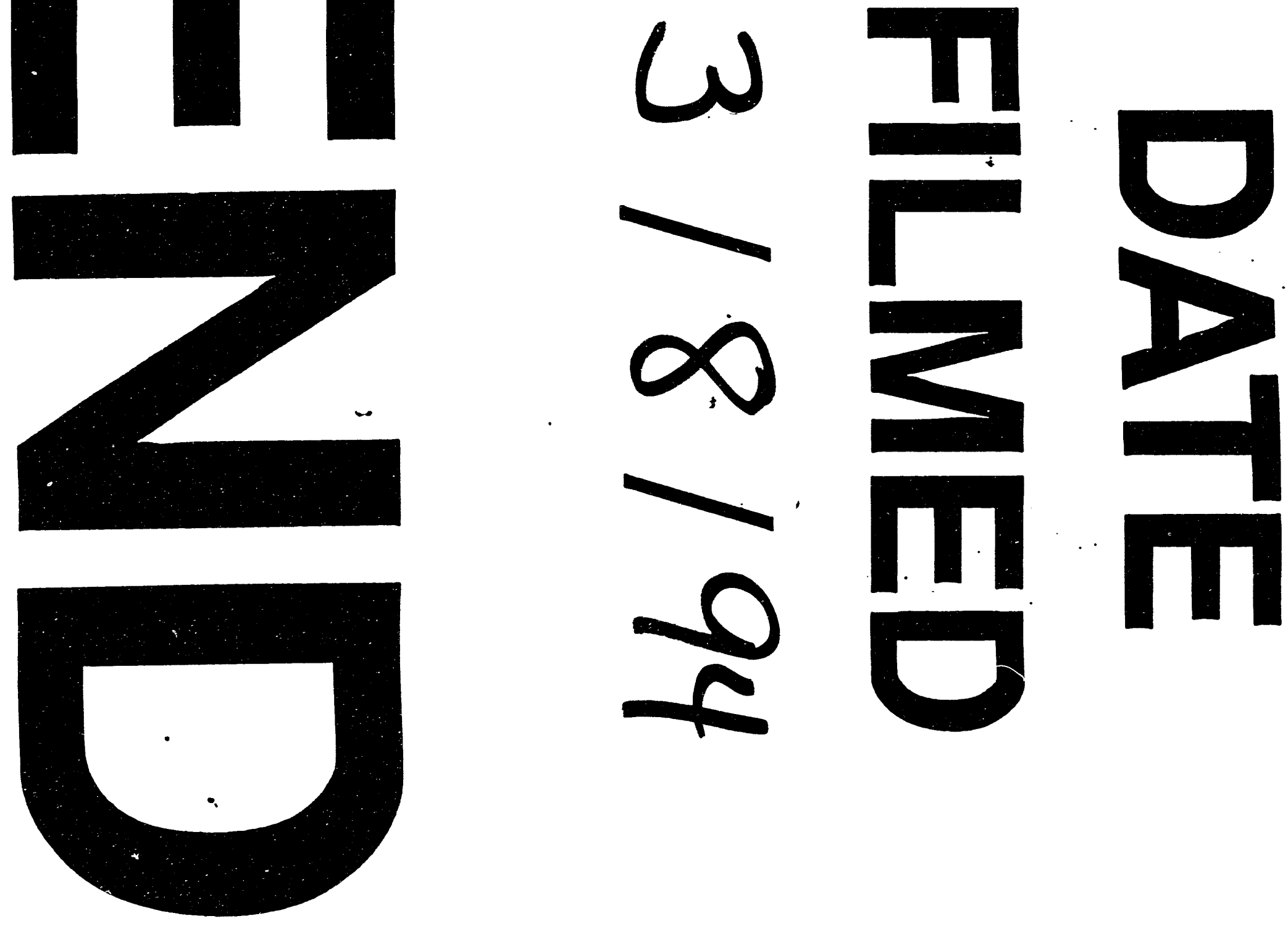
